\title{
WestVirginiaUniversity
}

THE RESEARCH REPOSITORY @ WVU

Graduate Theses, Dissertations, and Problem Reports

2007

\section{Pressure deflection behavior of candidate materials for a morphing wing}

Christopher Griffin

West Virginia University

Follow this and additional works at: https://researchrepository.wvu.edu/etd

\section{Recommended Citation}

Griffin, Christopher, "Pressure deflection behavior of candidate materials for a morphing wing" (2007). Graduate Theses, Dissertations, and Problem Reports. 1826.

https://researchrepository.wvu.edu/etd/1826

This Thesis is protected by copyright and/or related rights. It has been brought to you by the The Research Repository @ WVU with permission from the rights-holder(s). You are free to use this Thesis in any way that is permitted by the copyright and related rights legislation that applies to your use. For other uses you must obtain permission from the rights-holder(s) directly, unless additional rights are indicated by a Creative Commons license in the record and/ or on the work itself. This Thesis has been accepted for inclusion in WVU Graduate Theses, Dissertations, and Problem Reports collection by an authorized administrator of The Research Repository @ WVU. For more information, please contact researchrepository@mail.wvu.edu. 


\title{
PRESSURE DEFLECTION BEHAVIOR OF CANDIDATE MATERIALS FOR A MORPHING WING
}

\author{
by
}

\author{
Christopher Griffin
}

Thesis submitted to the College of Engineering and Mineral Resources at West Virginia University

in partial fulfillment of the requirements

for the degree of

Master of Science

in

Mechanical Engineering

Approved by

Wade Huebsch, Ph.D., Committee Chairperson

Jacky Prucz, Ph.D.

Darran Cairns, Ph.D.

Department of Mechanical and Aerospace Engineering

Morgantown, West Virginia

2007

Keywords: Morphing Wing, Flexible Material, Wing Skin, Bulge Test Copyright 2007 Christopher Griffin 


\section{ABSTRACT \\ PRESSURE DEFLECTION BEHAVIOR OF CANDIDATE MATERIALS FOR A MORPHING WING \\ By Christopher Griffin}

The research presented in this thesis evaluates different materials that are candidates to be used as a flexible skin on a morphing wing. A morphing wing has come to be known as any wing that changes shape. Although there has been a great amount of research involved in designing morphing mechanisms, the information for applicable wing skin material has been limited. A morphing wing skin needs to be flexible enough to deflect and morph to a new shape given a suitable amount of force, yet strong enough to resist the aerodynamic forces encountered during flight. It also must remain elastic throughout its use so there is no change in surface area which could produce unwanted air flow characteristics. A candidate material must also have excellent fatigue characteristics as well as provide environmental and chemical resistance, and withstand abrasion (e.g. rain) as conventional materials do.

This research was conducted alongside a project that developed an unmanned aerial vehicle (UAV) that utilizes wing morphing for control. The problems encountered during testing were the motivations for this study. A significant problem is the onset of material separation from the wing support structure, or ballooning, caused by the low pressure on the top surface of the wing. A bulge test facility was designed and constructed to investigate this effect and to help predict its onset. The fatigue characteristics are observed by cyclically pressurizing the material to see any change in center deflection.

A sample of rubber materials, a plastic material, a thermoplastic elastomer (TPE), polyurethane, and a woven material were evaluated. The rubber materials along with a combination of rubber and woven material were found to be the best candidates. They provided a healthy balance of flexibility and strength which is required by a flexible wing skin. A method for determining the onset of material deflection due to the surface pressure on a wing was also developed using the bulge test. Using this method one can approximately predict when and how much a material will deflect according to pressure coefficient, velocity, and altitude. Although abrasion, chemical, and environmental resistance is important it was not tested in this research. 


\section{DEDICATION}

This thesis is dedicated to my Grandfather, Douglas Griffin, an extremely talented engineer and wonderful role model. 


\section{ACKNOWLEDGEMENTS}

I would like to express my deepest gratitude for my committee members, especially my advisor Dr. Wade Huebsch, for providing direction and leadership. I'd also like to thank Richard Guiler who spent countless hours talking with me, helping me, and providing me with great ideas. Without his help none of this would be possible and I look forward to referring to him as Dr. Guiler. I'd also like to thank Dr. Kostas Sierros for helping with the bulge test analysis. Special thanks to NESC, especially Jen Hause, for providing me with financial support and a very fun and relaxing atmosphere to work in. I'd like to thank my supervisor, Kara Perritt, my project officer, Dave Fosbroke, and the rest of the management at NIOSH for thinking I'm worthwhile to keep around. Also at NIOSH I would like to especially thank John Powers who worked with me to develop the test apparatus that made this research possible. He spent a great deal of his own time working with me to get to this point. Brad Newbraugh and Tony McKenzie kept me smiling and also offered expert advice.

My deepest thanks go out to the Arthurs family for providing me with a home away from home and for making me feel so welcomed and a part of your family. Thanks to my girlfriend, Ashley, for keeping me levelheaded and focused on my goals. Thank you for everything you do for me.

Most importantly I'd like to thank my family for providing me with the life and opportunities I have today. Without your love and support none of this would be possible. I greatly appreciate everything you do for me and I hope I make you proud. 


\section{TABLE OF CONTENTS}

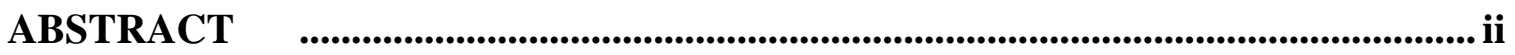

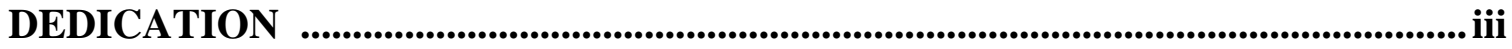

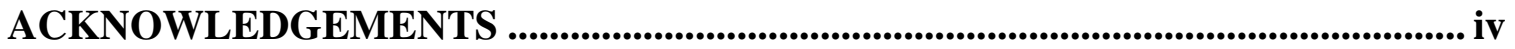

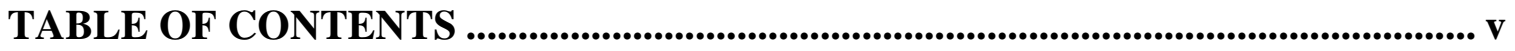

LIST OF TABLES ................................................................................................... vii

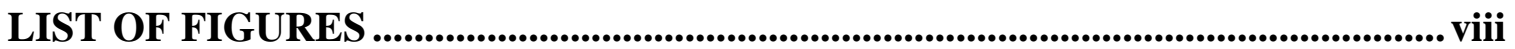

NOMENCLATURE ............................................................................................. $\mathrm{x}$

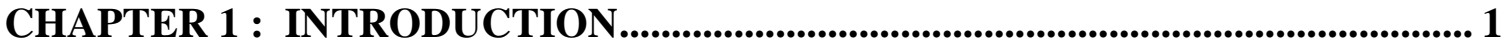

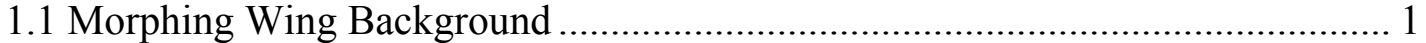

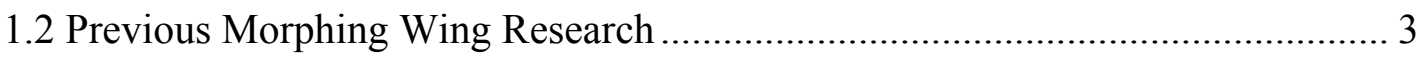

1.3 Current Morphing Wing Research.............................................................. 4

1.4 Reason for Flexible Wing Skin Material Research....................................... 7

CHAPTER 2 : MATERIAL SELECTION ............................................................. 12

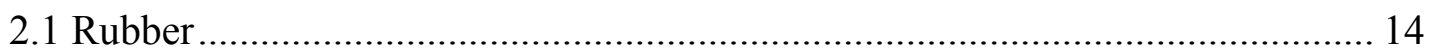

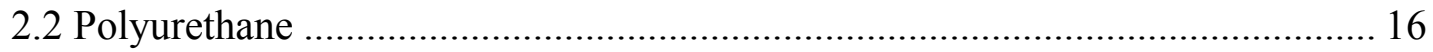

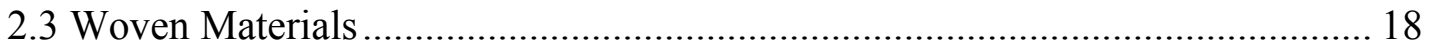

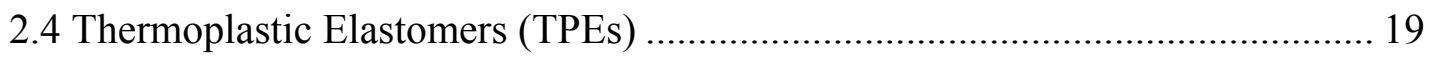

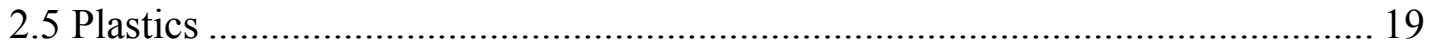

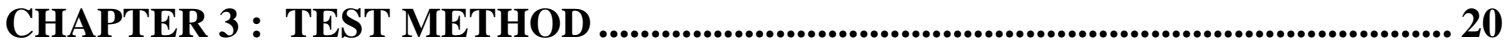

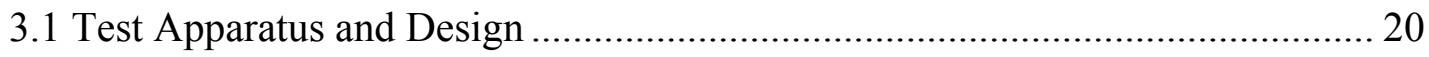

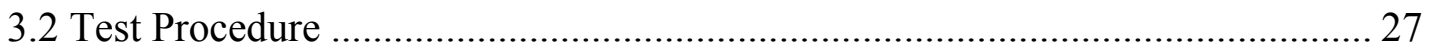

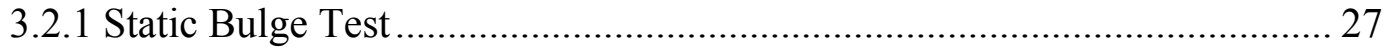

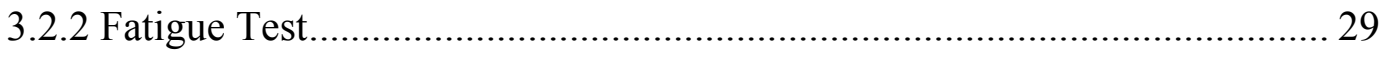

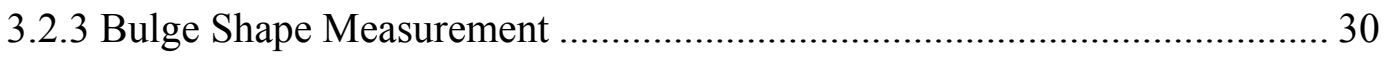

CHAPTER 4 : TEST RESULTS ............................................................................... 32

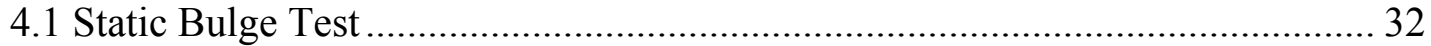

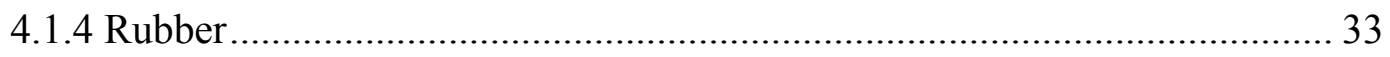

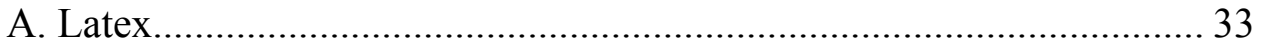

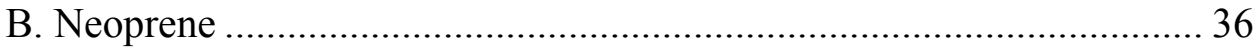

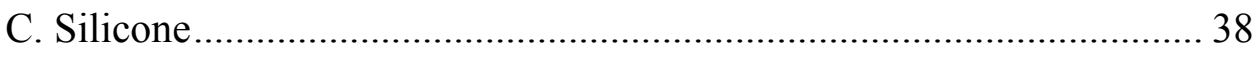

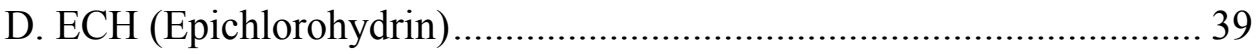




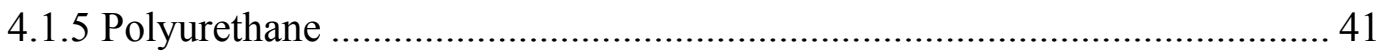

4.1.6 Woven Material ....................................................................................... 42

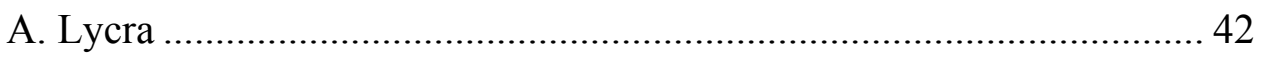

4.1.7 Thermoplastic Elastomer (TPE) ................................................... 43

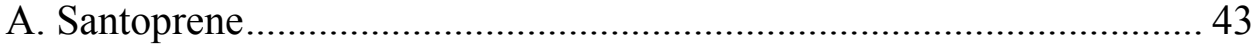

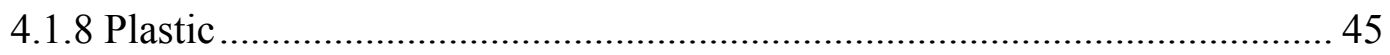

A. Polyvinyl Chloride (PVC) ...................................................... 45

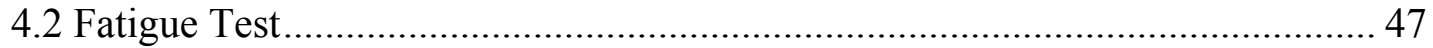

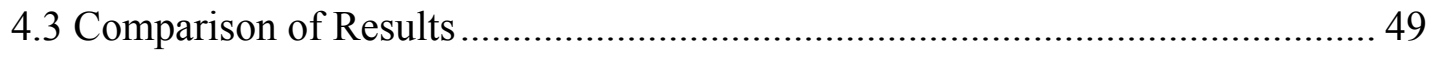

CHAPTER 5 ：DISCUSSION OF RESULTS ................................................. 53

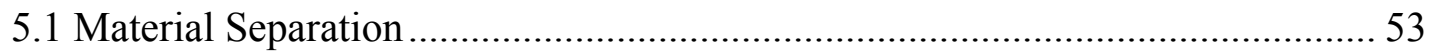

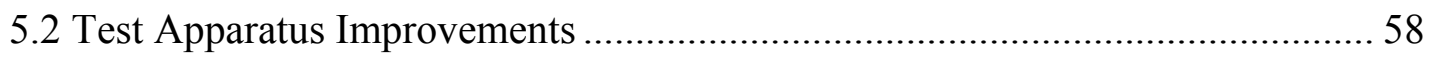

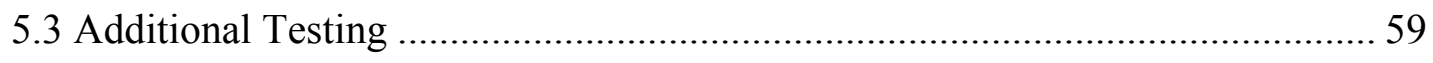

CHAPTER 6 : CONCLUSIONS ........................................................................................... 61

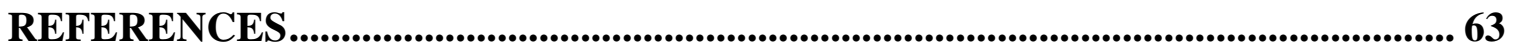

APPENDIX A: Material Properties of Candidate Materials ....................................... 67

APPENDIX B: Distance Sensor Specifications .......................................................... 71

APPENDIX C: Distance Sensor Calibration/Error................................................ 77

APPENDIX D: Pressure Transducer Specifications ..................................................... 78

APPENDIX E: Bulge Shape Measurements .................................................................... 79 


\section{LIST OF TABLES}

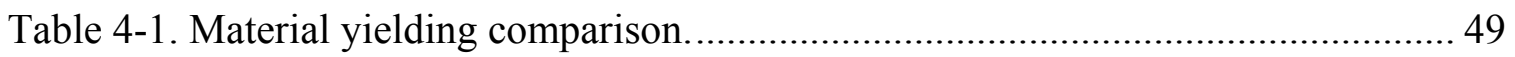

Table 4-2. Final displacement at initial pressure after recovery.................................. 50

Table 4-3. Amount of pressure required to create a center deflection of $0.35 \mathrm{~cm}(0.138$

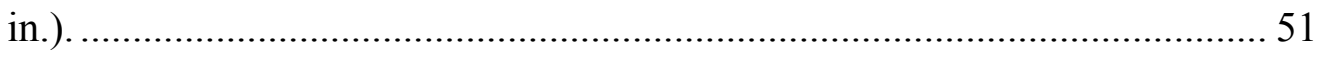




\section{LIST OF FIGURES}

Figure 1.1-1. The original Wright Flyer during its military flight tests [1] .................... 1

Figure 1.1-2. Images of an F-14 Tomcat and a B-1 Lancer, both of which utilize

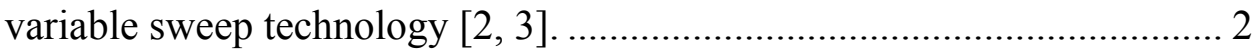

Figure 1.2-1. AFTI F-111 Mission Adaptive Wing in flight [4] .................................. 3

Figure 1.2-2. NASA's modified F/A-18 with Active Aeroelastic Wing [5] ................. 4

Figure 1.3-1. This image shows the idea of Lockheed Martin's (MAS Project) folding wing design [6].

Figure 1.3-2. University of Florida's 24 inch MAV with undeflected wing (left) and morphed wing (right) [7]

Figure 1.3-3. Morphing mechanism for the 24 inch MAV (left), which uses a bent torque rod, and the 12 inch MAV (right), which uses Kevlar threads [7]. . 6

Figure 1.3-4. The West Virginia University Morphing Flight Demonstrator. ................ 7

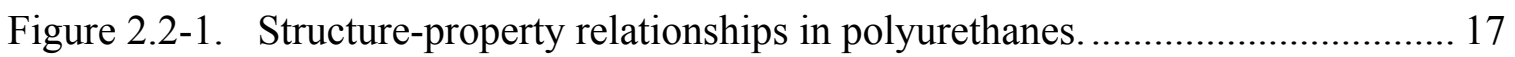

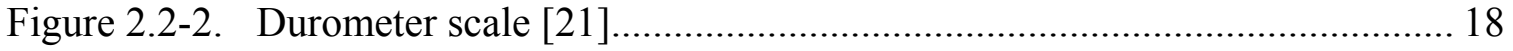

Figure 3.1-1. CAD drawing of bulge deflection test apparatus................................. 22

Figure 3.1-2. Exploded view of specimen holder..................................................... 22

Figure 3.1-3. Image of Sharp GP2D12 infrared LED distance sensor. ....................... 24

Figure 3.1-4. Display of triangulation method to determine distance from an object.... 24

Figure 3.1-5. Raw voltage output versus displacement.......................................... 25

Figure 3.1-6. Inverse of voltage versus displacement with correlating linear equation used to calculate distance................................................................... 26

Figure 3.2-1. Latex under pressure with white paper attached to center...................... 28

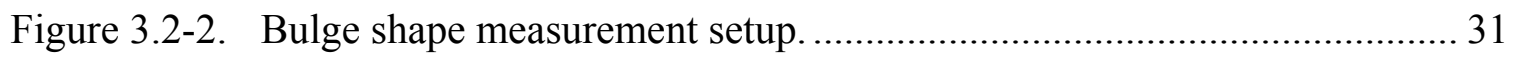

Figure 4.1-1. Pressure versus displacement results for three samples of latex rubber... 34

Figure 4.1-2. Latex rubber sample pressurized to rupture to validate bulge test design. 35

Figure 4.1-3. Latex rubber sample that was pressurized to rupture, showing the contact with the edge of clamping device. .................................................... 35

Figure 4.1-4. Bulge profile measurement for latex rubber........................................ 36

Figure 4.1-5. Pressure versus displacement results for three samples of neoprene rubber. 
Figure 4.1-6. Pressure versus displacement results for three samples of silicone rubber. 38

Figure 4.1-7. Plastic deformation of silicone rubber sample...................................... 39

Figure 4.1-8. Pressure versus displacement results for three samples of ECH rubber... 40

Figure 4.1-9. Plastic deformation of ECH rubber sample. ....................................... 40

Figure 4.1-10. Pressure versus displacement results for three samples of polyurethane. 41

Figure 4.1-11. Plastic deformation of polyurethane sample....................................... 42

Figure 4.1-12. Pressure versus displacement results for three samples of Lycra placed on top of latex rubber. 43

Figure 4.1-13. Pressure versus displacement results for three samples of Santoprene. ... 44

Figure 4.1-14. Plastic deformation of Santoprene sample. 45

Figure 4.1-15. Pressure versus displacement results for three samples of polyvinyl chloride (PVC). 46

Figure 4.1-16. Plastic deformation of polyvinyl chloride (PVC) sample....................... 46

Figure 4.1-17. Ruptured polyvinyl chloride (PVC) sample. ...................................... 47

Figure 4.2-1. Results of the cyclic fatigue tests for all materials. .............................. 48

Figure 5.1-1. Maximum velocity before critical material deflection due to wing surface pressure of NACA 2412 airfoil at $8^{\circ}$ angle of attack........................... 55

Figure 5.1-2. Pressure and deflection data for the second sample of neoprene rubber tested with the correlating linear curve fit and equation....................... 56

Figure 5.1-3. Theoretical velocity and deflection plot for neoprene rubber on a NACA 2412 airfoil with $8^{\circ}$ angle of attack and at 1000 feet altitude. 


\section{NOMENCLATURE}

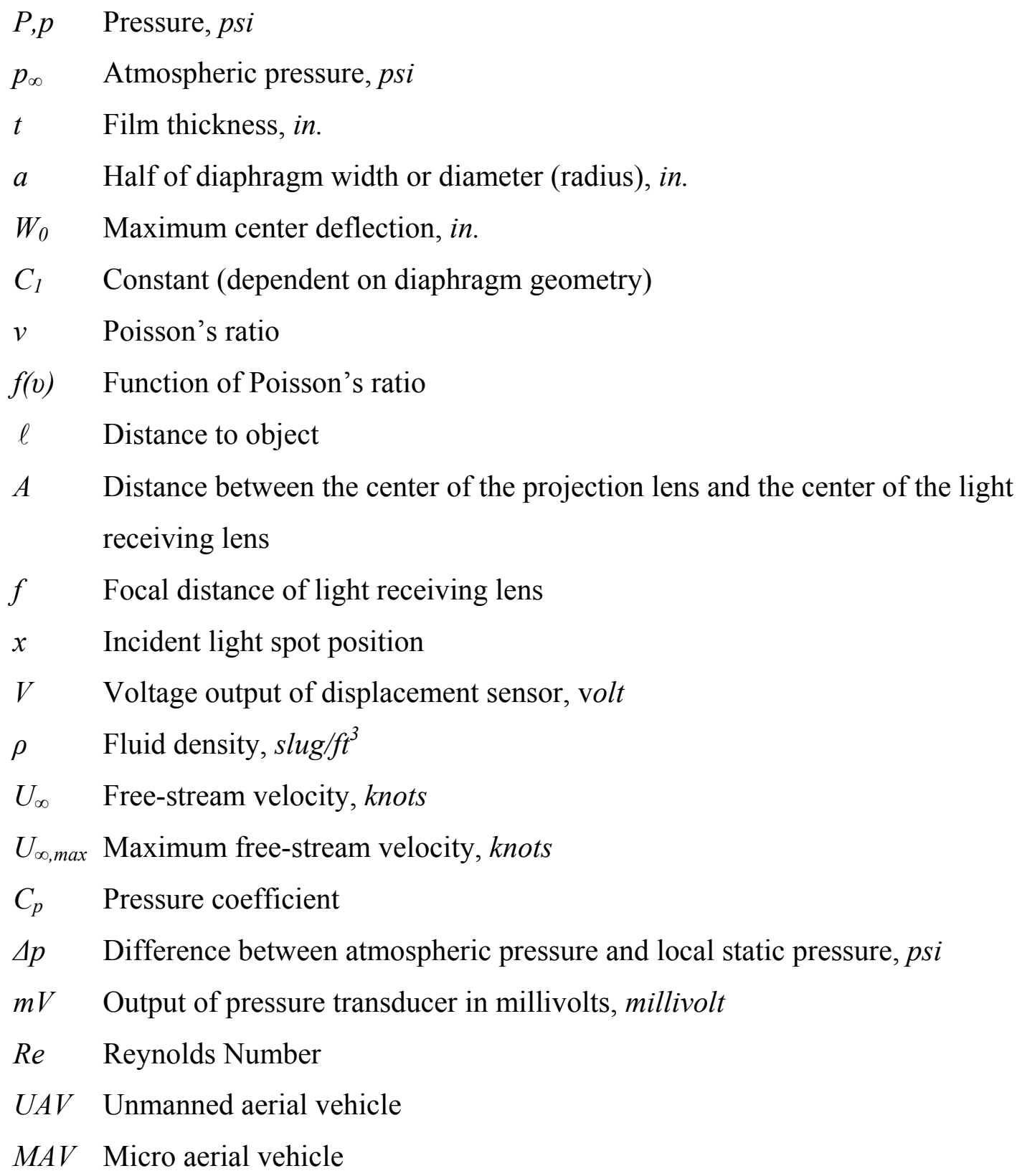




\section{CHAPTER 1: INTRODUCTION}

\subsection{Morphing Wing Background}

A morphing aircraft is generally accepted to be an aircraft whose shape changes during flight to optimize performance. In 1902 the Wright Flyer became the first powered aircraft and its flight control system used a wing morphing system called wing "warping" to twist the wing tips to produce roll. The wood frame and fabric wing skin, shown in Figure 1.1-1, were flexible enough to allow the warping effect. As engine performance and technology progressed it was no longer feasible to have fabric wings and flexible structures. This brought about the use of ailerons and flaps to control flight and change the wing's aerodynamic characteristics. The ailerons and flaps became separate control surfaces that were integrated into a rigid wing. The skin was usually made out of sheet metal since flexibility was no longer required.

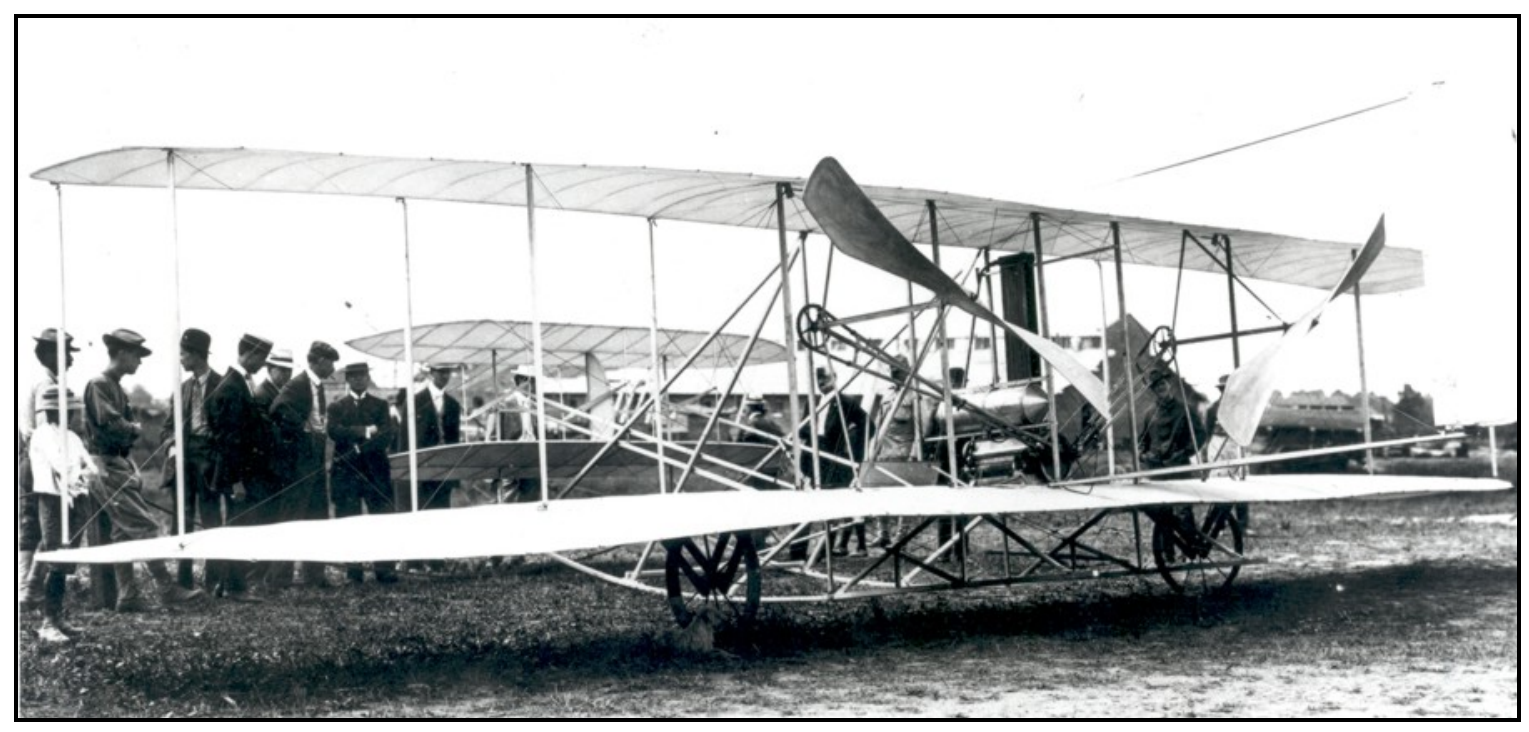

Figure 1.1-1. The original Wright Flyer during its military flight tests [1].

With aircraft approaching and surpassing supersonic speeds wing sweep was introduced. An aircraft with swept wings could fly closer to supersonic without transitioning than could a straight winged aircraft. A swept wing aircraft also behaved 
and maneuvered better in supersonic flight. However, swept wings are not ideal for low speed flight and require faster takeoff and landing speeds. To remedy this shortcoming the variable sweep wing concept was introduced. An aircraft's wing could change sweep according to flight regime. When taking off or landing the wing could be straight and when cruising at high speeds the wings could be swept back while in flight.

The U.S. Navy's F-14 Tomcat and the U.S. Air Force's B-1 Lancer, shown in Figure 1.1-2, are great examples of this technology. The F-14 was designed to be a supersonic fighter that could intercept Soviet bombers before they could launch missiles against the carrier group. This required a swept wing since it could travel at supersonic speeds. The F-14 was designed for the U.S. Navy as a carrier based fighter, which required slower landing and take off speeds [2]. This created the need for the ability to fly and maneuver at both slow and fast air speeds. The B-1 acts as a supersonic bomber, but with the variable sweep technology it can take off and land on shorter runways [3]. The main drawback of variable sweep aircraft is the complexity and weight of the mechanism that controls the sweep of the wing. This causes a decrease in fuel efficiency and an increase in maintenance.

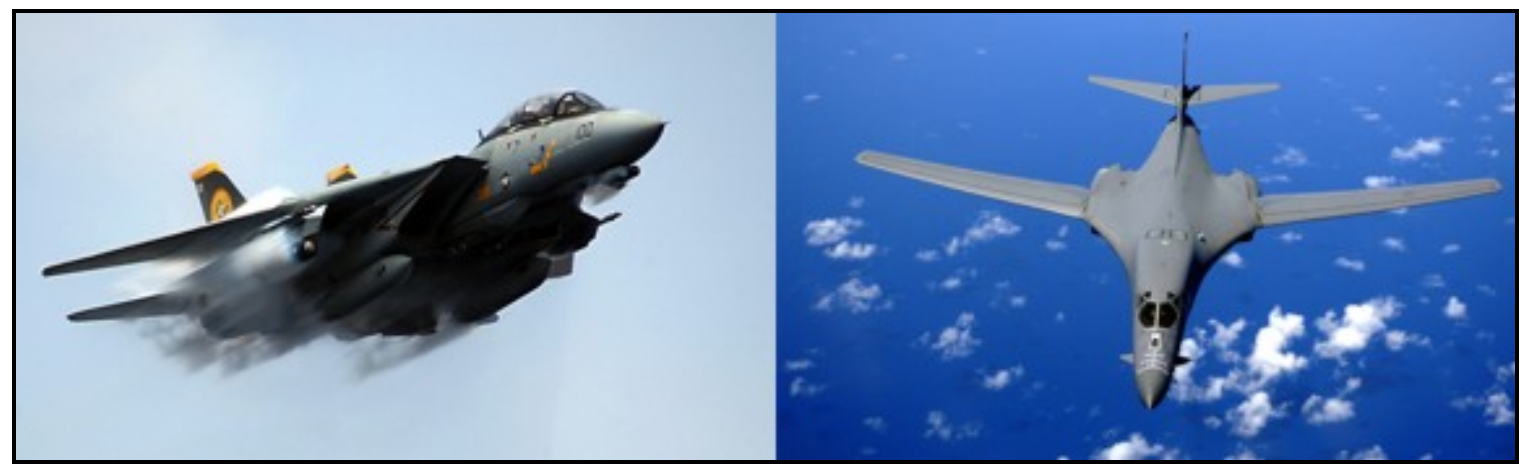

Figure 1.1-2. Images of an F-14 Tomcat and a B-1 Lancer, both of which utilize variable sweep technology $[2,3]$. 


\subsection{Previous Morphing Wing Research}

With the advancement of materials and technology, the ability to change the shape of the wing itself started to become reality. In the early 1980s a joint U.S. Air Force and NASA project was initiated called Advanced Fighter Technology Integration (AFTI) [4]. The supercritical wing on the F-111A aircraft, shown if Figure 1.2-1, was replaced with a wing built by Boeing Aircraft Company System called a "mission adaptive wing" (MAW). This wing had an internal mechanism to flex the outer wing skin and produce a high camber section for subsonic speeds, a supercritical section for transonic speeds, and symmetrical section for supersonic speeds. The AFTI/F-111 MAW system had 59 flights from 1985 through 1988. The flight test data showed a drag reduction of around 7 percent at the wing design cruise point to over 20 percent at an off-design condition [4].

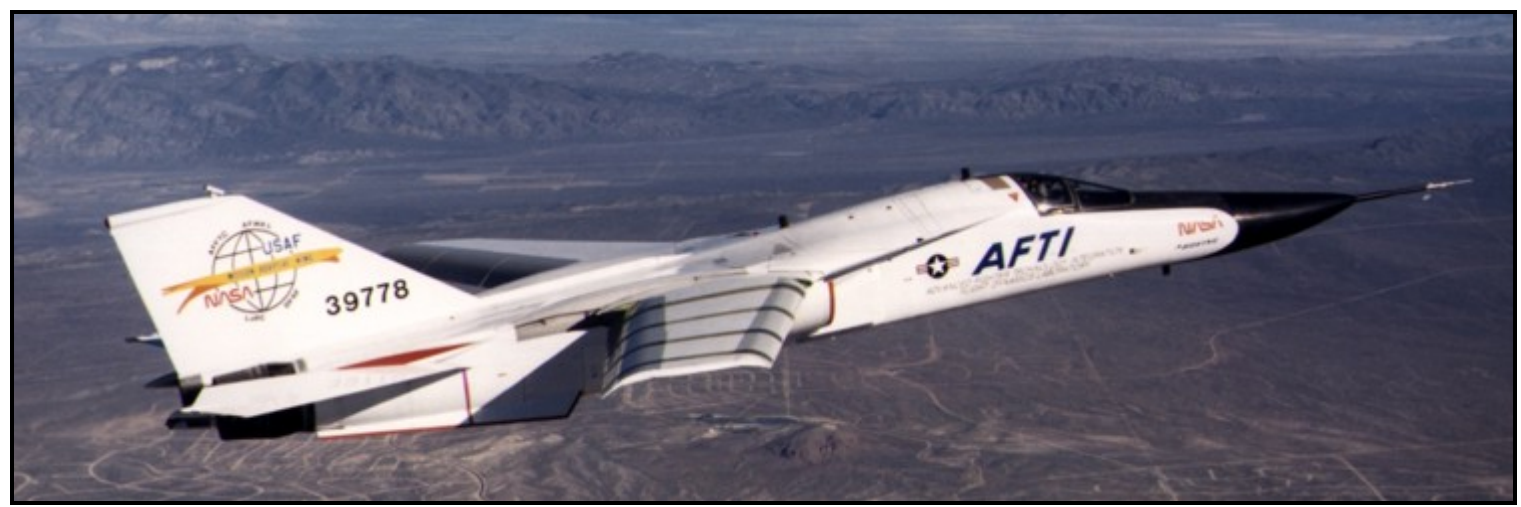

Figure 1.2-1. AFTI F-111 Mission Adaptive Wing in flight [4].

NASA's Dryden Flight Research Center, along with the U.S. Air Force Research Laboratory (AFRL) and Boeing Phantom Works, researched new flight control techniques using wing warping in the Active Aeroelastic Wing (AAW) program [5]. The goal of the AAW program was to demonstrate improved aircraft roll control through aerodynamically induced wing twist on a full-scale high performance aircraft at transonic and supersonic speeds. The AAW program used a modified F/A-18, shown in Figure 
1.2-2. The wings were modified by replacing some of the existing wing skin panels along the wing box just ahead of the trailing-edge flaps and the ailerons with thinner, more flexible skin panels. Also, the leading-edge flap was divided into inboard and outboard segments, and additional actuators were used to operate the outboard segments separately from the inboard leading-edge surfaces. Using this actuation of the outboard leading-edge flap and the aileron to twist the wing, the aerodynamic forces on the twisted wing provided the roll forces desired. The research showed that roll rates adequate for lateral control, or within 15 to 20 percent of that obtained by a production F/A-18, were obtained by use of active control of wing flexibility alone, without use of the differential rolling horizontal tail used by standard F/A-18s at transonic and supersonic speeds [5].

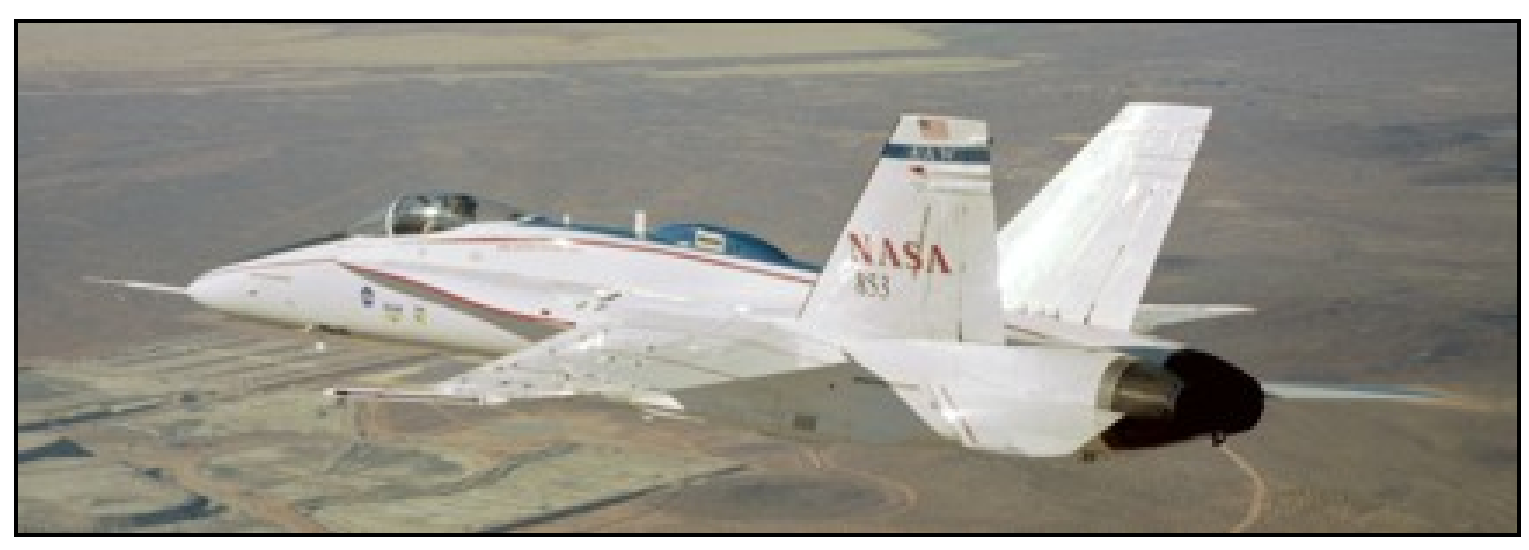

Figure 1.2-2. NASA's modified F/A-18 with Active Aeroelastic Wing [5].

\subsection{Current Morphing Wing Research}

The Defense Advanced Research Projects Agency (DARPA) is currently working on a project called the Morphing Aircraft Structures (MAS) program [6]. This project includes wing morphing concepts that include large area changes, sweep change, and span change. DARPA's goal is to produce aircraft that can perform drastically different missions by adapting their wing shape and size. An artist's rendering of the type of wing adaptations is shown in Figure 1.3-1. 

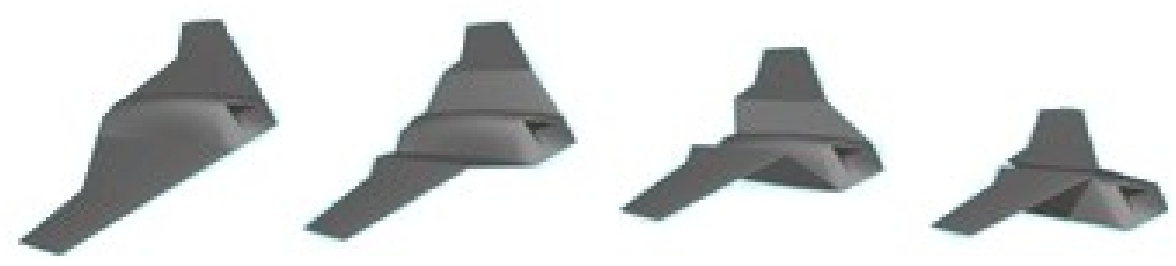

Figure 1.3-1. This image shows the idea of Lockheed Martin's (MAS Project) folding wing design [6].

The University of Florida researched the use of active wing morphing to control roll of a micro air vehicle (MAV) [7]. They developed two MAVs, one with a wing span of 12 inches, and another with a wing span of 24 inches, shown in Figure 1.3-2. Both aircraft had a thin airfoil wing and a conventional elevator and rudder tail. The leading edge and ribbing of the wings were made of carbon-fiber. The skin of the wings, however, differed between aircraft. The skin of the 12 inch MAV was made of latex rubber while the skin on the large MAV was made of a thin translucent plastic.

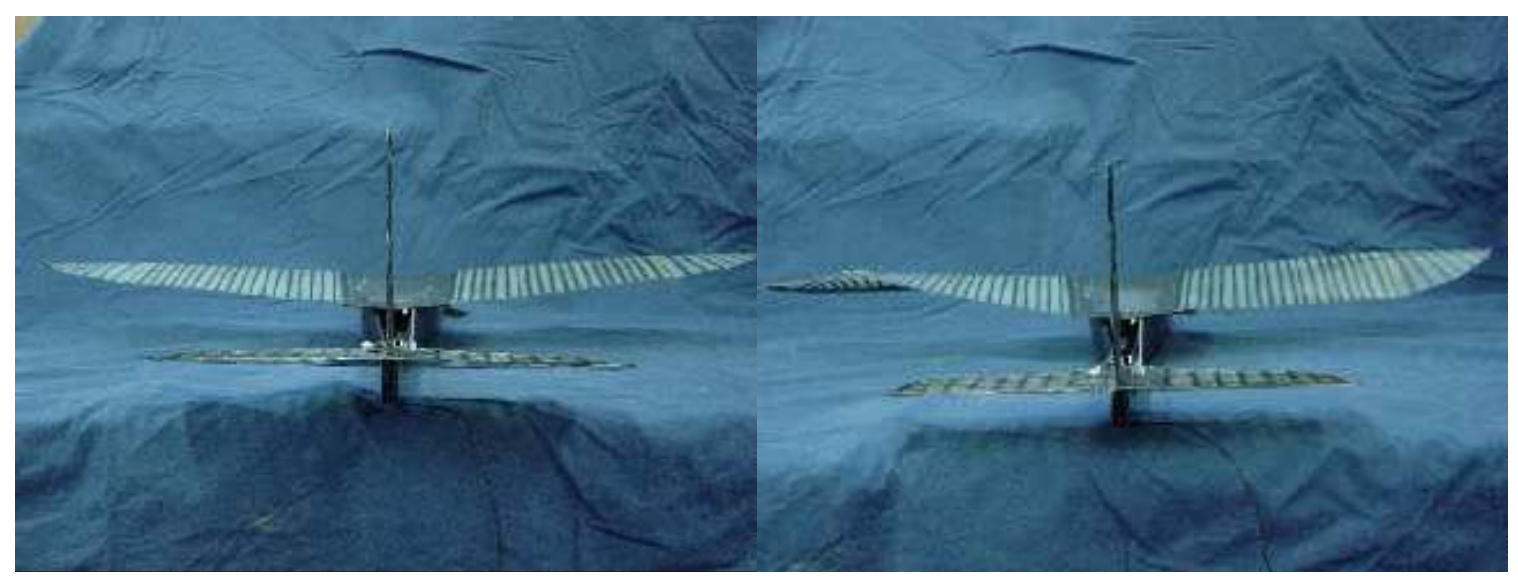

Figure 1.3-2. University of Florida's 24 inch MAV with undeflected wing (left) and morphed wing (right) [7].

The wing morphing mechanism also differed among the two MAVs. The smaller aircraft used Kevlar threads to twist the wings while the larger MAV used a torque rod. A servo located in the fuselage pulled on the threads to twist and curl the wing tips to provide control forces. The same idea was used to control the torque rod in the larger 
MAV. A servo rotated the torque rod, which was bent parallel to the fuselage approximately three quarters down the length of the wing. This bent portion would cause the wing tip to deflect and twist. The two different morphing mechanisms are shown in Figure 1.3-3. Roll and yaw rates of 70 and 20 degrees per second, respectively, were shown for the 12 inch MAV. This showed that morphing produces significant roll rates and provides significant controllability [7].

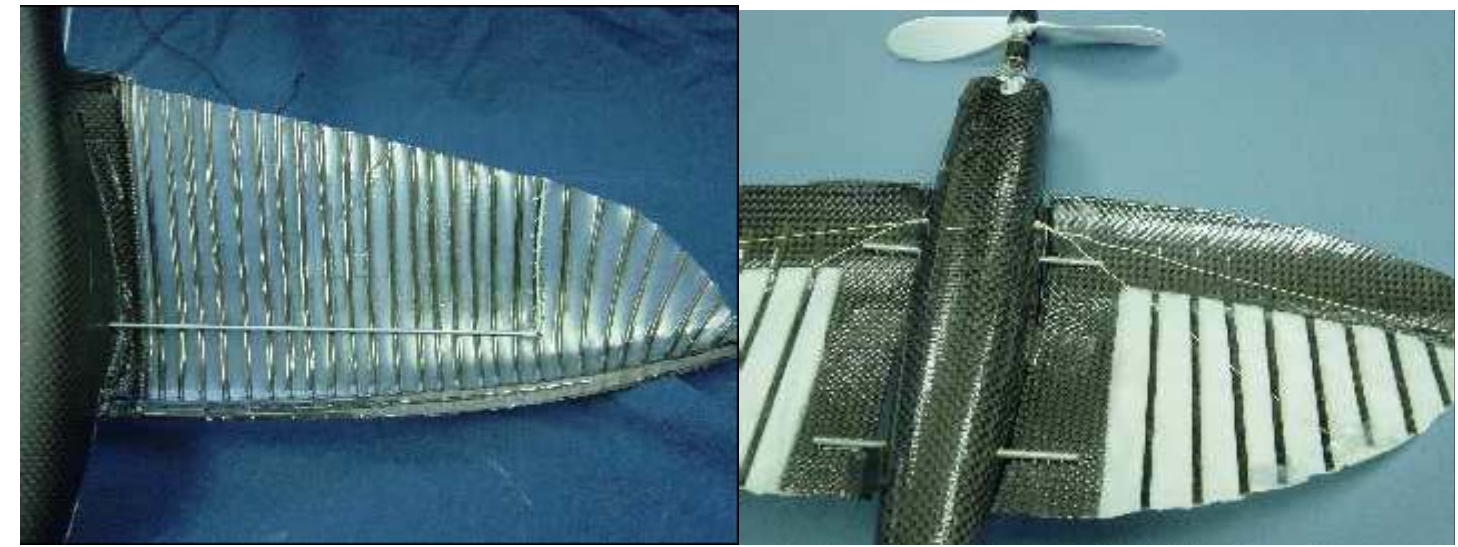

Figure 1.3-3. Morphing mechanism for the 24 inch MAV (left), which uses a bent torque rod, and the 12 inch MAV (right), which uses Kevlar threads [7].

Research is currently being conducted at West Virginia University to provide a UAV, unmanned aerial vehicle, with a flying wing configuration control through a wing morphing mechanism and to eliminate the need for constant wing wash-out [8]. Washout is needed to combat the adverse yaw created when initiating a turn. This is an even greater concern for flying wing configurations because there is no rudder to counteract adverse yaw. The use of a flying wing configuration provides a number of advantages over conventional aircraft including low parasitic drag and up to a $30 \%$ decrease in total drag. Propulsion, fuel, and, payload are all built into the wing structure, which allows the design of a very lightweight rigid structure [9]. The smooth lines with very few protrusions allow the design of an aircraft with a minimum electromagnetic signature, 
which is of increasing importance in today's military aircraft. For use as a UAV a flying wing configuration also gives the ability to be folded into small containers for military or planetary exploration type missions [8].

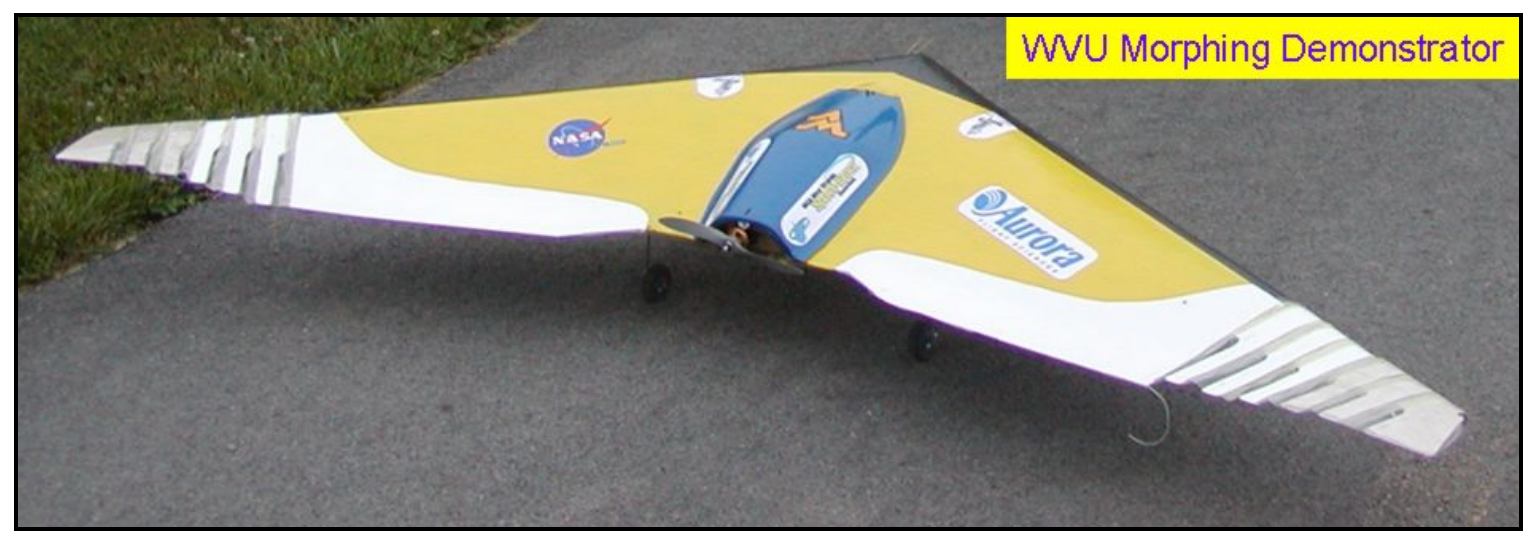

Figure 1.3-4. The West Virginia University Morphing Flight Demonstrator.

During wind tunnel tests above a certain speed the differential pressures over the morphing wing caused the latex skin to lift off the upper surface of the wing [8]. This material separation can create a change in wing camber or thickness, which can cause undesirable flow characteristics. Studying and predicting this phenomenon is a focus of this research.

\subsection{Reason for Flexible Wing Skin Material Research}

Although there has been much research into morphing wing shapes, mechanisms, and control, work on actual wing skin materials has been limited. The focus of wing morphing research so far has been aimed at mechanisms to morph the wing, not necessarily the materials that make up the wing skin.

This research is in support of the UAV currently being developed at WVU. Therefore, the evaluation of the candidate materials is tailored to the ability to be used on a UAV. The use of UAVs has become more popular in recent years to conduct missions such as aerial surveillance. As in the case of any aircraft, the design is centered on the 
mission of the aircraft. In the case of a UAV used in aerial surveillance the design criteria is to have low speed and efficient loiter with fast cruise speeds to and from the loiter area. Research conducted by Secanall et al. [10] investigated morphing the airfoil of a UAV to produce efficient flight at both design conditions and off-design conditions. Requirements were given for six different flight conditions; stall speed, takeoff run distance, climb gradient, rate of climb, cruise speed, and loiter speed. The results of their research proved that by using a morphing airfoil the UAV could reduce drag in design conditions and off-design conditions. The reduction in drag coefficient varies from $2.5 \%$ in the climb gradient condition to $15.2 \%$ in cruise condition $28.6 \%$ in the stall condition). In addition to these off-design drag coefficient reductions during loiter the reduction is $5.3 \%[10]$.

Secanell et al. concluded that the main changes of airfoil change came in camber, except for the airfoil used during stall which requires an increase in thickness at the leading edge. Therefore, the airfoil would be a thin airfoil with two morphing mechanisms; one mechanism to control camber by deforming the airfoil camber line shape and another to control the thickness variations near the leading edge. By utilizing airfoil morphing a reduction in fuel consumption and a decrease in power needed can be realized.

Research has also been conducted to investigate the low Reynolds Number, Re, flow associated with MAVs and low speed UAVs. Low Re flow has vastly different physics than does moderate and high $R e$ flow, which is associated with full scale aircraft. An advantage of a flexible wing is that it can facilitate passive shape adaptation, shape change caused by the flow around it, resulting in delayed stall [11]. Waszak et al. [12] 
showed experimentally at moderate angles of attack that both rigid and membrane wings show comparable lift characteristics. However, the membrane wings stall at a much larger angle of attack because of their passive surface deformation [13]. Lian et al. [11] investigated the effects of a membrane wing at low Re flow as compared to a rigid wing. They were able to see a prominent vibration frequency in the flexible skin. Because of this vibration, energy is transferred from the flexible surface to the flow and the separated flow is energized. This causes a change in separation and transition positions over the airfoil as compared to the rigid wing.

Although the research presented here concentrated on flexible materials to be used on a UAV, there is also application to full-scale piloted aircraft. By utilizing wing morphing there is potential for reducing drag and increasing lift. Also, by developing a wing morphing mechanism similar to the one used for the WVU UAV, there would be no need to have additional control surfaces on the wing. This would lead to an obvious decrease in drag by eliminating gaps inherent to conventional control surfaces [14].

NASA's Aircraft Morphing Program is investigating a wide range of ideas and concepts [15]. One area of research is smart materials and devices. NASA is investigating their ability to be used for active aerodynamics, active noise control, active aeroelastic control, airframe health monitoring, and active shape control. These smart materials will be developed to address structural vibration and fatigue, noise and aerodynamics. NASA is also investigating active flow control to dynamically alter the global flow field by interacting with and controlling localized flow instabilities and flow structures. They are investigating the use of piezoelectric materials for gust alleviation, buffet load alleviation, and flutter suppression. 
The Aircraft Morphing Program views piezoelectric actuators as the most promising actuator technologies for the implementation of a wide variety of aerospace applications. A shortcoming of piezoelectric actuators is their relatively small displacement performance. Researchers have combated this by developing new high displacement actuator technologies, RAINBOW (Reduced INternally-Biased Oxide Wafer) and THUNDER (THin layer composite UNiform ferroelectric DrivER and sensor. NASA plans to develop a mechanical model of these high displacement piezoelectric actuators to optimize their performance for vibration suppression, noise cancellation, and flow control and to increase the force output of these bender actuators [15].

Research has also been conducted to evaluate the efficacy of using piezoelectric actuators to reduce or eliminate wing flutter. Wing flutter is a growing oscillation of a wing caused by the fluid-structure interactions. Wing flutter can create amplitudes and stresses large enough to cause structural failure. Nam et al. [16] created an aeroservoelastic design for flutter suppression of a composite plate-wing with segmented piezoelectric actuators. By mathematically modeling the interaction between unsteady aerodynamic forces and finding the optimal placement of the piezoelectric actuators flutter suppression can be obtained. To suppress flutter piezoelectric actuators are bonded to both the top and bottom surfaces of the laminated plate to produce a pure bending stress. The application of this bending stress at certain frequencies counteracts the flutter oscillations.

These examples of research provide clear advantages to flexible structures on aircraft. In the case of a UAV or MAV an aircraft can be designed to be efficient at multiple flight regimes and exhibit more efficient low Re flight. By controlling full scale aircraft using 
wing morphing great strides to reduce drag and therefore increase efficiency can be made. Flight can become even safer by being able to control and suppress wing flutter. To realize all these advantages research into flexible materials and structures must be conducted. 


\section{CHAPTER 2: MATERIAL SELECTION}

Finding a suitable material to act as the wing skin is an extremely difficult task. There is an inherent contradiction in the characteristics that the material has to have. The material must be flexible enough to change shape as needed, yet be strong enough to withstand the aerodynamic forces that the material will be subjected to while in flight [17].

The material must also behave elastically while being morphed. If the material enters a plastic deformation regime it will not return to its original shape and size when the wing is returned to its original position. This plastic deformation would cause an increase in material surface area that can increase drag or create other unwanted airflow characteristics. The material must also behave elastically throughout its use. Therefore, the fatigue characteristics of the material must be known so an increase in material surface area is not gradually created over time.

The material must also have resistance to all weather conditions, as well as good resistance to chemicals. Aircraft may be exposed to various chemicals including wing deicing solutions, fuel, and cleaning solvents. Conventional aircraft today can fly in all weather and are exposed to various temperatures. The material characteristics should not differ with a change in temperature. The morphing wing material must also provide abrasion protection as sheet metal does for conventional aircraft.

Although this research focused on the flexibility and fatigue characteristics of the materials, it is important to note that the requirements of a morphing wing discussed above are equal in importance to the flexibility and fatigue requirements. This research provides a starting point to evaluate candidate materials and nominate them for further investigation. 
As discussed, a key characteristic of a candidate morphing wing skin is its ability to deform and return to its original state while withstanding the aerodynamic loads during flight. This requires a material with good elasticity and strength. It is this characteristic and material property that motivates the search for a morphing wing skin. The first type of material chosen to be tested is rubber. Rubber is a natural synthetic material that can be or is already vulcanized to a state in which it has high extensibility and forcible, quick retraction [18]. The specific types of rubber that were tested were latex, neoprene, silicone, and ECH (epichlorohydrin) rubber. All of these materials were readily available in the form of a thin film. Different thicknesses are available which may affect the results of this application. One thickness was tested for each material. Latex is a natural rubber that has been used in previous flexible wing designs and provides a good combination of strength and stretch. Neoprene is a versatile synthetic rubber that was originally developed as an oil-resistant substitute for natural rubber [19]. Silicone rubber is a synthetic elastomer made from a cross-linked polymer which is reinforced with silica [20]. ECH rubber has excellent resistance to fuel, oil, and ozone [21].

Another class of material that was selected to be tested was polyurethane. Polyurethanes "include those polymers containing a plurality of urethane groups in the molecular backbone, regardless of the chemical composition of the rest of the chain" [22]. Since the chemical composition of the rest of the chain can vary, the material properties of polyurethanes can be varied depending on application. This allows the polyurethane to combine the characteristics of a strong plastic with the elasticity of a rubber. A third type of material that was investigated was a woven material. Woven materials have high stretch and recovery capability along with high strength. 
A type of thermoplastic elastomer (TPE) was also considered as a candidate material. Thermoplastic elastomers are rubber-like materials that, unlike conventional vulcanized rubbers, can be processed and recycled like thermoplastic materials. TPEs can also be processed with the speed, efficiency, and economy of thermoplastics while providing functional performances and properties similar to thermoset rubber products [23]. Santoprene was the specific type of TPE tested. Santoprene combines the characteristics of rubber and plastic to produce a material that offers excellent weather and chemical resistance while still retaining its ability to stretch and recover to its original shape. [21].

Although plastics are not known for their stretch and recover characteristics, one was tested. Polyvinyl chloride, also known as PVC, offers good resistance to water, chemicals, and weathering.

\subsection{Rubber}

Four different types of rubber were chosen to be tested: latex, neoprene, silicone, and ECH (epichlorohydrin). Latex is a natural rubber that has good strength and stretch properties. It also has great extensibility, deformability, and it does not require much stress to deform. This characteristic is a positive and negative attribute of a candidate wing skin. On the positive side the mechanism used to morph the wing will require less energy to deform the wing skin, which will translate to a less expensive, lighter mechanism that consumes less power. On the other hand, the wing skin may deform due to external pressure loads while in flight. This may cause a change in wing camber and undesired flow effects. Latex rubber also has great recovery, in that after the rubber is deformed it will return to its original shape and size up to a certain deformation. 
Neoprene is a synthetic rubber that has a unique combination of properties. Neoprene has the ability to resist degradation from sun, ozone, and weather. It also performs well in contact with oils and other chemicals, remains useful over a wide temperature range, has outstanding physical toughness, resists burning, and exhibits great resistance to damage caused by flexing and twisting [19]. Neoprene has been used on flexible wing models used in wind tunnel testing at West Virginia University. It showed promising results with its ability to flex with small stresses and recover well. During wing tunnel tests a velocity limitation was found for the neoprene wing skin. If the velocity exceeded this limit, the low pressure region on the upper surface of the wing was strong enough to cause the skin to separate from the wing structure changing the wing camber and thickness. This created an undesired effect on the wing's flow characteristics. Latex was also tested on flexible wing models in the wind tunnel and showed similar behavior above a certain air speed.

Silicone rubber, as stated previously, is a synthetic elastomer made from a crosslinked polymer which is reinforced with silica. This material exhibits a good combination of mechanical and chemical properties. Its desirable qualities include ease of fabrication; stable at high and low temperatures; weatherability; and chemical resistance. The ability for silicone rubber to remain stable at high and low temperatures is an attractive attribute for the application of a morphing wing skin. Aircraft wings encounter large extremes in temperature. Most organic rubbers tend to deform more easily at high temperature and become hard and brittle at low temperatures, limiting their usefulness [20]. 
$\mathrm{ECH}$ rubber is a special purpose rubber, curable with diamines or ammonium compounds, and resistant to ozone and organic liquids. ECH rubber also shows a good resistance to dynamic stressing, as well as abrasion and tear resistance [24].

\subsection{Polyurethane}

Polyurethane was invented by Prof. Otto Bayer in 1937 when he was synthesizing polymer fibers to compete with nylon. Polyurethanes are a heterogeneous family of polymers and comprise an array of different products, ranging from rigid foams to soft, malleable gums [24]. Figure 2.2-1 presents a summary of the structure-property relationship for polyurethanes. Branching/cross-linking is plotted on the ordinate and intermolecular forces are plotted on the abscissa. By plotting the relationship in this way we can show all the commercially available polyurethanes. At the upper right corner, representing extreme branching and chain stiffness, are the rigid urethane foams. The lower left corner represents just the opposite, the low degree branching and loose chain attraction of the malleable elastomers. 


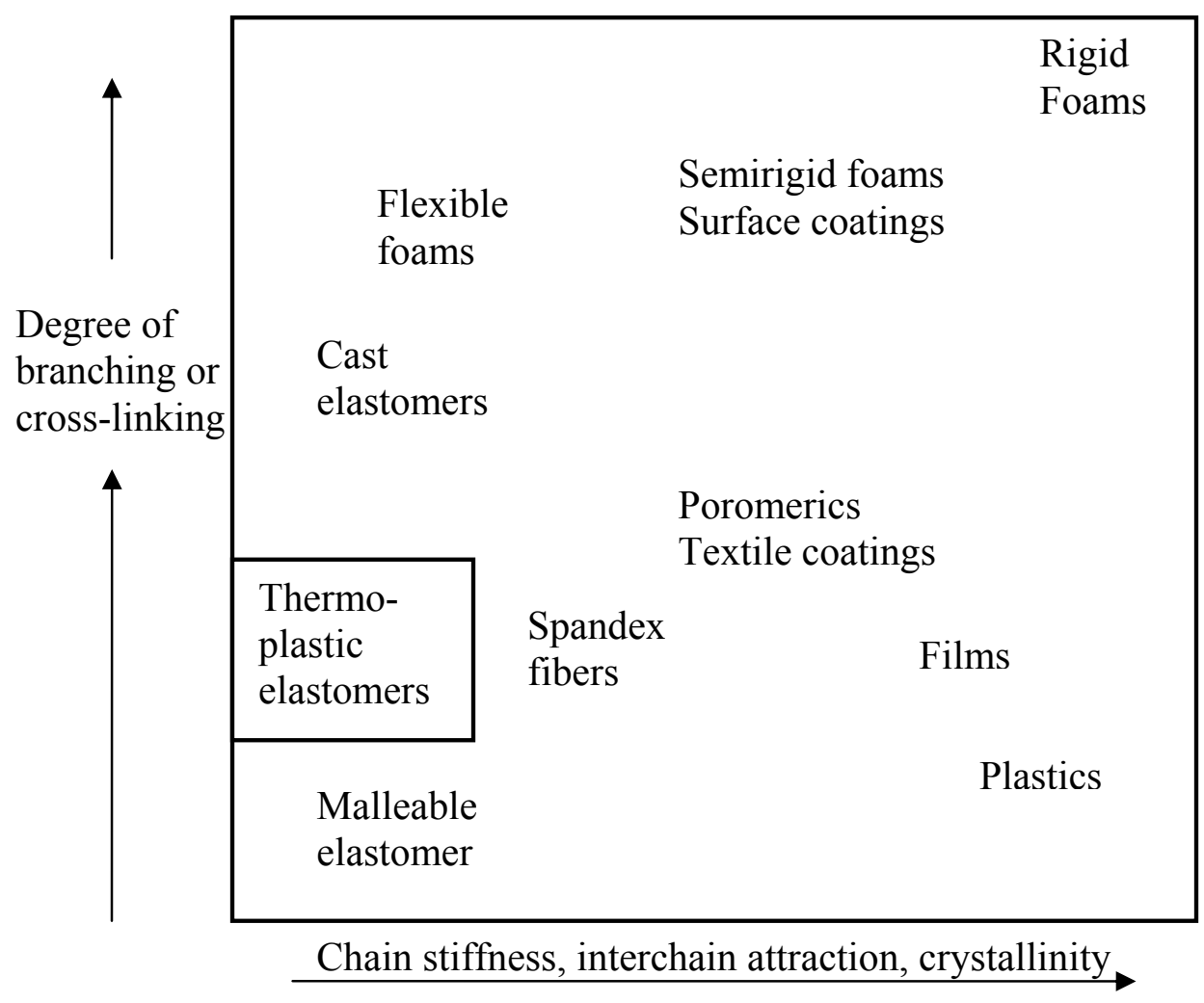

Figure 2.2-1. Structure-property relationships in polyurethanes.

Polyurethanes are a combination of simple molecules called monomers. Monomers are compounds whose properties are discrete. Unlike monomers, polyurethanes do not have discrete properties, but have average properties that represent a range of molecules. The type of polyurethane used in this research is a polyurethane elastomer. Polyurethane elastomers provide a combination of rubber like elasticity with the hardness of metals. Additional advantages of polyurethane elastomers are high abrasion and chemical resistance, excellent mechanical and elastic properties, and blood and tissue compatibility [22].

Since polyurethane elastomers are synthetic compounds the formula can be chemically altered to provide different material properties. One way of defining a polyurethane elastomer is by using the Durometer Scale, which is shown in Figure 2.2-2. 
Durometer is the international standard for measuring the hardness of rubber, plastic, and most nonmetallic materials including polyurethanes. The hardness of a material is its resistance to penetration. Harder materials will have more wear resistance, but will also be less flexible [21]. For a flexible wing skin a compromise will need to be used. The polyurethane elastomer tested in this research had a Durometer number of 85 Shore A.

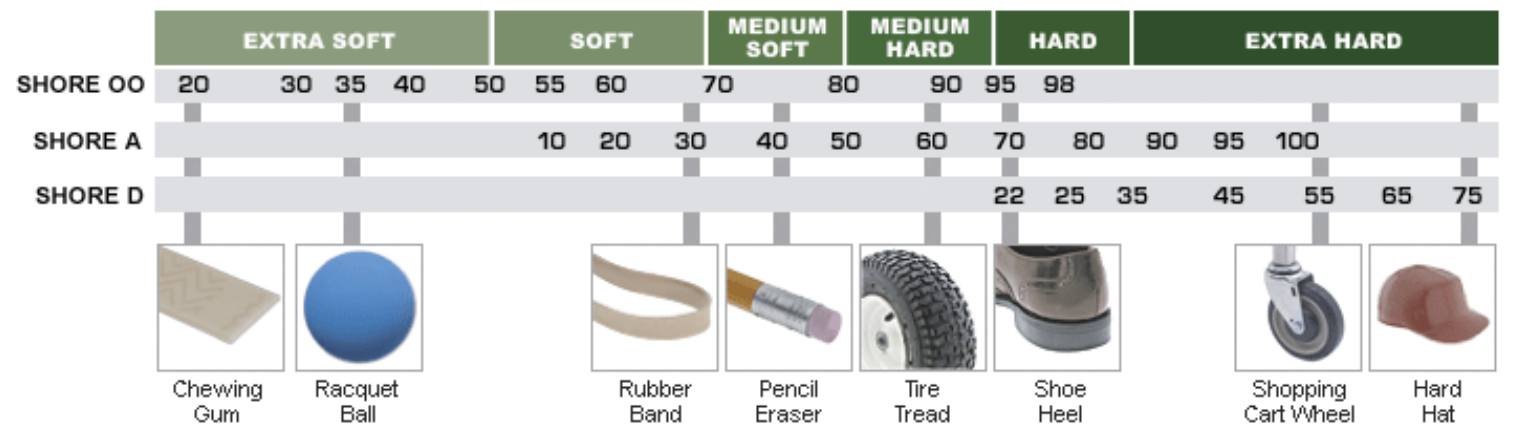

Figure 2.2-2. Durometer scale [21].

\subsection{Woven Materials}

Spandex is a long-chain polymeric fiber. It was first used as a replacement for rubber in women's foundation garments. Joseph C. Shivers invented DuPont's spandex fiber in 1959, which is called by its trade name Lycra [25]. Lycra is always blended with other natural and man made fibers such as cotton, wool, silk, and linen. It is lighter in weight than rubber thread and unlike rubber it does not break down with exposure to body oils, perspiration, lotions, or detergents.

Recent research conducted by Kikuta pointed out the fact that woven materials allow air to pass through, thus not being fit for a wing skin [17]. Kikuta also noted that "another possibility is combining yarn materials" with other materials. Since woven materials such as Lycra have more hard chains as opposed to the other materials evaluated, a combination of the materials may provide an answer to the problem of air passing through. The Lycra could provide the strength to resist deformation due to 
external pressure loads while in flight, and an additional material such as latex rubber could prevent air from flowing through the wing skin.

This is the approach taken to test the woven material. Since it would be useless to test just the woven material using the bulge deflection test, a dual layer technique was utilized. The inner layer would be latex rubber and the outer layer would be Lycra. This way the air would not pass through the Lycra, yet the combination of materials would exhibit stronger material properties than the latex rubber by itself.

\subsection{Thermoplastic Elastomers (TPEs)}

Santoprene rubber is a thermoplastic elastomer (TPE) that is commonly used as tubing in the medical industry. It is widely used because it combines the desirable characteristics of vulcanized rubber, like flexibility, with the processing ease of thermoplastics. Santoprene can operate in a wide range of temperatures without cracking or tackiness. This TPE also exhibits excellent resistance to cut growth while flexing, high tear strength and superior resistance to fatigue, and good resistance to many acids, bases and aqueous solutions [23].

\subsection{Plastics}

Polyvinyl chloride (PVC) is a plastic that often overlaps into the rubber field by acting as a substitute or replacement for crude rubber. PVC also possesses a number of rubber-like properties as well as some characteristics superior to those of rubber. It is made by polymerizing vinyl chloride and was heavily developed by B. F. Goodrich Laboratories [26]. Properties include resistance to sunlight, prolonged flexing, strong corrosives, and oxidation. PVC also has high abrasion resistance, which makes it ideal for a morphing wing application. 


\section{CHAPTER 3: TEST METHOD}

\subsection{Test Apparatus and Design}

A bulge test facility was designed and built in support of this research effort. The bulge test was used to evaluate the effectiveness of materials as surface material for a flexible wing. The bulge test was initially thought of as a way to find the mechanical properties of solid thin films. Using this method, pressure is applied to a thin film that has been clamped over a circular or square opening. By observing the load-deflection behavior of the film, the biaxial modulus and in-plane residual stresses can be calculated using equations derived to model the behavior of the bulging film [27]. One assumption is that the deflection of the center of the film will be much larger than the thickness of the film. This assumption allows the strain energy due to bending to be neglected [28]. The deflection of the flexible skins evaluated in this research met this criterion with deflection magnitudes much larger than the material thickness. Therefore, the assumption that the mechanical properties of a flexible skin could be evaluated using the bulge test was valid.

As stated previously this research was conducted in parallel with a project that developed a UAV using a flying wing configuration and wing morphing to provide control. During wind tunnel tests the flexible wing skin lifted off the wing support structure due to the pressure differential on the upper surface of the wing [8]. The bulge test provides a way of investigating and predicting the deflection of a material due to the pressure on the surface of the material.

Deflection measurements are taken at various pressure settings and then plotted. The residual stress, $\sigma_{0}$, and Young's modulus, $E$, values are then extracted from the linear and cubic coefficients of Equation (3-1) using a least-squares fit [27]: 


$$
P=\frac{t}{a^{2}} W_{0}\left[C_{1} \sigma_{0}+\frac{f(v)}{a^{2}} \frac{E}{1-v} W_{0}^{2}\right]
$$

where $P=$ pressure; $t=$ film thickness; $2 a=$ diaphragm width or diameter; $W_{0}=$ maximum center deflection; $C_{1}=$ constant (dependent on diaphragm geometry); $v=$ Poisson's ratio; and $f(v)=$ function of Poisson's ratio. The setup for testing the wing skin materials used a circular diaphragm, which gave $C_{1}=4.0$ and the value for $f(v)$ was found using Equation (3-2) [27].

$$
f(v)=2.67(1.026+0.233 v)^{-1}
$$

The bulge deflection test can also be used to investigate the fatigue of the candidate material. By cyclically pressurizing the material to a known pressure for a given number of cycles we were able to measure the change in deflection as a function of cyclic pressurization. This provided an idea of how the material would behave after being stretched and then relaxed a repeated number of times. As stated previously this is an important characteristic of a morphing wing skin.

Figure 3.1-1 is a computer aided design drawing of the bulge deflection test apparatus. As shown the pressure is controlled by a regulator and is measured by a pressure transducer. The two solenoid valves are used for testing fatigue characteristics. A circular membrane shape was decided to eliminate stress concentrations and is similar to the shape of ballooning seen on the wing of the wind tunnel models. 


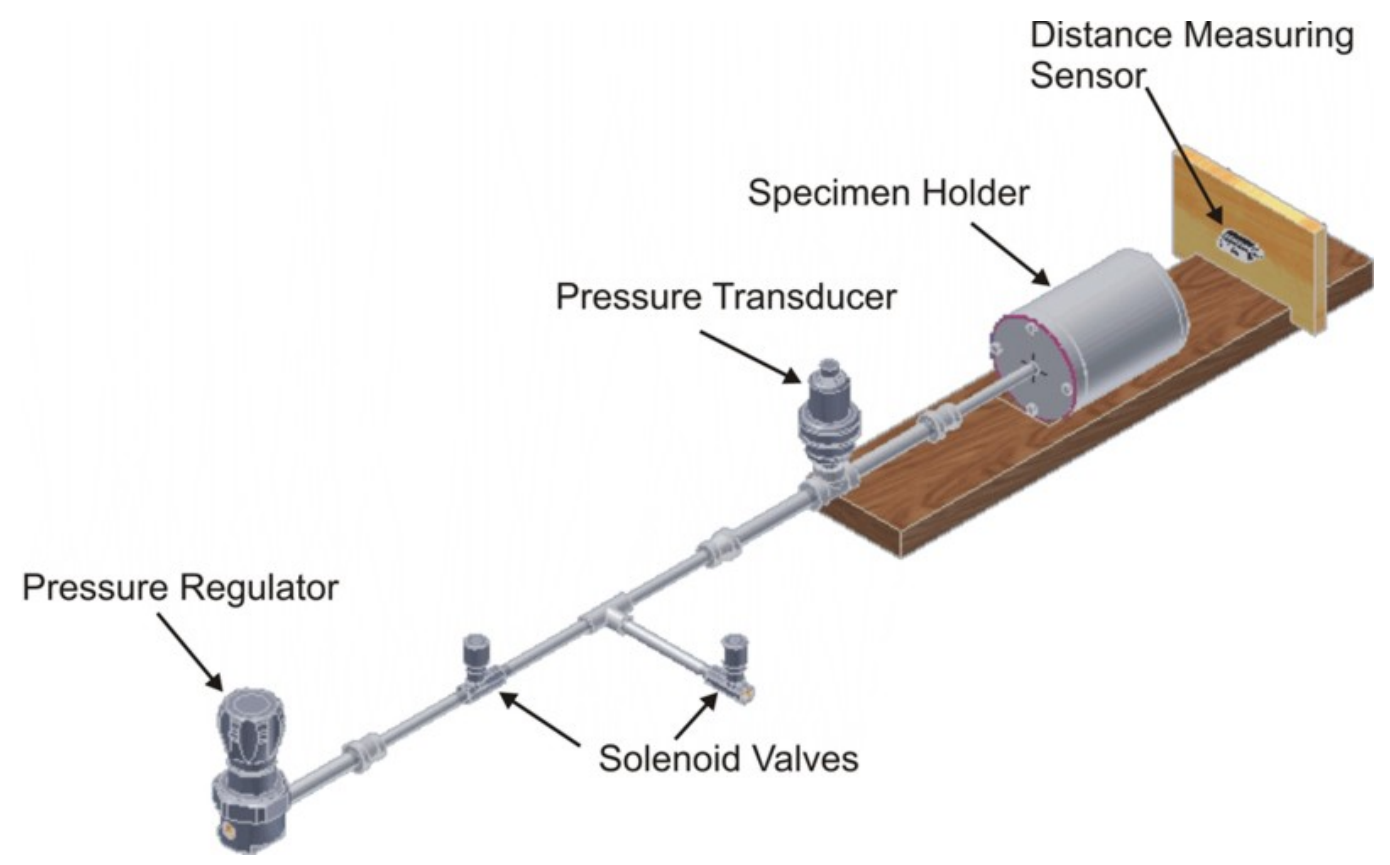

Figure 3.1-1. CAD drawing of bulge deflection test apparatus.

Figure 3.1-2 is a detailed CAD drawing of the specimen holder and clamping mechanism. The material to be tested is placed on a lip within the holder, which is then held in place by an o-ring and clamp that is screwed into place.

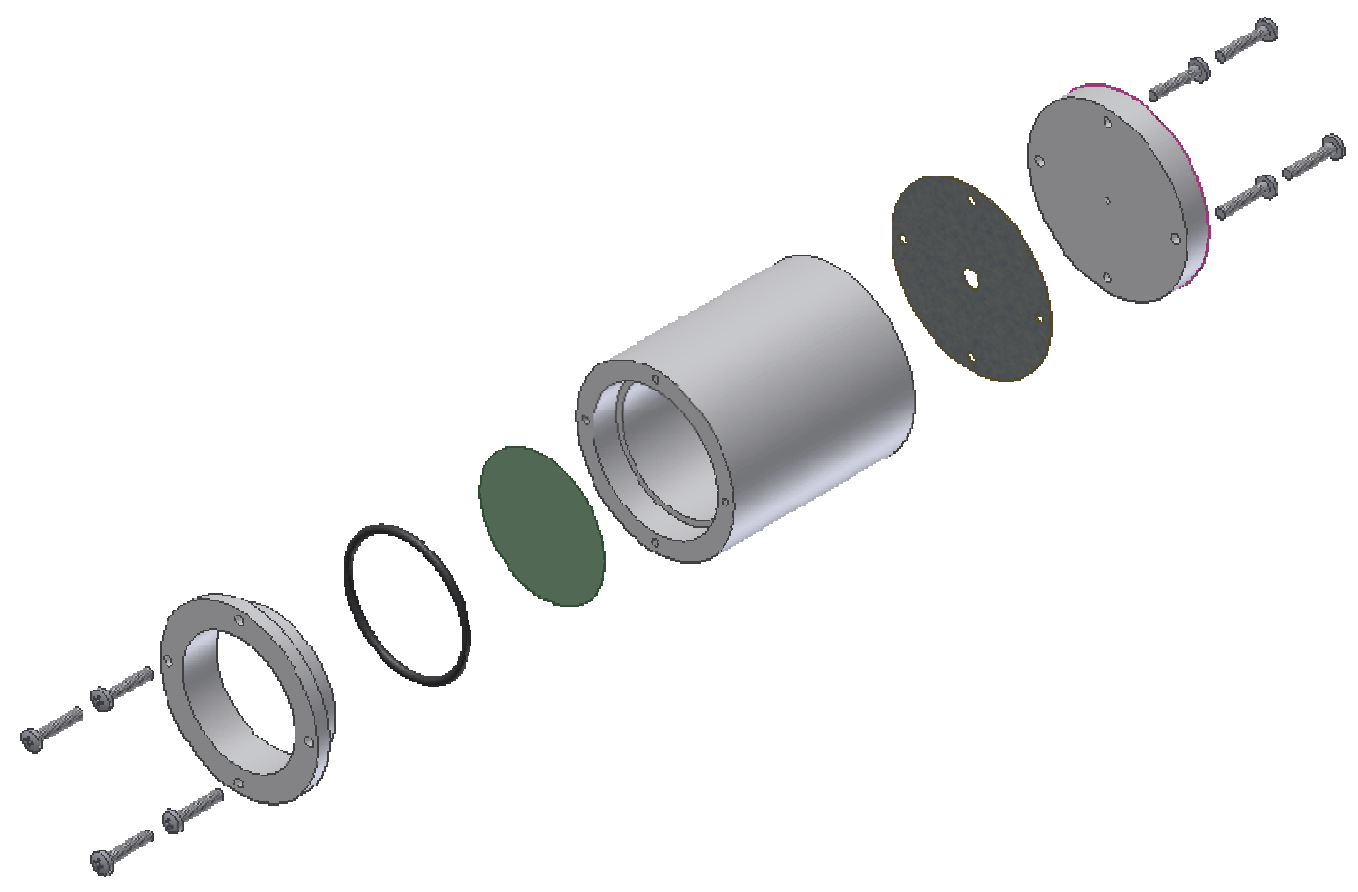

Figure 3.1-2. Exploded view of specimen holder. 
One of the key data elements of this work was accurate quantitative measurements on the material displacement given the applied pressure. The first method that was used to measure the material displacement was a dial indicator. The probe of the dial indicator was placed on the center of the material and as the material deflected the dial indicator would provide a displacement measurement. Although the dial indicator provided an excellent level of accuracy, it actually retarded the deflection of the material. The spring force in the dial indicator was large enough to push the material inward at its center, causing the material to bulge up and around the probe.

After encountering this problem it was decided a non-contact measurement device would need to be used. An infrared LED distance measuring sensor was purchased and evaluated. The sensor used was Sharp model GP2D12, shown in Figure 3.1-3. This sensor utilizes the triangulation method for its distance measurements. Light emitted from an infrared emitting diode passes through a projection lens designed to yield LED light with exceptionally sharp directionality, and irradiates the detection object. The light is diffusely reflected from the object, and if the incident light is concentrated on a light receiving element with a light receiving lens, then the position of the incident light spot on the element will vary according to the distance to the object. The distance to the detection object can thus be found by electrically detecting this incident light spot position [29]. 


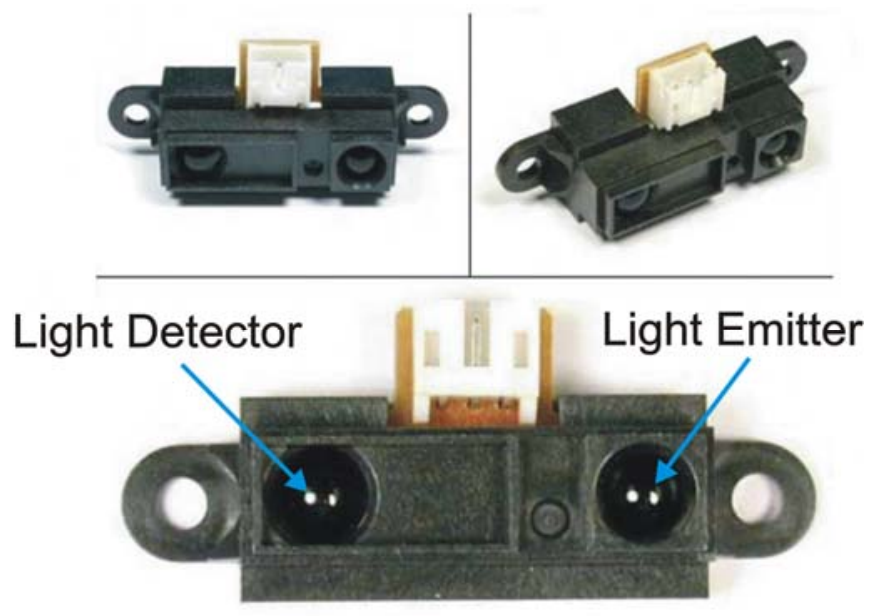

Figure 3.1-3. Image of Sharp GP2D12 infrared LED distance sensor.

Referring to Figure 3.1-4, if we let $A$ be the distance (base length) between the centers of the projection lens and light receiving lens, $f$ be the focal distance of the light receiving lens, and $x$ be the incident light spot position, we can calculate the distance to the reflected object, $\ell$, using the following equation.

$$
\ell=\frac{A \cdot f}{x}
$$

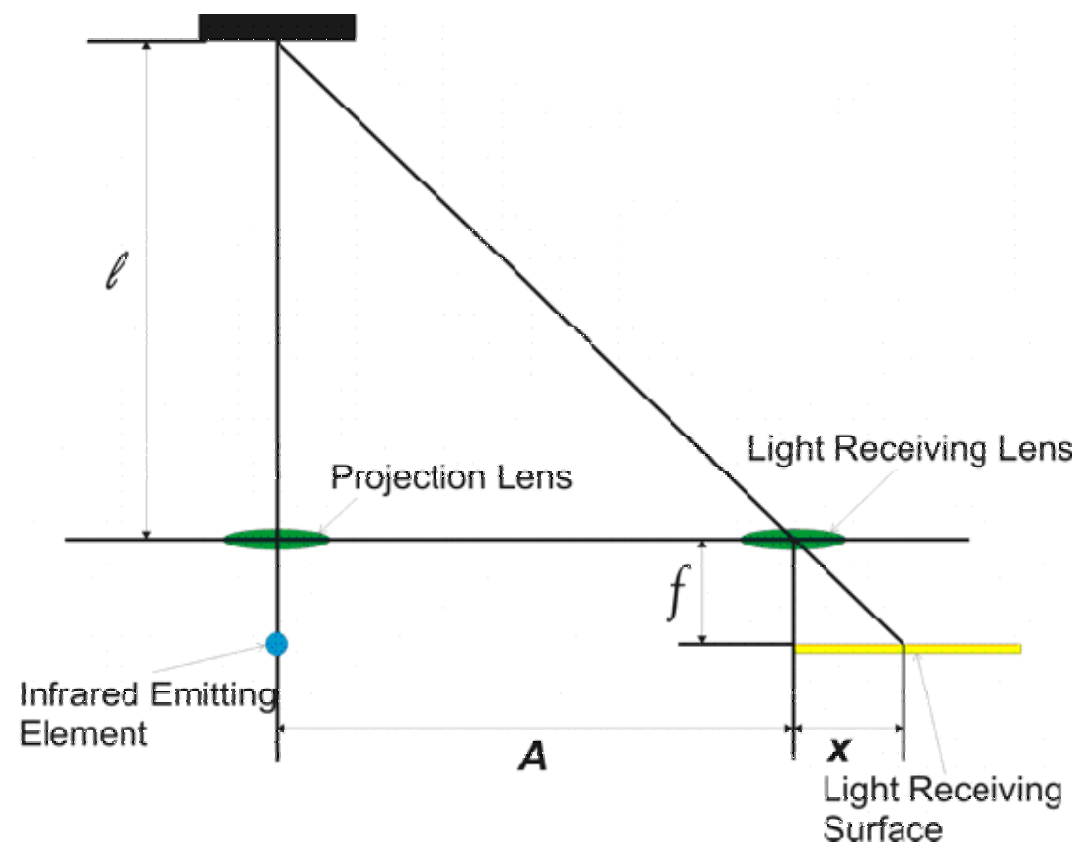

Figure 3.1-4. Display of triangulation method to determine distance from an object. 
The Sharp GP2D12 produces an analog DC voltage that is inversely proportional to the distance from an object. Therefore, the raw voltage output of the distance sensor is non-linear, as shown in Figure 3.1-5. By taking the inverse of the voltage output of the distance sensor a linear relationship is formed, as shown in Figure 3.1-6.

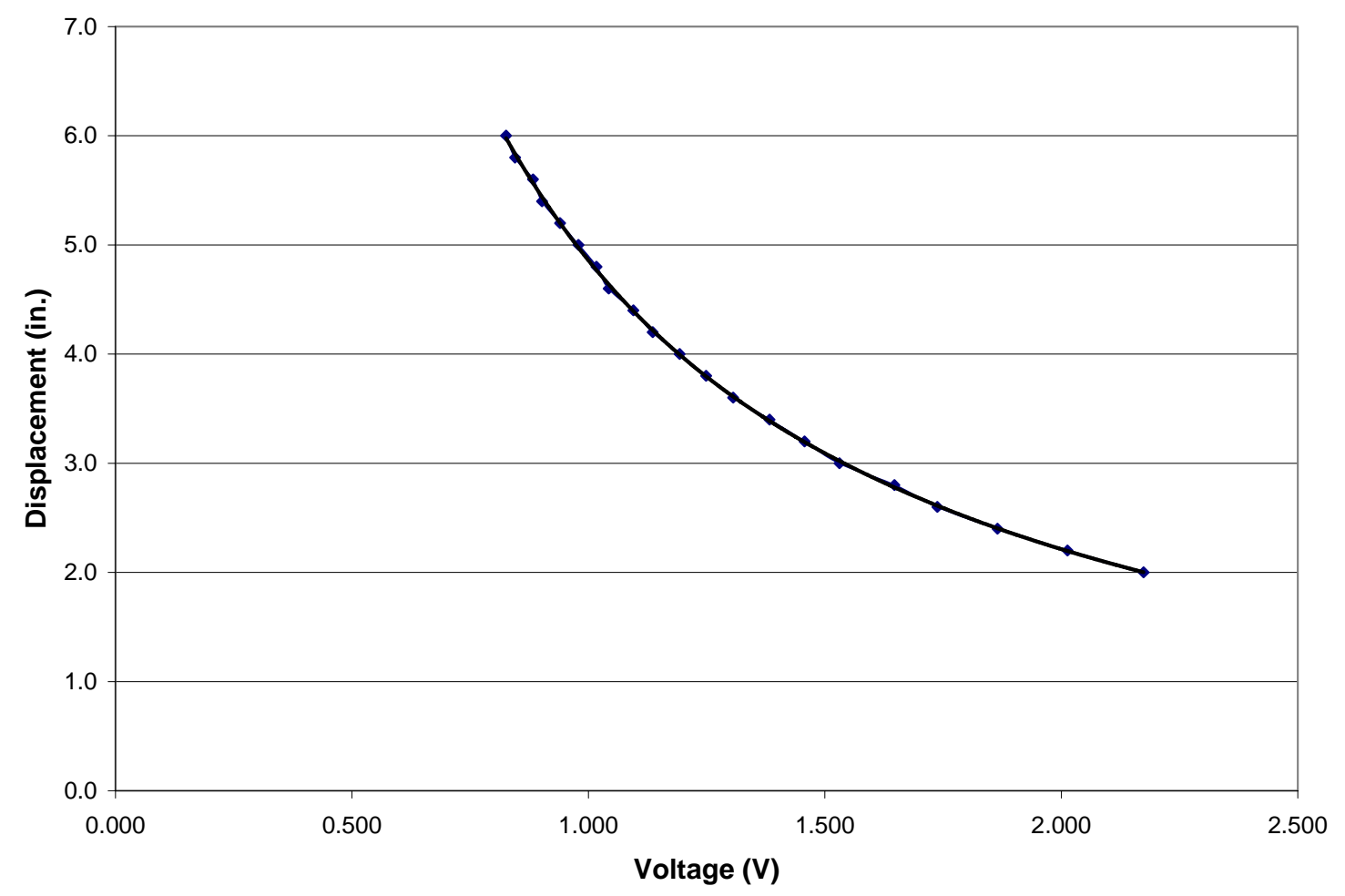

Figure 3.1-5. Raw voltage output versus displacement. 


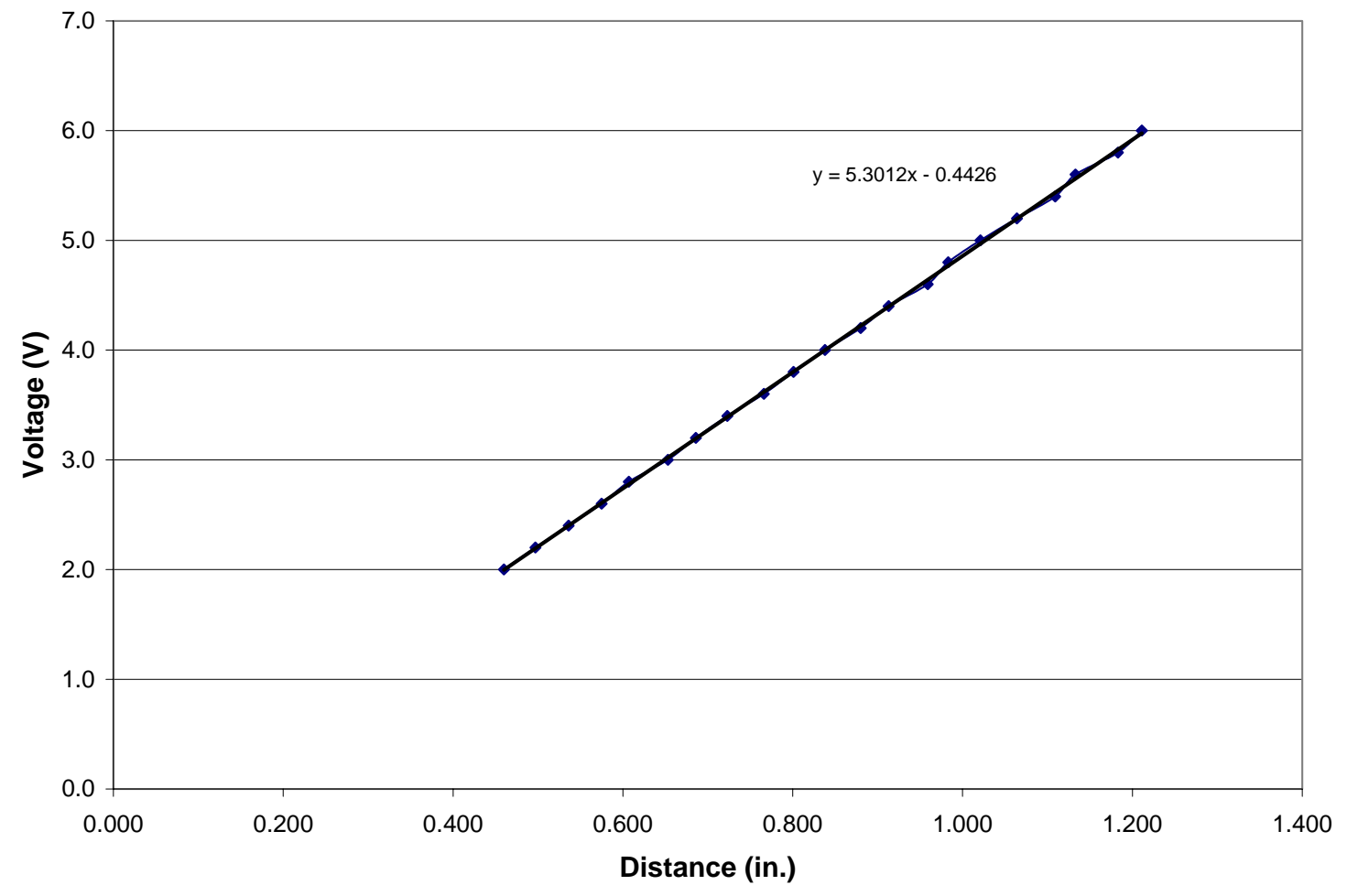

Figure 3.1-6. Inverse of voltage versus displacement with correlating linear equation used to calculate distance.

The distance sensor is powered by a 5 volt DC power supply. The output voltage is displayed by a multimeter and recorded into a spreadsheet that automatically calculates the distance based on the equation derived from the curve fit. The equation derived from the calibration curve is shown in Equation 3-4

$$
\ell=\frac{5.3012}{V}-0.4426
$$

where $\ell$ is the distance to the object in inches and $V$ is the voltage output of the displacement sensor in volts.

The pressure is measured by a pressure transducer, Omega model PX612. The pressure transducer outputs a millivolt signal that is proportional to the gauge pressure 
within the system [30]. The equation used to calculate the pressure is shown in Equation 3-5.

$$
P=\frac{3 m V}{10}
$$

$P$ is the pressure is psig and $m V$ is the output of the pressure transducer in millivolts.

\subsection{Test Procedure}

\subsubsection{Static Bulge Test}

The following outlines the procedure used to test each material using the bulge deflection test apparatus. At the time of each test the temperature and atmospheric pressure were recorded. The selected material is cut into 2.75 inch diameter circle samples. A sample is placed onto the specimen holder as described in Section 3.1. Great care must be taken to make sure there is no initial slack or stretch of the material. A rubber o-ring is then placed on top of the material to be tested. The clamp is then put into place and sealed by tightening the four bolts. Once the material is secure pressurization

of the system can occur. A small piece of white stiff paper is attached to the center of the sample to ensure the displacement sensor is reading the center deflection as shown in Figure 3.2-1. This also ensures there is no change in displacement measurement due to a change in material or its color. 


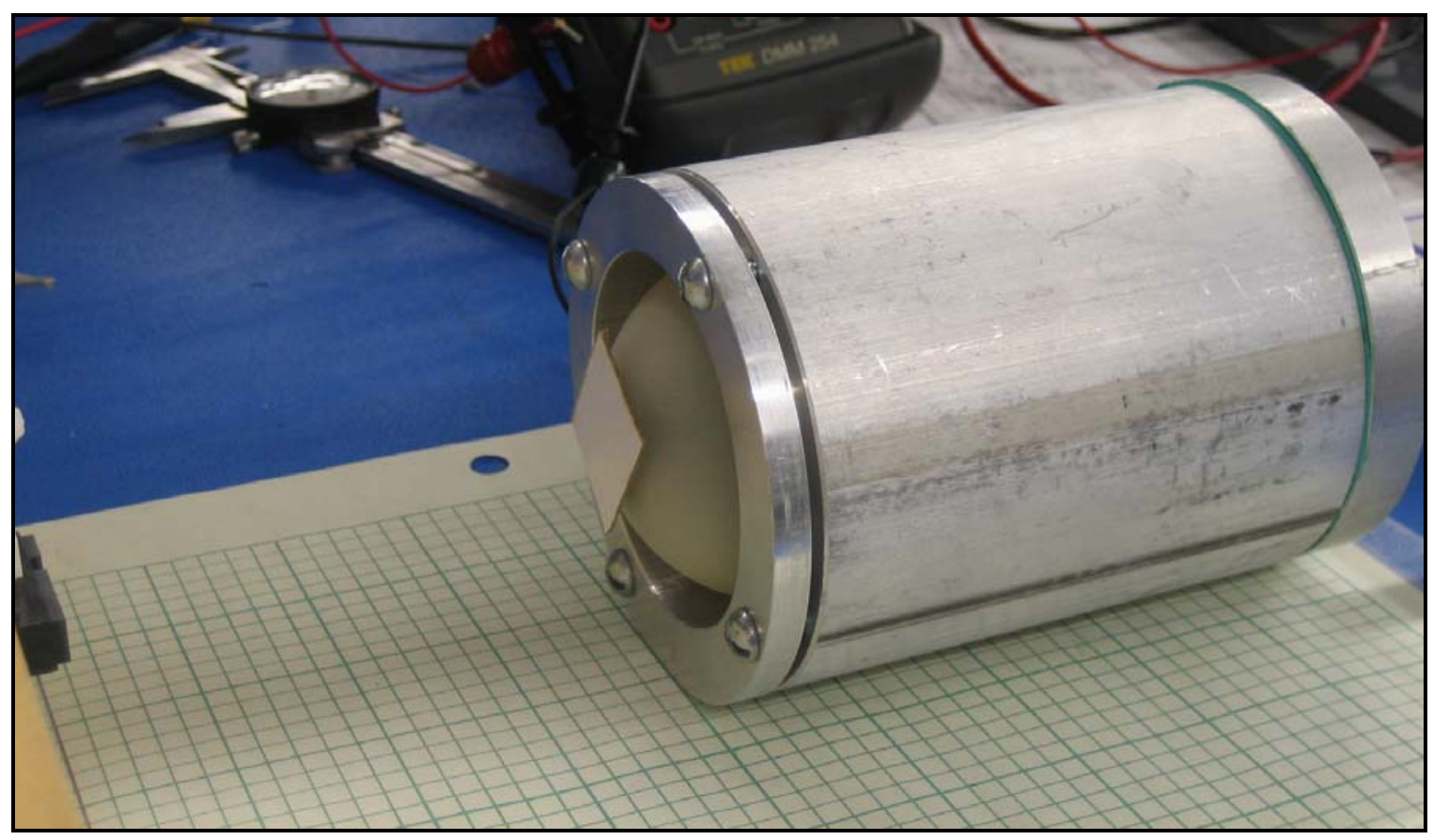

Figure 3.2-1. Latex under pressure with white paper attached to center.

The entire system is then set to its initial pressure, which is dependent on material, and the displacement sensor output is recorded. This initial displacement is then used as a zero displacement reference. This method is used as opposed to using the zero pressure point as the zero displacement reference so that if there was any slack left in the material during installation it could be accounted for by starting at a zero slack pressure. In addition, this system is based on relative displacement, which means that although a sample that had slack during installation would deflect to a different point at the same initial pressure as a sample that had zero slack, each deflection from that point should be consistent on both samples.

The system is then pressurized through a series of incremental pressure values. The pressure increment depends on the particular material being tested. For example, when testing latex rubber the displacement reached about 0.5 inches at $1.2 \mathrm{psig}$. Therefore the increment by which the pressure was increased was 0.2 psig. An increment any higher 
would cause the latex rubber to displace greatly and eventually fail before an adequate number of data points were acquired to produce a sufficient plot of pressure versus displacement. In contrast, the polyvinyl chloride (PVC) material deflected only 0.3 inches at about 15 psig. The increment used for the PVC was 1.5 psig since an increment less than that would have a series of displacements that were the same value.

After the pressure was adjusted to the next increment a small amount of time was given to allow transients to die out and the material to "relax", this was approximately 5 seconds. The voltage from the distance sensor would then be recorded. This was to make sure the material did not continue to displace or retract to a stable condition prior to measurement. Since the recovery of the material is an important aspect the material was not pressurized to rupture, at least not intentionally. Two samples of PVC accidentally ruptured before recovery measurements could be taken. Once the material exhibited signs of yielding, when the material continued to deflect as the pressure was held constant, the pressure was decreased to the same increments used to deflect the material. The pressure was also decreased at the point where the side of the material came into contact with the side of the clamping device if this occurred prior to yielding. Again, a small amount of time was given to allow the material to "relax" and then the voltage output of the distance sensor was recorded. This resulted in a plot of the recovery ability of the materials. This process was repeated on three different samples for each type of material to ensure accurate results, repeatability, and consistent data collection.

\subsubsection{Fatigue Test}

To test the fatigue characteristics of each material an adaptation of the bulge test procedure was developed. At the time of each test the temperature and atmospheric pressure were recorded. Depending on the particular material being tested a suitable 
maximum pressure was set by the regulator. The pressure used for the fatigue test was $80 \%$ of the pressure observed to initiate yielding of the particular material. This maximum pressure remained constant for the entire fatigue test. The initial output voltage from the displacement sensor was recorded at this pressure. The solenoid valves would then be activated to return the bulge system to atmospheric pressure $(0 \mathrm{psig})$. After a suitable amount of time passed to allow the system to return to atmospheric pressure the solenoid valves were then de-energized, which caused the bulge system to return to the initial pressure set by the regulator. The output voltage from the distance sensor was then recorded. This cycle was repeated 500 times to investigate any change in displacement caused by cyclic fatigue.

The frequency of pressurizing the system for each material was about 10 cycles per minute. This is a relatively small frequency which is due to the time it takes for the system to reach the designated pressure after returning to atmospheric pressure. This frequency was used for all materials to ensure each test was comparable to one another.

\subsubsection{Bulge Shape Measurement}

To ensure the Young's Modulus can be calculated using Equations 3-1 and 3-2 the shape of the bulge needed to be measured and compared to a theoretical shape. The first thought was to mount the infrared LED distance sensor onto a traversing mechanism which would move across the axis of the bulge to provide a shape profile. After initial tests the distance sensor proved to not be accurate in the lateral direction (i.e. away from the center of the bulge). This was caused by the width of the beam being too great to accurately detect the curve of the bulging material.

To remedy this problem an electronic caliper was used. The caliper was attached to a traversing mechanism that would move across the lateral axis of the material. The caliper 
would be set to zero at the edge of the material and then measurements taken at every 0.125 inches. Figure 3.2-2 displays this setup.

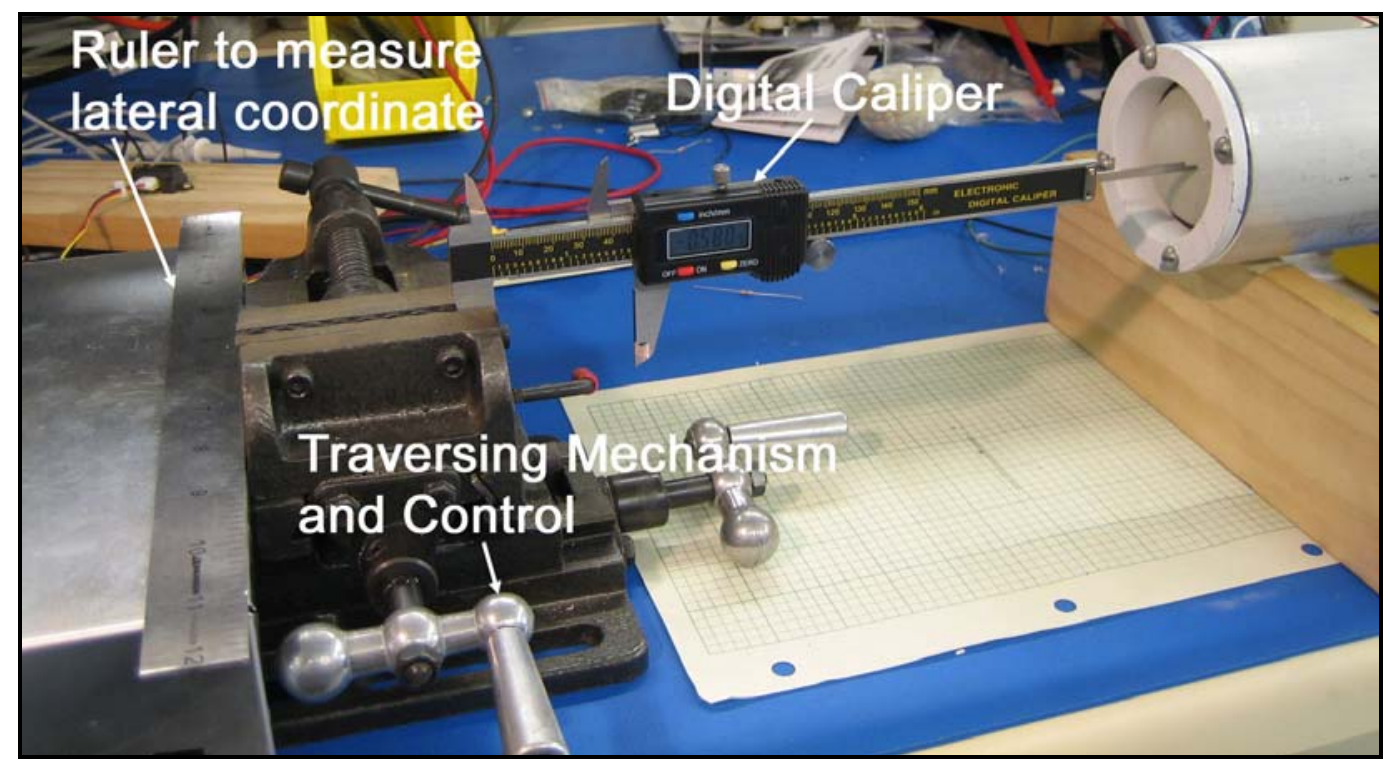

Figure 3.2-2. Bulge shape measurement setup. 


\section{CHAPTER 4: TEST RESULTS}

\subsection{Static Bulge Test}

The following section describes the results of the static bulge test. The results are organized by material and a figure is given for each material which displays the pressure versus displacement behavior of the material. The displacements are for the center of the material, which is also the point of maximum deflection. Each figure also displays all three samples of each material to show the accuracy and repeatability of the test. The solid lines for each sample represent the displacement as the pressure was increased. The dashed lines represent the recovery ability of the material or the displacement as the pressure was decreased.

Also provided in Appendix $\mathrm{E}$ is the bulge shape at three different pressures and the comparison to the theoretical shape given by Maier_Schneider et al. [31]. All three pressures are displayed on a single figure to give insight if there is any change in general shape with a change in pressure. The theoretical shape is given by Equation 4-1 [31].

$$
w(x, 0)=w_{0}\left(1+\left(0.401 \cdot \frac{x^{2}}{a^{2}}\right)\right) \cdot \cos \left(\frac{\pi x}{2 a}\right)
$$

Where $w_{0}$ is the maximum center deflection and $x$ is the radial distance from the center normalized to the maximum radius.

Error bars are present in each figure to account for test apparatus error. Appendix C describes the error induced by the distance sensor. Since a curve fit was used to find a relationship between voltage and distance there was an inherent error involved with estimating the equation of the curve. This estimation error is what is shown on the $\mathrm{x}$-axis of each pressure vs. displacement figure. The error of the pressure transducer is the error bars shown on the y-axis of the same figures. The cause of the pressure transducer error 
is accuracy limitations documented by the manufacturer [30]. This error was shown to be greater than any error caused by repeatability. The error bars appear to be different values for different materials. This is simply a difference in axis scales between materials.

\subsubsection{Rubber}

\section{A. Latex}

The results of the static bulge test for the latex rubber are shown in Figure 4.1-1. The latex samples were 0.014 inches in thickness and had a density of $58 \mathrm{lbs} / \mathrm{ft}^{3}$. The latex behaved relatively linear until the pressure reached about $1.30 \mathrm{psig}$. At this point the material started to deflect exponentially as the pressure was increased and continued to deflect even as the pressure was held constant. Therefore, any use of the material would need to stay below this pressure to prevent unpredictable displacement. The recovery of the latex was satisfactory when compared to the other materials tested. 


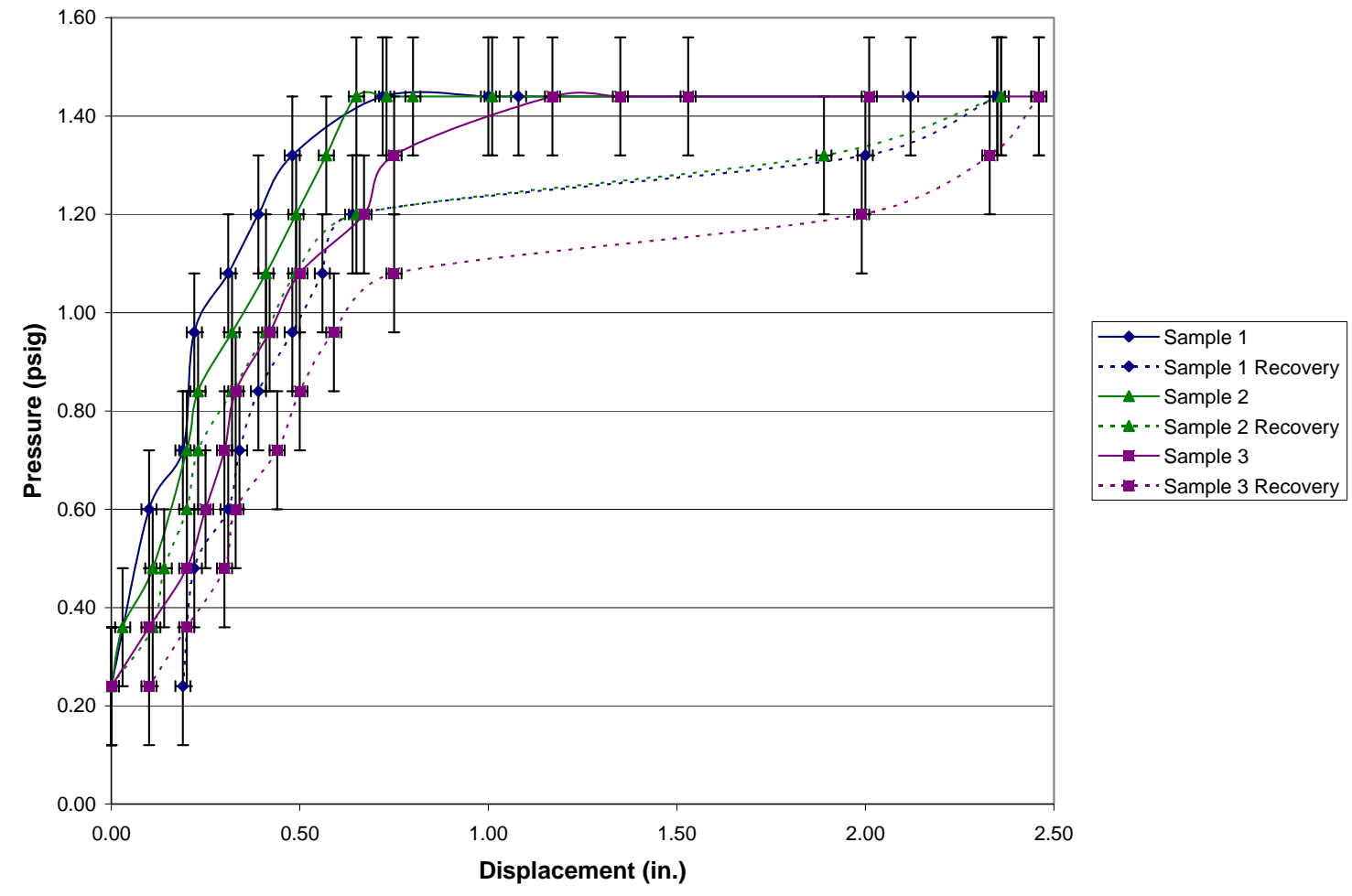

Figure 4.1-1. Pressure versus displacement results for three samples of latex rubber.

One sample of latex was pressurized to rupture to validate the design of the bulge test apparatus. When the latex ruptured the failure occurred in the middle of the sample, which validated the design, as shown in Figure 4.1-2. If the material was to fail at the edge this would indicate a stress concentration at that point. The latex sample ruptured at 2.5 psig, which is not shown in Figure 4.1-1. This is due to the fact that beyond about 1.50 psig the latex material started to come into contact with the rim of the clamping device as shown in Figure 4.1-3. In an effort to reduce errors caused by this contact the corresponding data was ignored. 


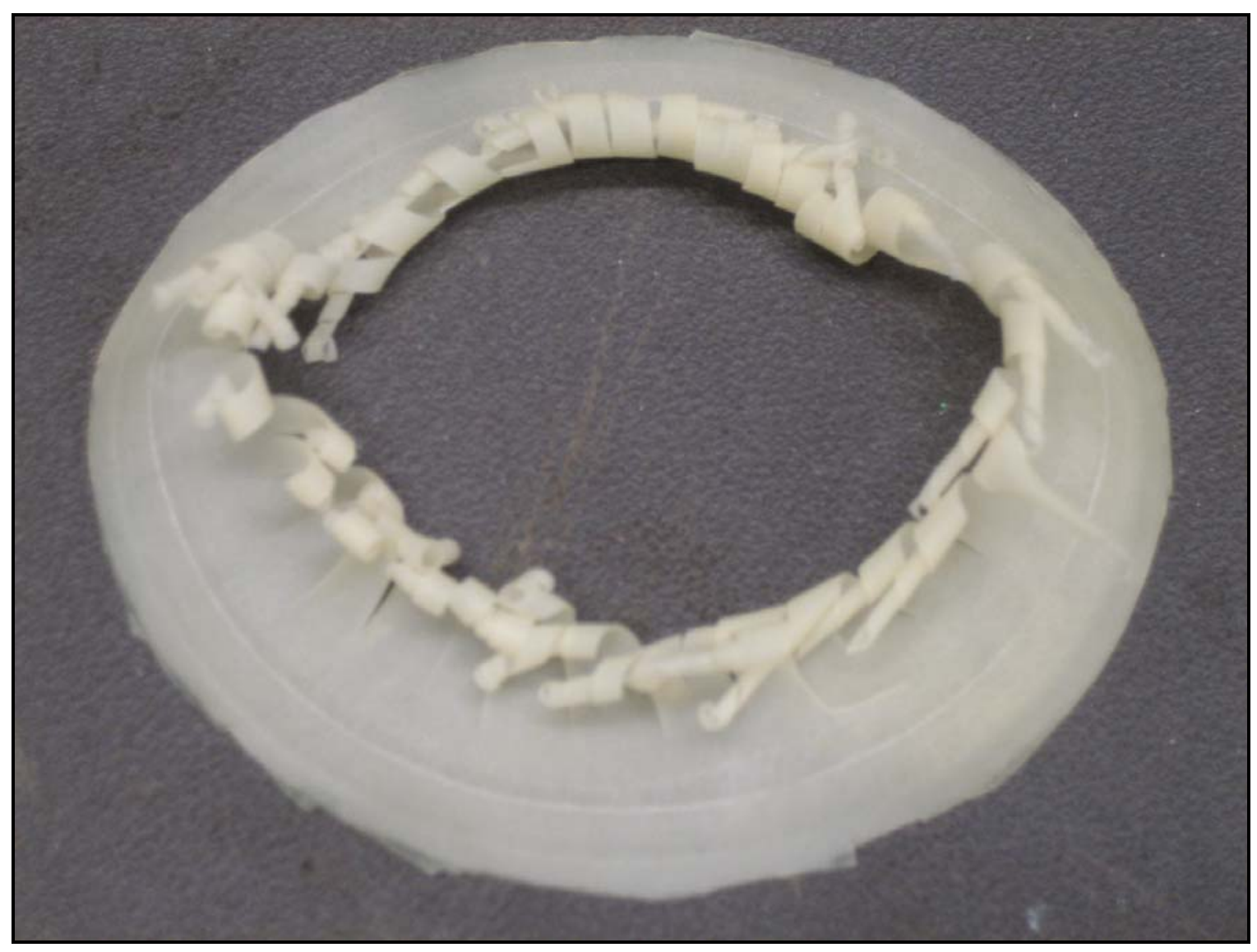

Figure 4.1-2. Latex rubber sample pressurized to rupture to validate bulge test design.

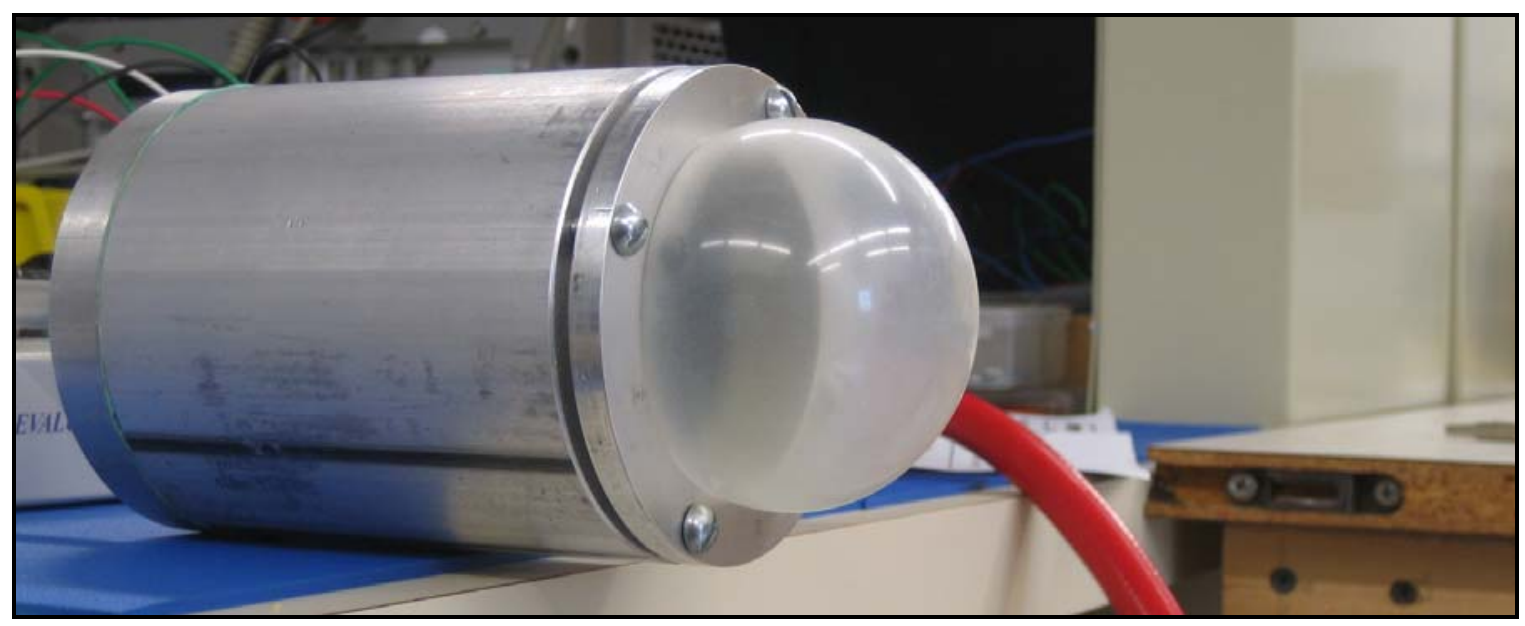

Figure 4.1-3. Latex rubber sample that was pressurized to rupture, showing the contact with the edge of clamping device.

Shown in Figure 4.1-4 is the shape measurement of a latex sample at three different pressures: 0.33 psig, $1.08 \mathrm{psig}$, and $1.2 \mathrm{psig}$. The comparison to the theoretical model is 
also shown as the solid line. The adherence to the theoretical shape is relatively consistent for all the materials tested. As the pressure was increased the correlation between experimental and theoretical results became closer. Since this is the behavior for all the materials tested the shape measurement are listed in Appendix E as opposed to in each material's results section.

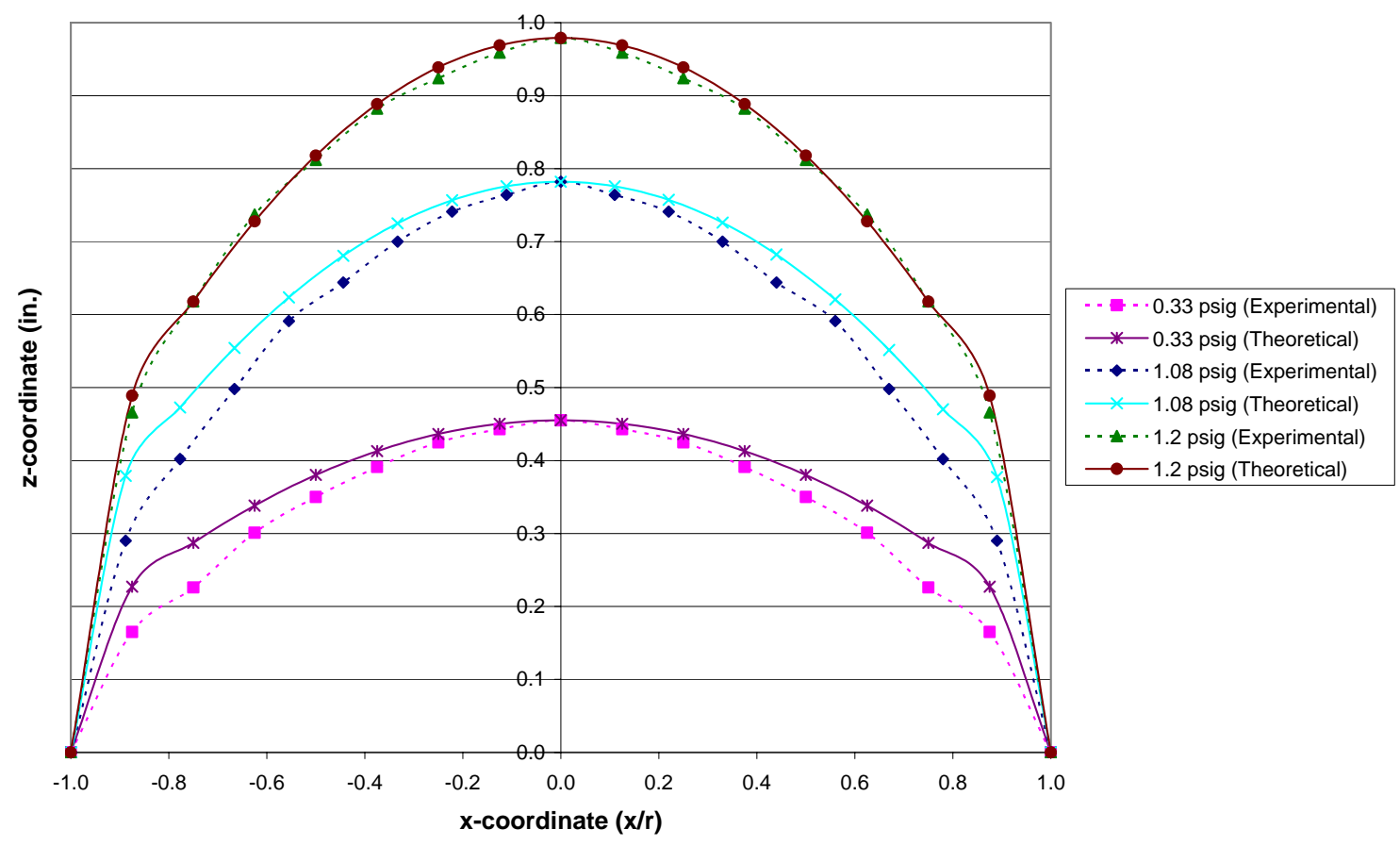

Figure 4.1-4. Bulge profile measurement for latex rubber.

\section{B. Neoprene}

The results of the static bulge test for the neoprene rubber are shown in Figure 4.1-5. The neoprene samples were 0.015 inches thick and had a density of $74 \mathrm{lbs} / \mathrm{ft}^{3}$. All the neoprene samples tested did not rupture. The maximum pressure for the test was limited to contact between the deflecting sample and the edge of the clamping device. The figure shows that the neoprene deflected almost linearly throughout the testing and did not reach a pressure that represented yielding, as the latex did. 


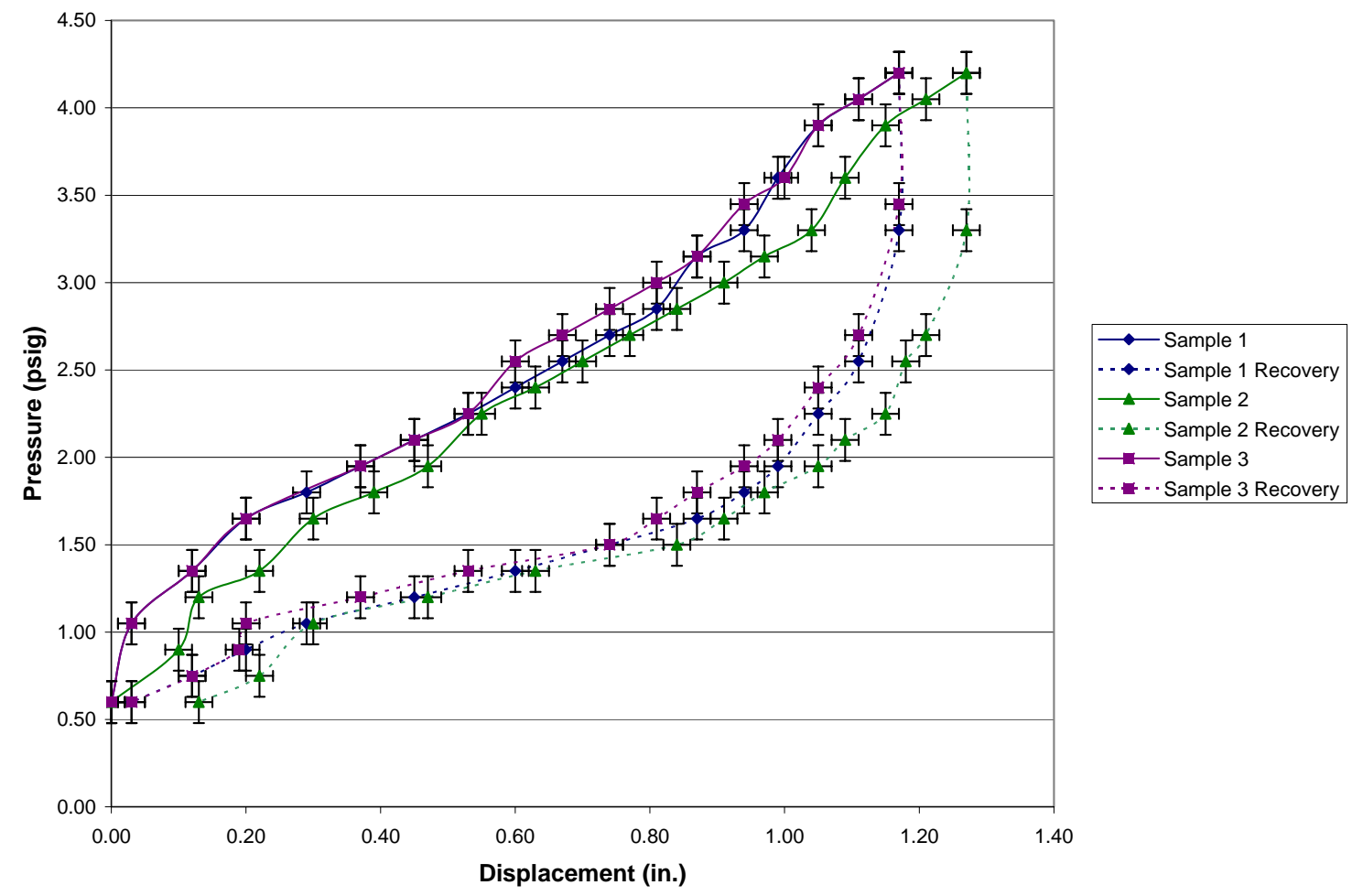

Figure 4.1-5. Pressure versus displacement results for three samples of neoprene rubber.

The recovery of the neoprene was not as good as that of latex, but still satisfactory. As shown in Figure 4.1-5, as in almost all of the materials tested to some extent, the neoprene samples did not follow the pressure deflection relationship during the recovery curve. At a given pressure the center displacement was greater during the recovery portion as opposed to the initial pressurization. This is caused by the chains in the material becoming more aligned during the pressurization curve. As the pressure is decreased it takes time for the chains to become more random and return to the state they were in before pressurization. 


\section{C.Silicone}

The results of the static bulge test for the silicone rubber are shown in Figure 4.1-6. The silicone samples were 0.015 inches thick and had a density of $76 \mathrm{lbs} / \mathrm{ft}^{3}$. As in the case for the neoprene the limit of the pressure was induced by contact between the material and the side of the clamp. The silicone behaved relatively linear throughout the pressurization, yet it showed significant signs of permanent deformation. Again, there is noticeable difference between the initial pressurization curve and the recovery curve.

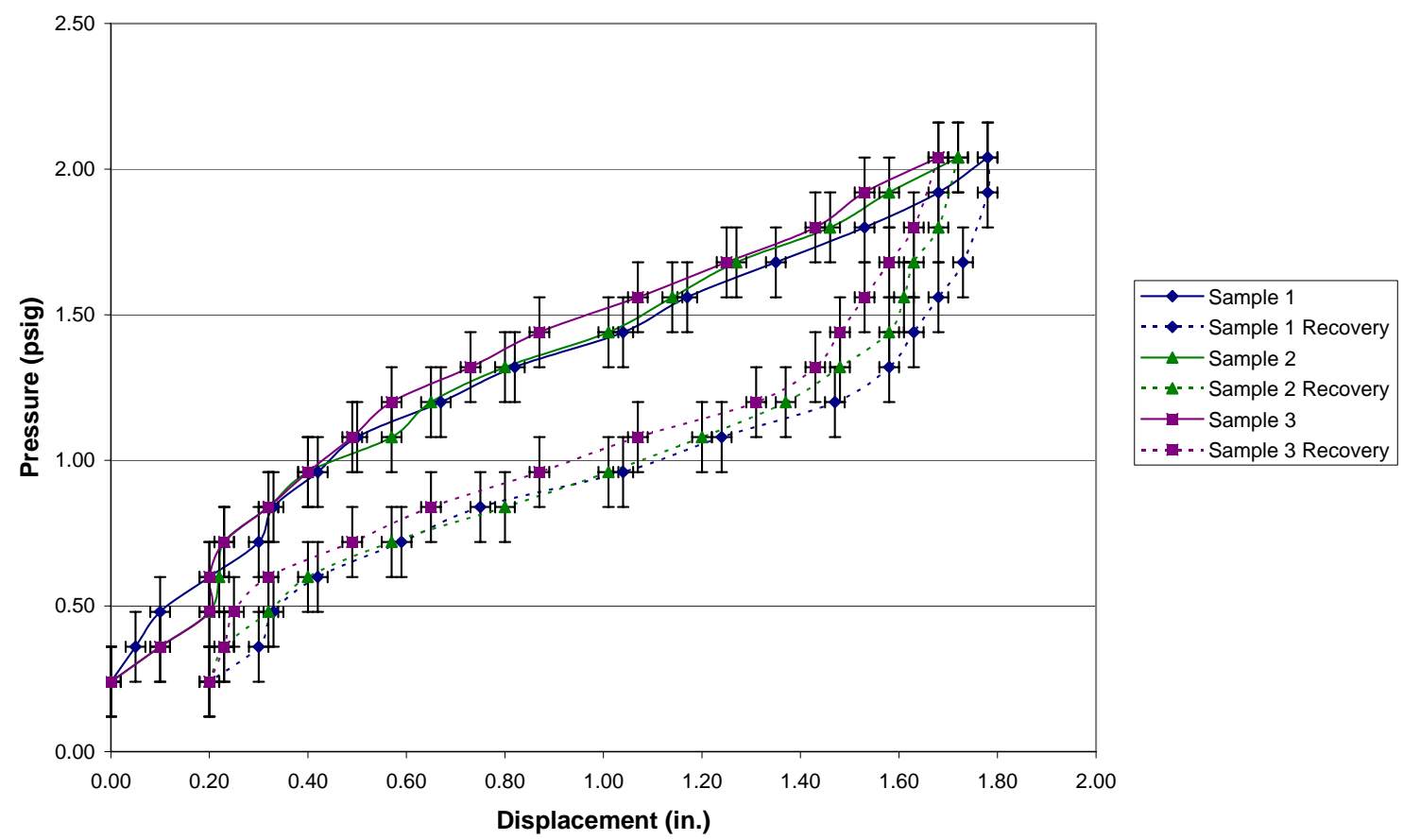

Figure 4.1-6. Pressure versus displacement results for three samples of silicone rubber.

After removing the silicone sample from the bulge test apparatus there was a noticeable amount of plastic (permanent) deformation as shown in Figure 4.1-7. In the figure the maximum plastic deformation is shown to be about 0.21875 inches (7/32"). 


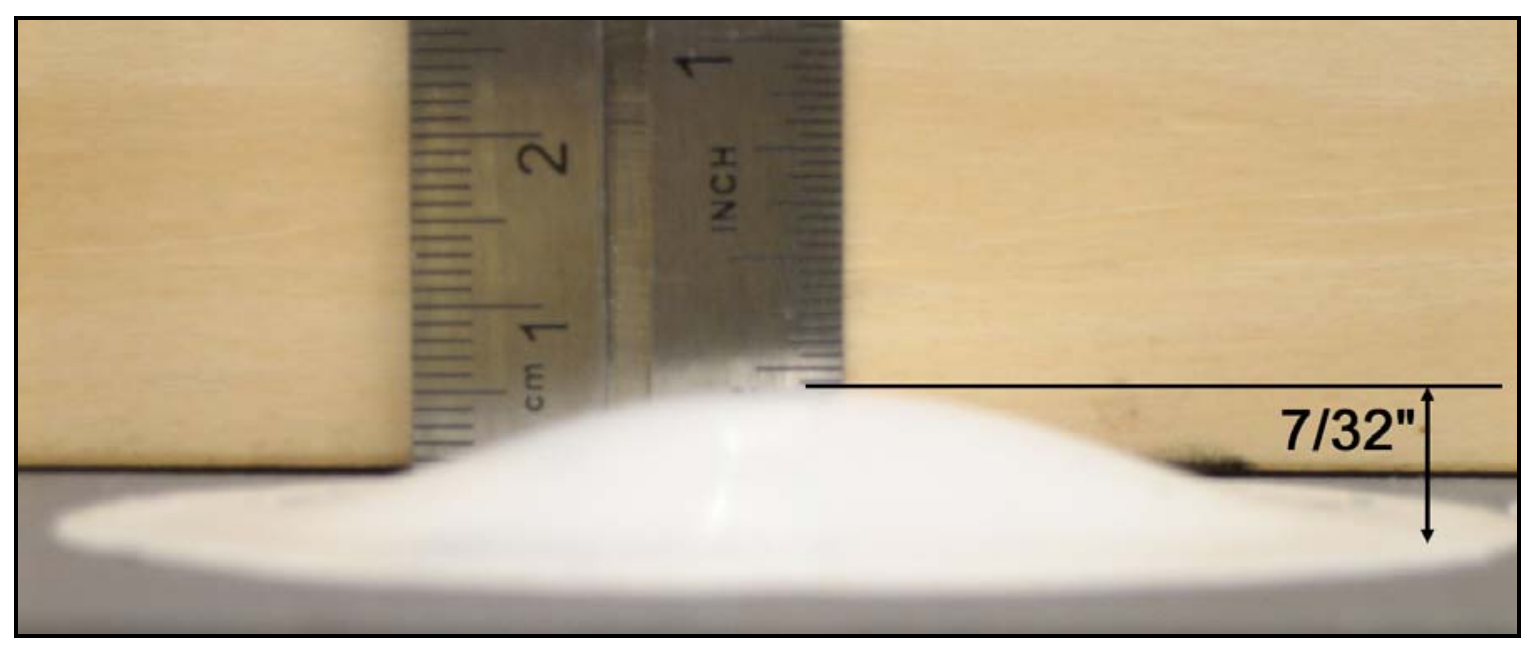

Figure 4.1-7. Plastic deformation of silicone rubber sample.

\section{D.ECH (Epichlorohydrin)}

The results for the static bulge test for the ECH rubber is shown in Figure 4.1-8. The samples of ECH rubber tested were 0.03125 inches thick and had a density of $87 \mathrm{lbs} / \mathrm{ft}^{3}$. The slope of the curve is non-linear, showing that the material deflects exponentially more as the pressure is increased. A yield limit can also be seen at about $9.00 \mathrm{psig}$. At this point the material continues to deflect as the pressure is held constant, although at a slower rate than that of latex. The recovery of the material is also considerably worse than the previous tested materials. The recovery curve is clearly the worst out of all the rubbers tested. There is a great difference between the pressure displacement relationship during initial pressurization and during recovery. This was also the thickest rubber material tested, which may have had an effect on its recovery characteristics. 


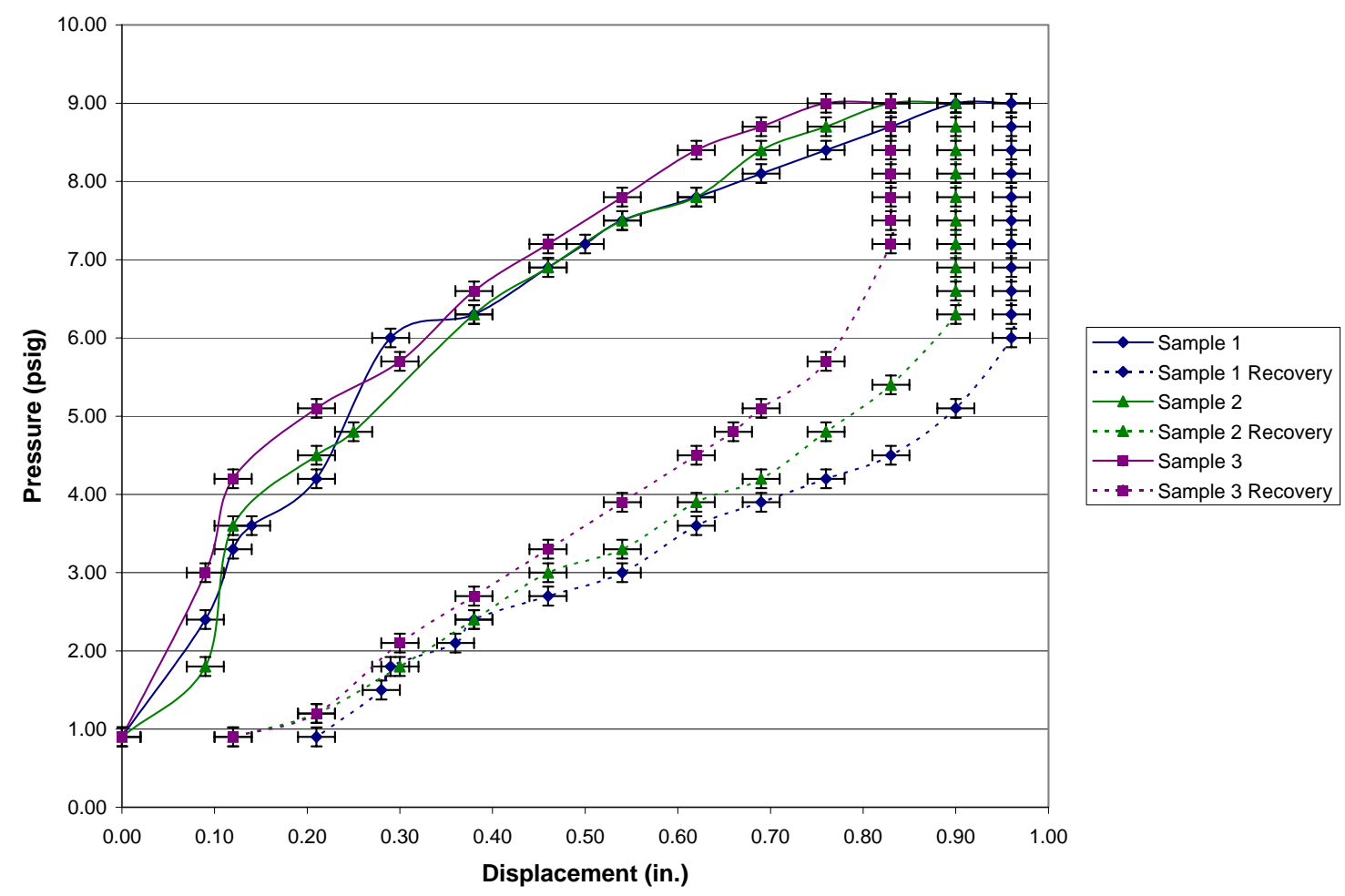

Figure 4.1-8. Pressure versus displacement results for three samples of ECH rubber.

The ECH samples also showed permanent deformation after testing. This plastic deformation can be seen in Figure 4.1-9. The maximum amount of plastic deformation is about 0.1875 inches (3/16").

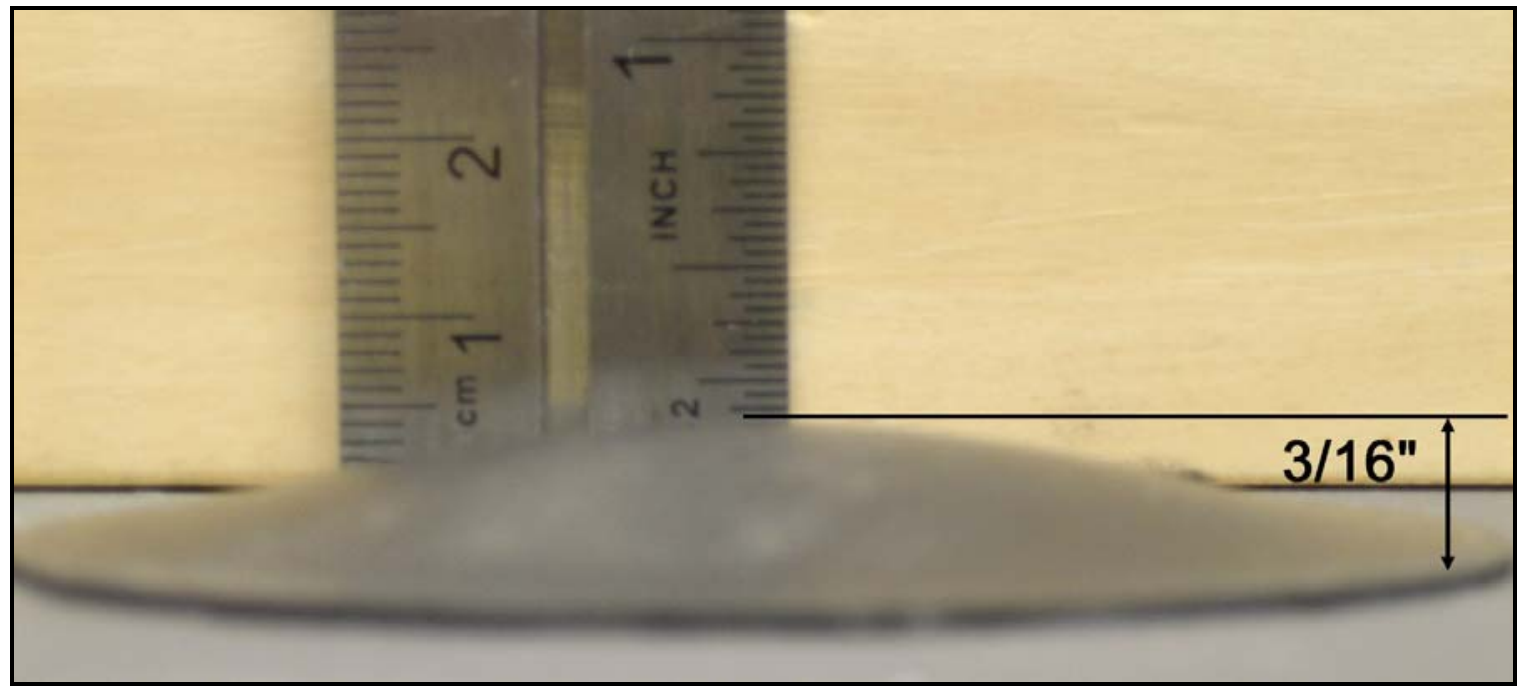

Figure 4.1-9. Plastic deformation of ECH rubber sample. 


\subsubsection{Polyurethane}

The results of the static bulge test for polyurethane are shown in Figure 4.1-10. The polyurethane samples tested were 0.015 inches thick and had a density of $74 \mathrm{lbs} / \mathrm{ft}^{3}$. The displacements of the polyurethane samples remain linear up to about $10.8 \mathrm{psig}$. After that point the displacement increases exponentially until yield at $12.00 \mathrm{psig}$. At this point the polyurethane samples continue to deflect while the pressure is held constant. The recovery of the polyurethane is also quite poor. The recovery curve of the polyurethane is also quite worse than that of all the rubbers. It is also shown that there is relatively a small center displacement before yielding occurs and the pressures required for this material were larger than that of the rubbers tested.

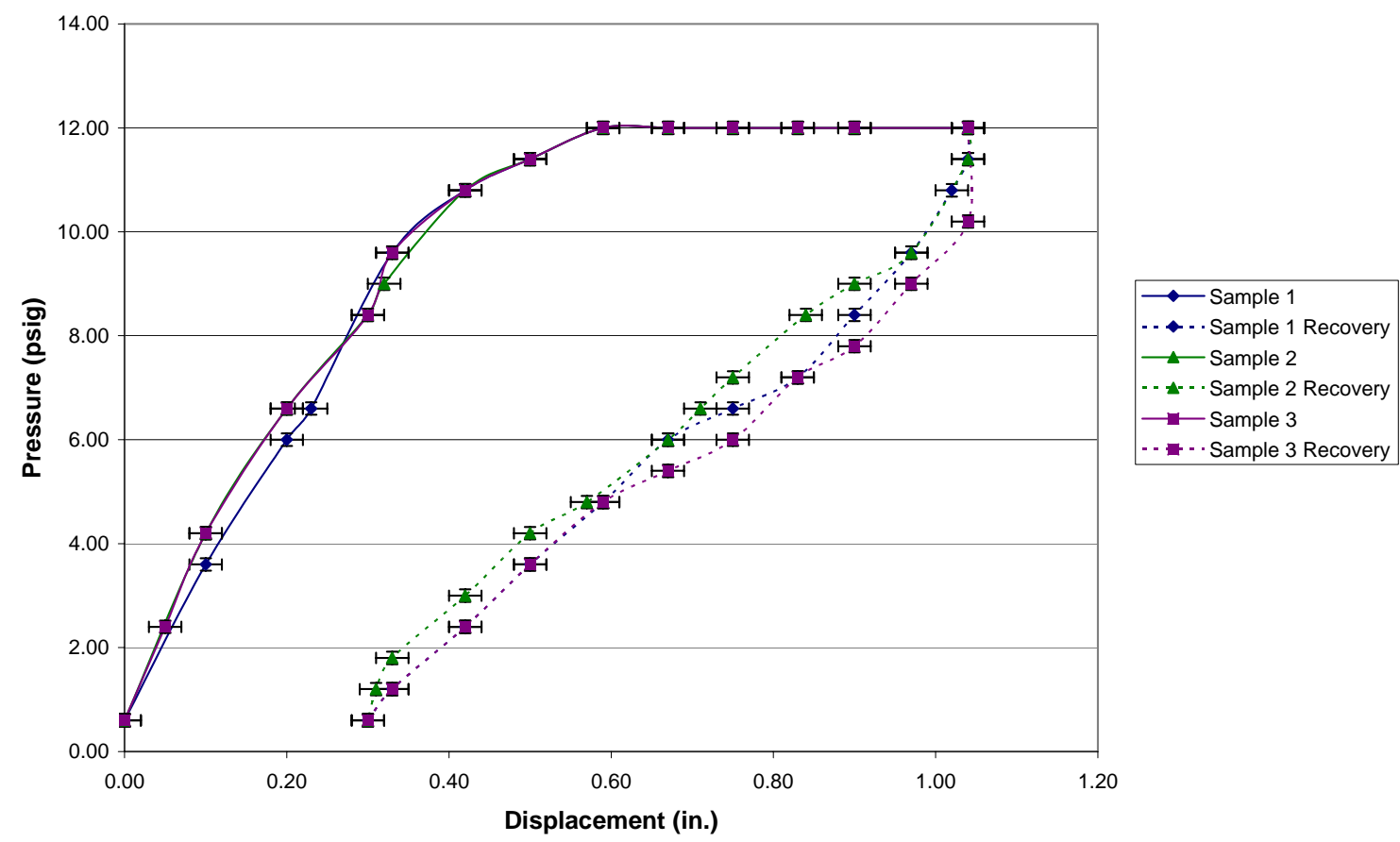

Figure 4.1-10. Pressure versus displacement results for three samples of polyurethane.

After testing the samples there was a noticeable amount of plastic deformation as shown in Figure 4.1-11. The polyurethane samples were not pressurized to rupture, 
although there was obvious yielding and plastic deformation. The maximum amount of plastic deformation can be seen from the figure, which is about 0.4375 inches (14/32").

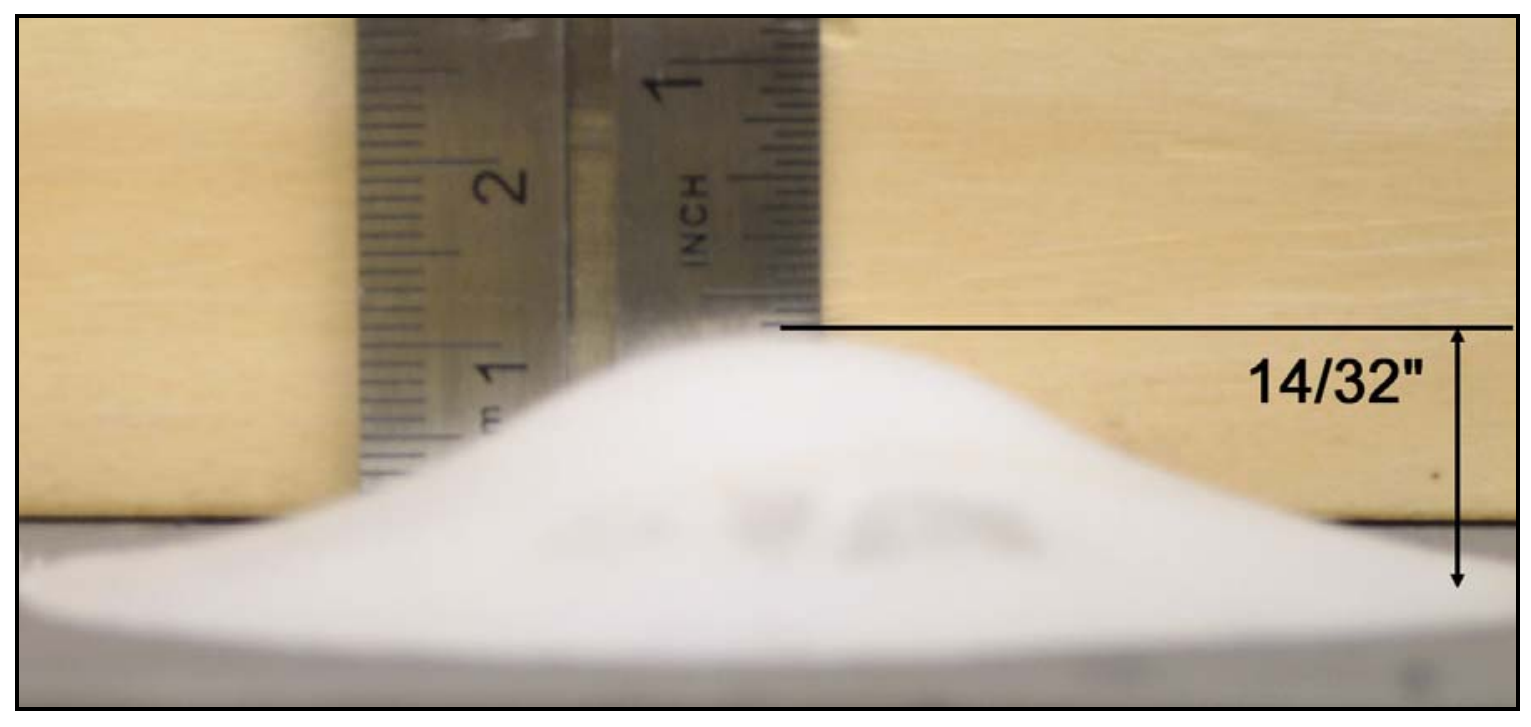

Figure 4.1-11. Plastic deformation of polyurethane sample.

\subsubsection{Woven Material}

\section{A.Lycra}

The results of the static bulge test for the Lycra are shown in Figure 4.1-12. The samples of Lycra were 0.025 inches thick and had a density of $15 \mathrm{lbs} / \mathrm{ft}^{3}$. In contrast to the other materials tested the Lycra samples showed a point at which the material resisted stretching with an increase in pressure, at about 2.5 psig. In addition, the rate of recovery is similar to the rate of pressurization. This is observed by the similarity in slope for both curves (solid lines and dashed lines). 


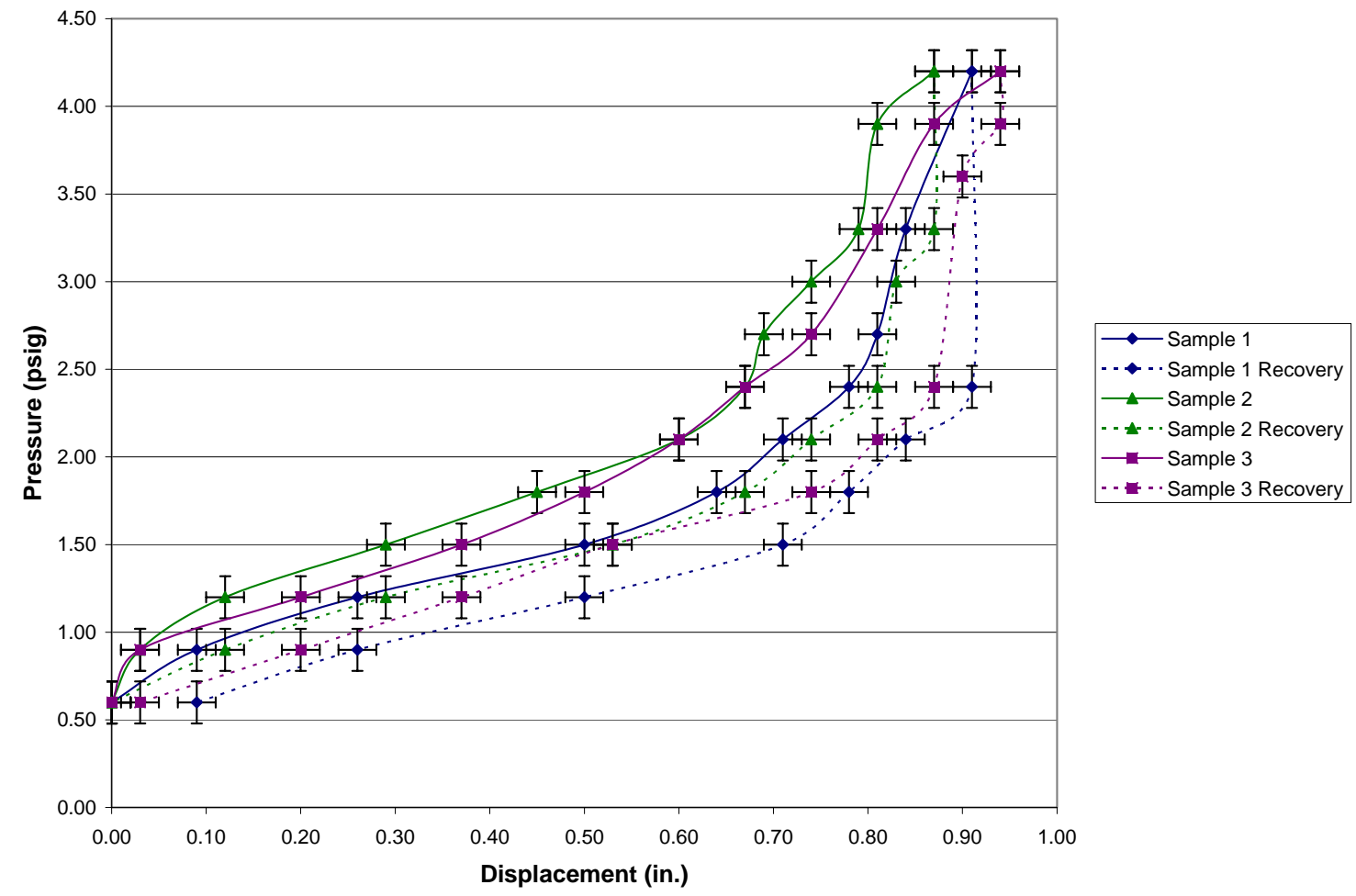

Figure 4.1-12. Pressure versus displacement results for three samples of Lycra placed on top of latex rubber.

\subsubsection{Thermoplastic Elastomer (TPE)}

\section{A.Santoprene}

The results of the static bulge test for the Santoprene samples are shown in Figure 4.1-

13. The Santoprene samples were 0.03125 inches thick and had a density of $75 \mathrm{lbs} / \mathrm{ft}^{3}$. As shown in the figure the samples deflected in a non-linear nature up to about $6.30 \mathrm{psig}$, at which point there was obvious yielding. At this point the pressure was held constant and the Santoprene continued to deflect. 


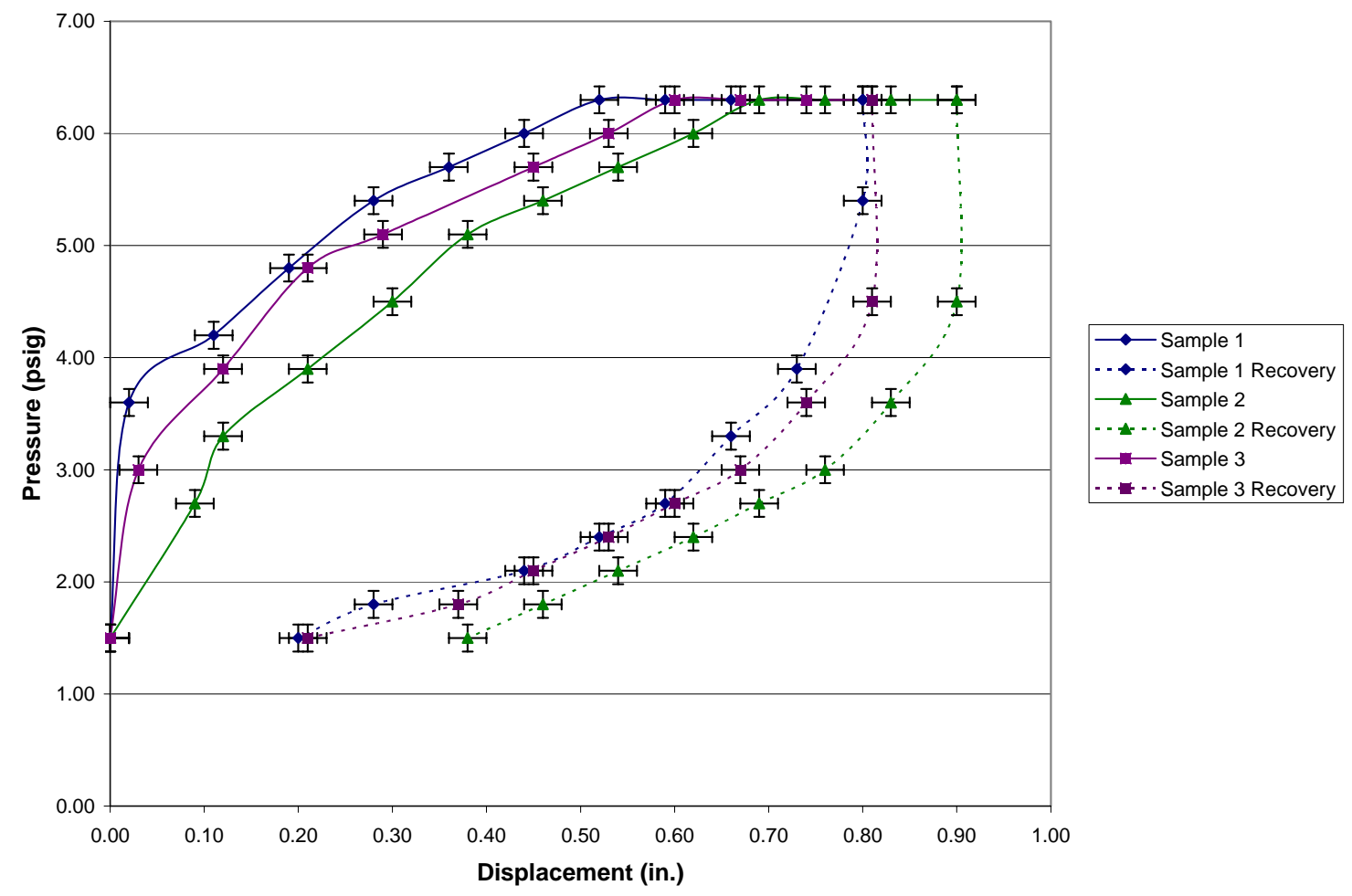

Figure 4.1-13. Pressure versus displacement results for three samples of Santoprene.

Although the Santoprene samples were thicker than the polyurethane samples they yielding at a lower pressure. The recovery curve is also quite poor as is its ability to return to its initial shape. After testing, the Santoprene samples also showed signs of plastic deformation. The maximum amount of permanent deformation is shown to be 0.25 inches (1/4”) in Figure 4.1-14. 


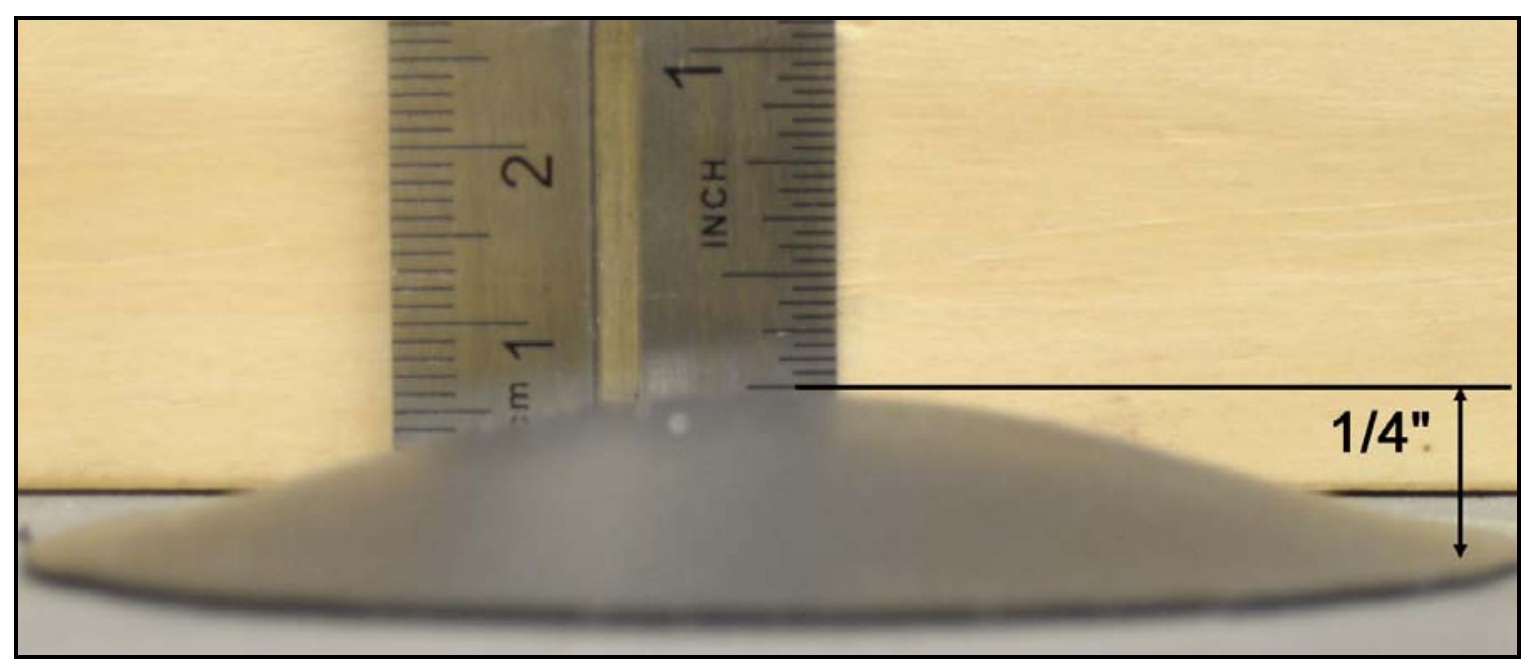

Figure 4.1-14. Plastic deformation of Santoprene sample.

\subsubsection{Plastic}

\section{A.Polyvinyl Chloride (PVC)}

The results of the static bulge test for the polyvinyl chloride (PVC) are shown in Figure 4.1-15. The PVC samples were 0.0625 inches thick and had a density of 96 $\mathrm{lbs} / \mathrm{ft}^{3}$. There was a clear point of yielding in the PVC samples at about $20.00 \mathrm{psig}$, as shown in the figure. At this point the samples start to deflect exponentially as the pressure is increased. Two of the three samples ruptured, both at about $24.00 \mathrm{psig}$. To make sure a recovery plot could be made the third sample was only pressurized to 21.00 psig. As shown the recovery of the PVC sample is extremely poor. 


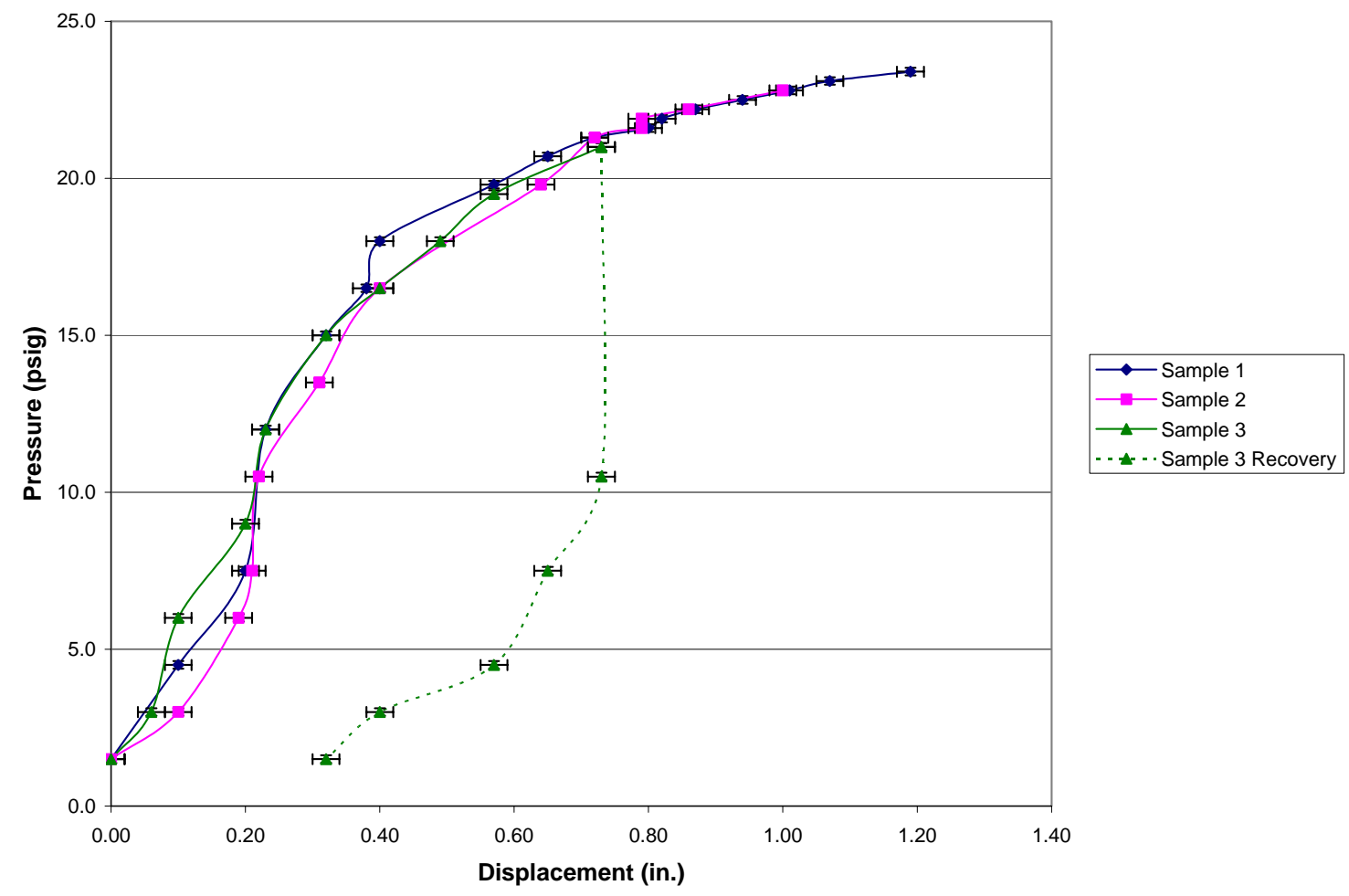

Figure 4.1-15. Pressure versus displacement results for three samples of polyvinyl chloride (PVC).

On the ruptured samples and the non-ruptured sample, there was obvious plastic deformation which is shown in Figure 4.1-16. The maximum amount of deflection is shown to be about 0.3125 inches (5/16”).

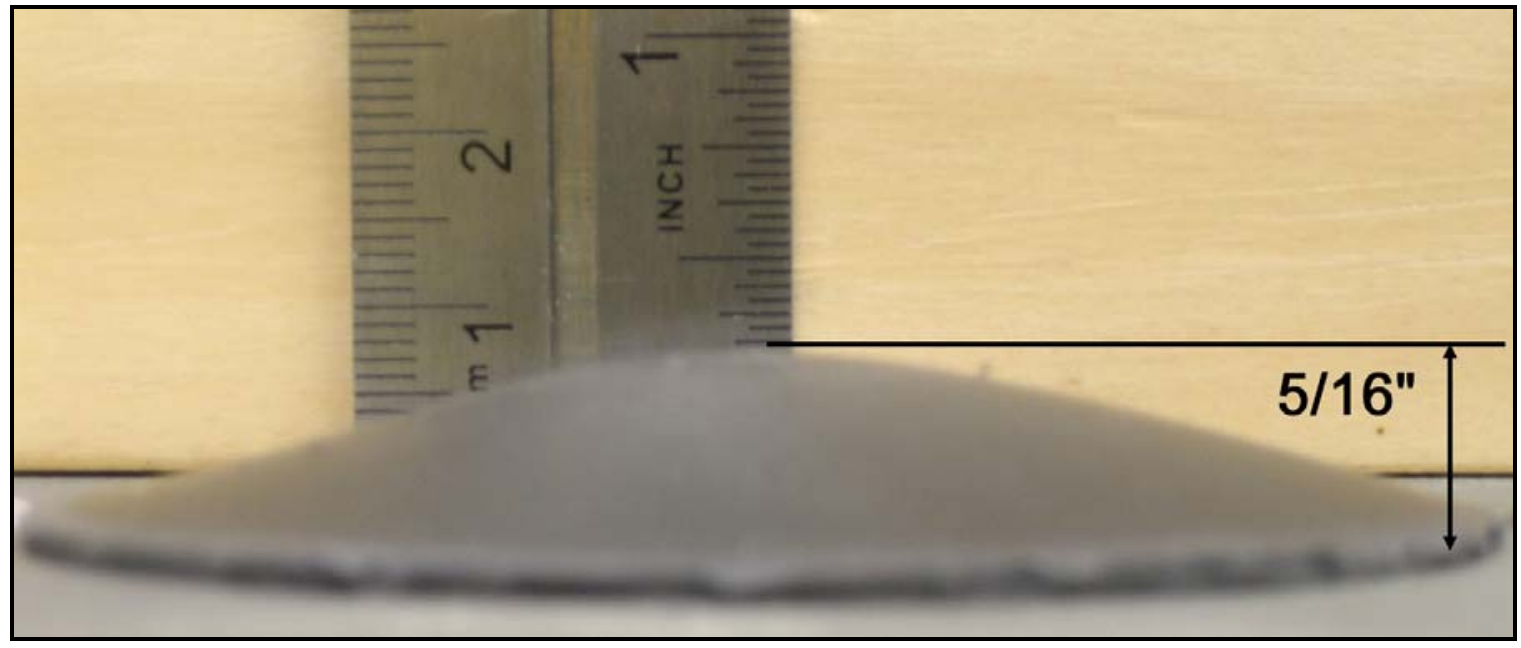

Figure 4.1-16. Plastic deformation of polyvinyl chloride (PVC) sample. 
Both ruptured samples of PVC ruptured in the center of the sample as shown in Figure 4.1-17. This adds to the validation of the bulge test design and clamping mechanism.

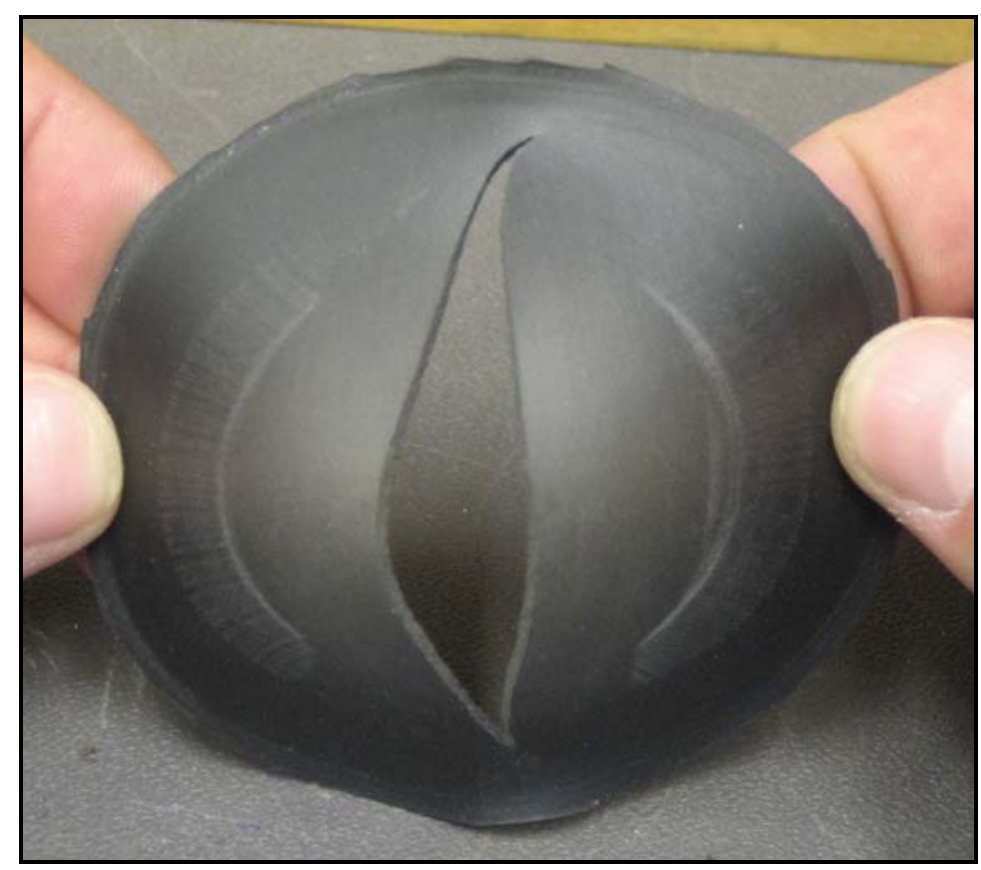

Figure 4.1-17. Ruptured polyvinyl chloride (PVC) sample.

\subsection{Fatigue Test}

As stated in the test procedure the frequency of the cyclic fatigue test was about 10 cycles per minute. This limited the amount of cycles that could be done due to the procedure not being automated. This required a researcher to manually cycle the pressures by energizing the solenoid valves. Although only 500 cycles were completed during the fatigue testing, the results are still a good comparison of the materials tested. This amount of cycles was enough to show fatigue in most of the materials.

The best way to display the fatigue results is in a single plot of displacement versus cycles. This way all materials can be easily compared to one another. This plot is shown in figure 4.2-1. 


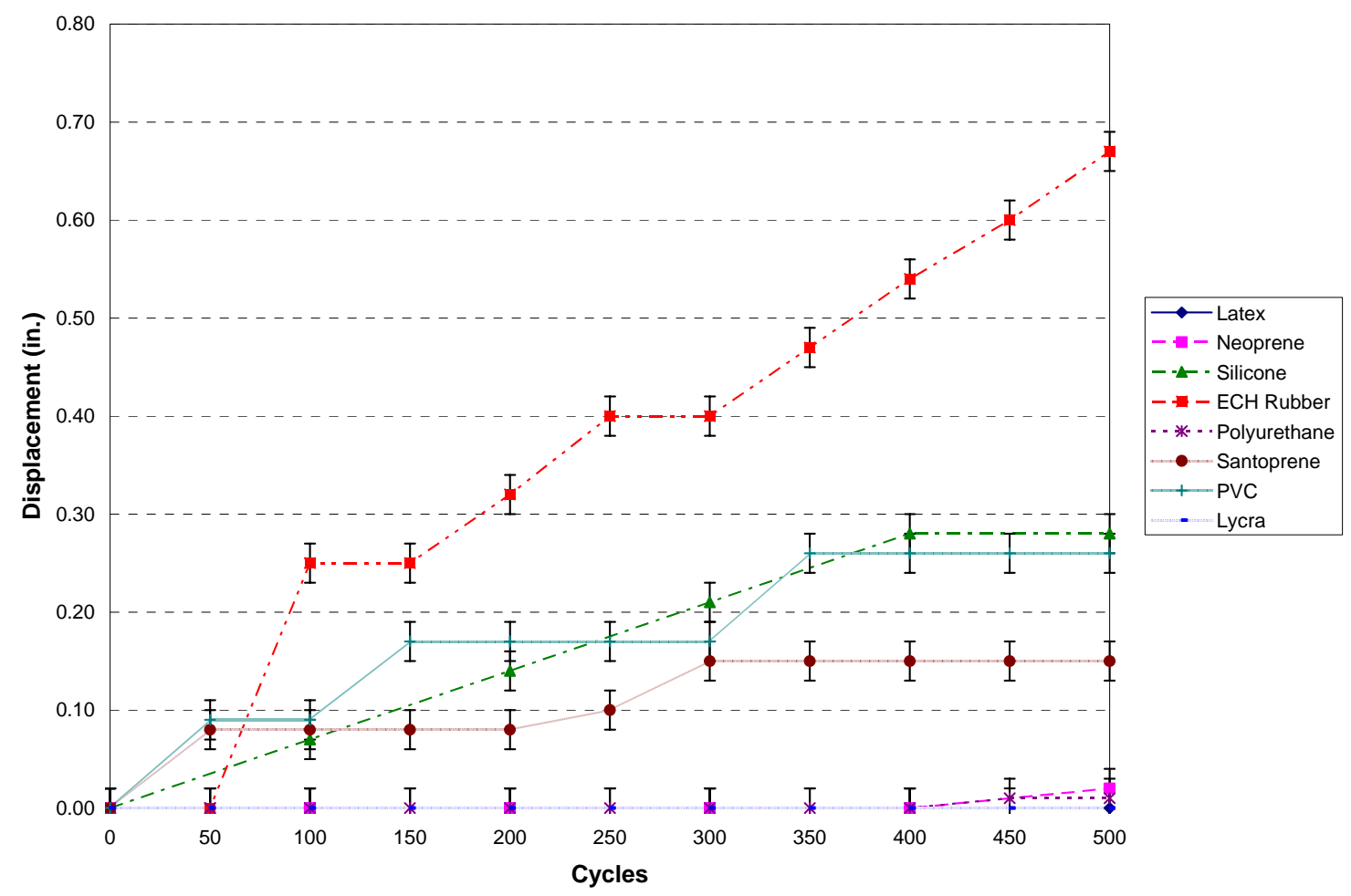

Figure 4.2-1. Results of the cyclic fatigue tests for all materials.

By viewing the results one can see that both the latex and Lycra samples did not show any signs of fatigue throughout the tests. The polyurethane and neoprene samples showed very small signs of fatigue near the end of the tests. A flexible material used on a morphing wing would be stretched each time a maneuver (turn, climb, dive, etc...) was performed. Therefore it is reasonable to compare the use of the flexible material to that of an aileron on a conventional aircraft. The mechanisms of an aileron are the most utilized component of an aircraft's control system, giving evidence to the need for a material that has excellent fatigue characteristics. A thermocouple was also attached to a sample of Santoprene to investigate whether temperature effects were induced by the fatiguing cycle. There was only a $0.2^{\circ} \mathrm{F}$ change in temperature during the entire test. Therefore, fatigue due to thermal stress was negligible. 


\subsection{Comparison of Results}

Table 4.3-1 provides a comparison of the materials based on the yielding characteristics. Provided in the table is the point in pressure when yielding occurred and the corresponding displacement at that point. This is the displacement measured at the onset of yield.

Table 4-1. Material yielding comparison.

\begin{tabular}{|l|c|c|}
\hline \multicolumn{1}{|c|}{ Material } & $\begin{array}{c}\text { Pressure at Yielding (psig) } \\
( \pm 0.12 \mathrm{psig})\end{array}$ & $\begin{array}{c}\text { Displacement at Yielding (in.) } \\
( \pm 0.02 \text { in. })\end{array}$ \\
\hline Latex & 1.3 & 0.57 \\
\hline Neoprene* & N/A & N/A \\
\hline Silicone* & N/A & N/A \\
\hline ECH & 9.0 & 0.76 \\
\hline Polyurethane & 10.8 & 0.42 \\
\hline Lycra** & 2.5 & 0.74 \\
\hline Santoprene & 6.3 & 0.60 \\
\hline PVC & 20.0 & 0.64 \\
\hline
\end{tabular}

*Neoprene and Silicone samples did not reach a yielding point. The values given are the values at time of contact with edge of bulge test apparatus.

**Lycra samples showed a limit in stretch with increase in pressure at this point in pressure.

Latex rubber encountered yielding at the lowest pressure of all the materials while the PVC samples experienced yielding at the greatest pressure. The silicone rubber and neoprene rubber samples did not experience yielding and also displayed the greatest amount of stretch without yielding.

The previous table displaying latex yielding at the lowest pressure and PVC at the highest pressure seems to be related to the next comparison. Table 4.3-2 lists the amount of displacement encountered after the pressure was returned to zero. This is a version of a recovery comparison. Although the latex yielded at the lowest pressure, it performed satisfactory in recovery, ranking number third. Contrary to this the PVC was the worst out of all the materials tested even though it did not experience yielding until 20.0 psig. The top performer in recovery was the combination of Lycra and latex rubber. The 
combination of Lycra and latex also showed the best rate of recovery when compared to the rest of the materials. This makes the Lycra stand out from the rest of the materials tested because of its predictability when the pressure is increased or decreased.

Table 4-2. Final displacement at initial pressure after recovery.

\begin{tabular}{|l|c|}
\hline \multicolumn{1}{|c|}{ Material } & $\begin{array}{c}\text { Displacement after Recovery (in.)* } \\
( \pm 0.02 \text { in. })\end{array}$ \\
\hline Latex & 0.10 \\
\hline Neoprene & 0.06 \\
\hline Silicone & 0.20 \\
\hline ECH & 0.15 \\
\hline Polyurethane & 0.30 \\
\hline Lycra & 0.04 \\
\hline Santoprene & 0.26 \\
\hline PVC & 0.32 \\
\hline
\end{tabular}

*Value is the average for the three samples tested of each material, except for PVC in which two samples ruptured.

The UAV developed by WVU was test flown using latex rubber as the flexible material located on the morphing wing. The amount of stretch was measured by placing a total of four dots on the latex, a set of two to measure the chord-wise stretch and another set of two to measure the span-wise stretch of the latex. The chord-wise stretch, which was the greatest amount, was $0.35 \mathrm{~cm}(0.138 \mathrm{in}$.). The span-wise stretch was 0.1 $\mathrm{cm}(0.04$ in.). The amount of stretch was measured while the wing was in full deflection. Table 4.3-3 displays the amount of pressure required to create a center deflection of 0.35 $\mathrm{cm}(0.138$ in.) for each material. 
Table 4-3. Amount of pressure required to create a center deflection of $0.35 \mathrm{~cm}(0.138 \mathrm{in}$.$) .$

\begin{tabular}{|l|c|}
\hline \multicolumn{1}{|c|}{ Material } & $\begin{array}{c}\text { Pressure (psig)* } \\
( \pm 0.12 \mathrm{psig})\end{array}$ \\
\hline Latex & 0.54 \\
\hline Neoprene & 1.36 \\
\hline Silicone & 0.45 \\
\hline ECH & 3.93 \\
\hline Polyurethane & 4.96 \\
\hline Lycra & 1.11 \\
\hline Santoprene & 3.99 \\
\hline PVC & 5.73 \\
\hline
\end{tabular}

*Value is the average for the three samples tested of each material.

The latex samples needed the least amount of pressure to deflect the needed amount. This relates to the amount of energy or force a servo or other type of device would need to deflect the latex. As expected the PVC required a much greater amount of pressure to deflect the same amount. This data is paramount when trying to find a combination of material and flexing mechanism to keep the efficiency of a morphing wing attainable.

From the data collected using the bulge test the material that seems to provide a good compromise of properties is neoprene rubber. It does not require a large amount of pressure to deflect, recovers well, and did not reach a yielding point during testing. The UAV developed by WVU was first designed to use neoprene, although a few complications arose. First, the density of neoprene is about $74 \mathrm{lbs} / \mathrm{ft}^{3}$, which was heavy enough the push the center of gravity too far aft. Also, it was seen that the neoprene had a tendency of ripping easily if a small tear was introduced. After these setbacks the neoprene was replaced with latex, which performed extremely well during test flights. As a comparison the density of latex is $58 \mathrm{lbs} / \mathrm{ft}^{3}$.

Another material that performed well was Lycra. Lycra also did not require a large amount of pressure to deflect and had the best recovery properties of all the materials tested. In addition, the density of the Lycra was about $15 \mathrm{lbs} / \mathrm{ft}^{3}$, which is nearly a quarter 
of the density of latex. It would be very interesting and worthwhile to develop a way to cure latex with a woven structure so that it combines the best properties of each material. 


\section{CHAPTER 5: DISCUSSION OF RESULTS}

The static bulge test and the cyclic fatigue test attempted to evaluate the candidate materials for flexibility, elasticity, and fatigue behavior. Although the tests do not cover all the requirements previously mentioned for a candidate flexible wing skin, they provide a starting point for recommending materials for further study. This further study could help predict the problems that were encountered with the neoprene rubber on the WVU UAV flight demonstrator, including the tear strength of the material.

\subsection{Material Separation}

As stated previously a key motivation for using the bulge test method was to investigate the point in which a material will separate from the wing support structure due to the pressure on the surface. The cause of the material deflection is due to the difference in pressure on the wing's surface and the surrounding atmosphere. A dimensionless coefficient called the pressure coefficient is used to evaluate this pressure difference. The equation to find the pressure coefficient at a point on the surface of a wing is given in Equation 5-1.

$$
C_{p}=\frac{p-p_{\infty}}{\frac{1}{2} \rho U_{\infty}^{2}}=\frac{\Delta p}{\frac{1}{2} \rho U_{\infty}^{2}}
$$

Where $p$ is the pressure at that point on the wing, $p_{\infty}$ is the atmospheric pressure around the wing, $\rho$ is the density of the fluid the wing is surrounded by (usually air), $U_{\infty}$ is the free stream velocity of the fluid moving past the wing, and $\Delta p$ is the difference in pressure between the point on the wing's surface and the atmospheric pressure around the wing. This pressure difference, $\Delta p$, can be equated to the gage pressure used to deflect the material tested by the bulge apparatus. 
The pressure coefficient is a function of airfoil geometry and angle of attack [32]. Therefore, if the pressure coefficient for a particular airfoil or wing is known, the corresponding air speed needed to deflect a material due to the pressure on the wing surface can be found. As stated before, any change in wing camber or thickness can increase drag or cause other unwanted aerodynamic conditions. If a critical material deflection value is calculated, the corresponding maximum velocity, $U_{\infty, \max }$, can be evaluated by rearranging Equation 5-1, the resulting equation is shown below. It is important to note that the set of equations and examples that follow are derived from 2-D flow characteristics below a Mach number of 0.3. Above a Mach number of 0.3 compressibility effects become apparent and the pressure coefficient varies with Mach number [32]. This is a simplification of the actual 3-D flow that is seen on an actual wing. Although this simplification is made and limits the applicability, this does give insight on the methodology used to predict the onset of ballooning and a useful approximation.

$$
U_{\infty, \text { max }}=\sqrt{\frac{2 \Delta p}{C_{p} \rho}}
$$

For example, a Cessna 172 aircraft's wing uses a NACA 2412 airfoil shape. At an angle of attack of $8^{\circ}$ there is a pressure coefficient of almost -4 near the leading edge. Assume that if there is a change in thickness greater than 0.1 inches, unwanted flow characteristics will occur. By consulting the results of the bulge test one can see that latex will deflect 0.1 inches at about 0.48 psig and neoprene will deflect the same amount at about $0.97 \mathrm{psig}$. With the given values the maximum velocity before deflection can be found at a certain altitude. Figure 5-1.1 displays the relationship between maximum velocity and altitude. 


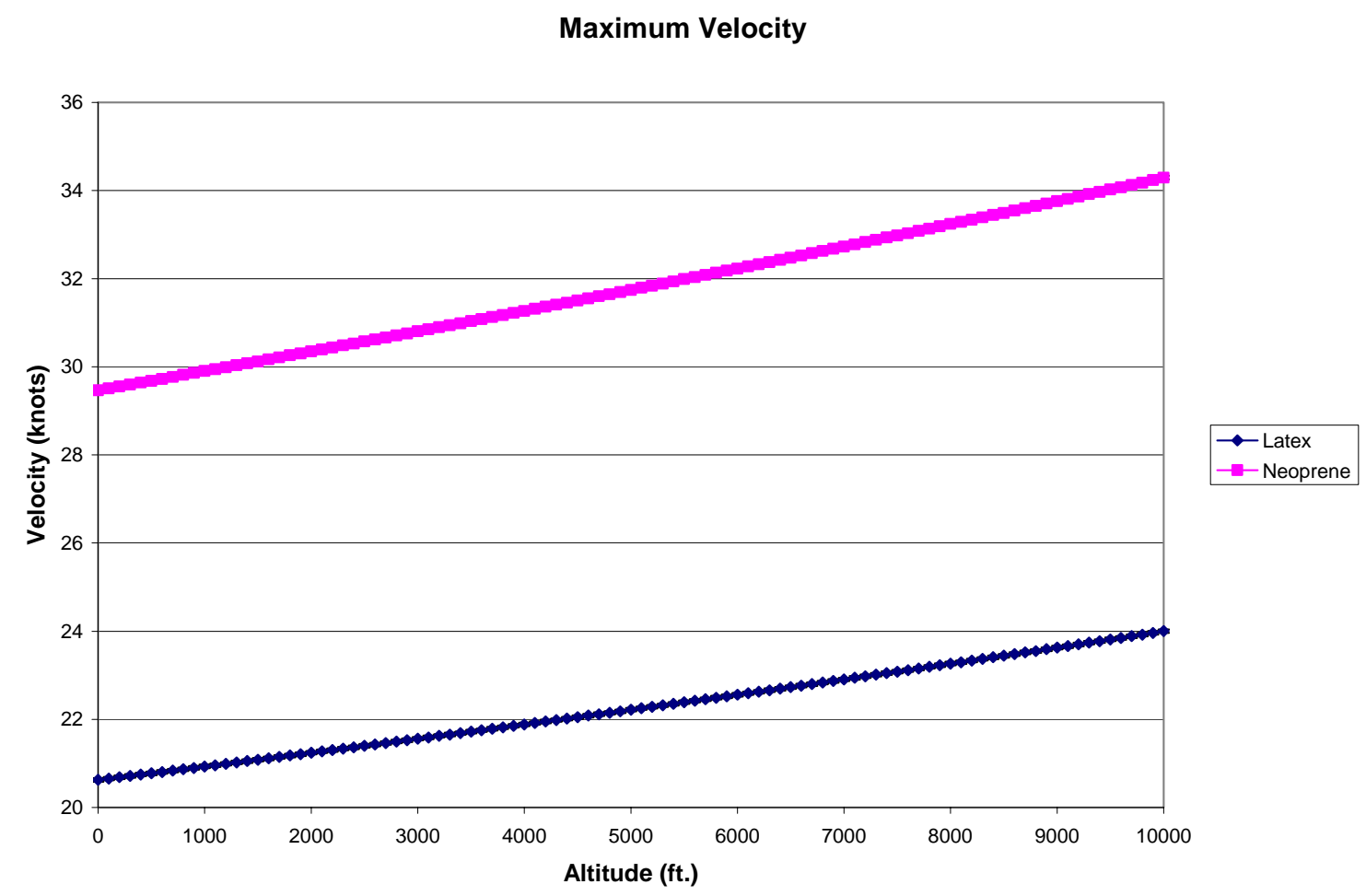

Figure 5.1-1. Maximum velocity before critical material deflection due to wing surface pressure of NACA 2412 airfoil at $8^{\circ}$ angle of attack.

This example plot gives an idea of how the information provided by the bulge test can be utilized to predict certain conditions. This can become a great tool when developing aircraft that utilize flexible materials. By conducting wind tunnel tests or computational fluid dynamics (CFD) analysis the pressure coefficients along a wing can be found. Using these pressure coefficients an analysis similar to the example above can be done to predict material deflection and to choose materials based on documented results as opposed to trial and error.

Another useful piece of information provided by the bulge test is the relationship between velocity and material deflection. To find this, first a relationship between the gauge pressure and deflection needs to be found by the plots provided by the bulge test. To find this relationship consider Figure 4.1-5, this is the pressure deflection data for the 
neoprene rubber samples. The neoprene behaves relatively linear throughout the pressure increase. To better illustrate this, Figure 5.1-2 displays the pressure deflection data for the second sample of neoprene along with a linear curve fit equation.

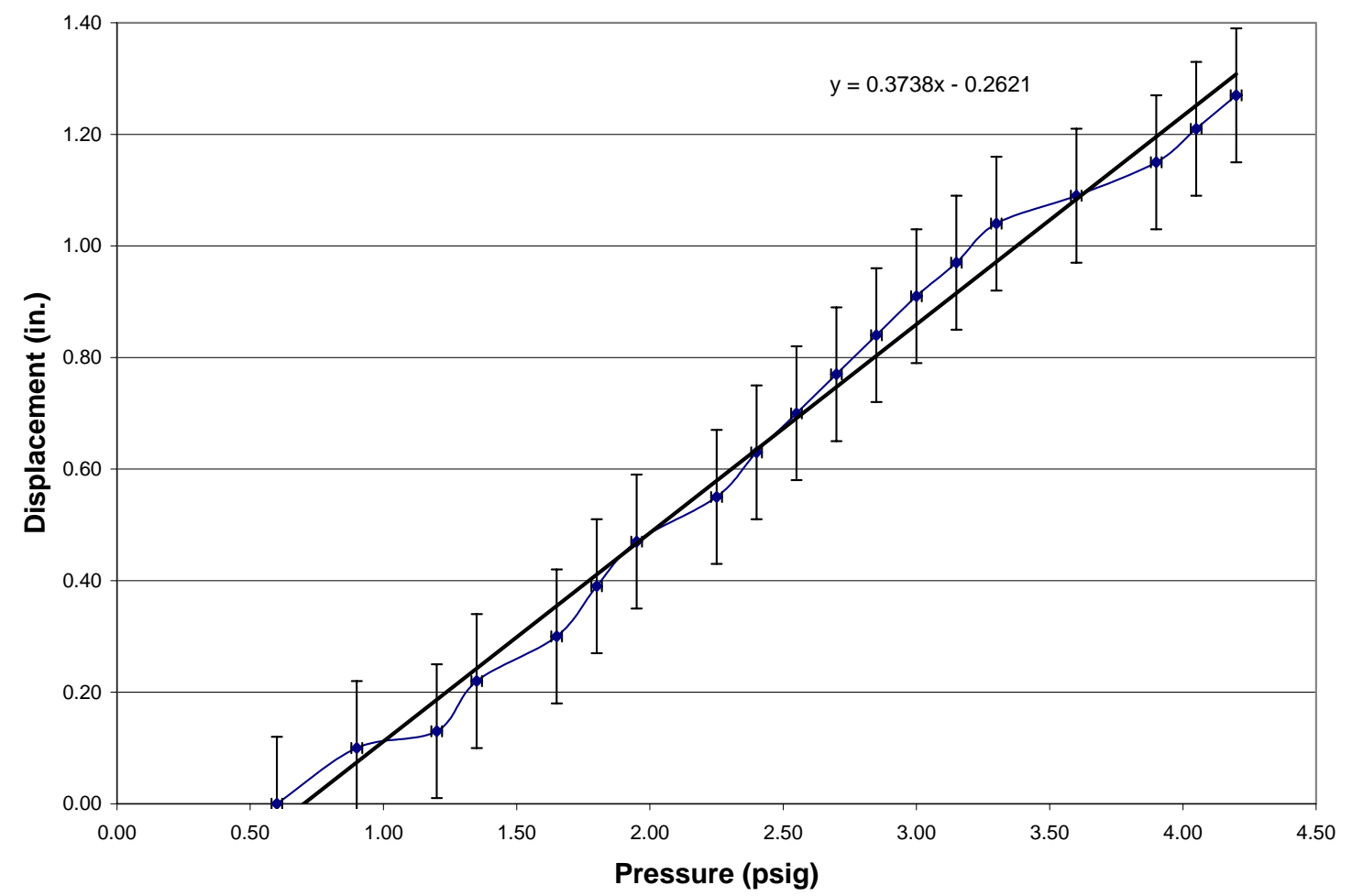

Figure 5.1-2. Pressure and deflection data for the second sample of neoprene rubber tested with the correlating linear curve fit and equation.

The equation provided by the linear curve fit is shown below.

$$
W_{0}=0.3738 p-0.2621
$$

Where $W_{0}$ is the deflection and $p$ is the gauge pressure.

By simply rearranging Equation 5-3 to solve for $p$, which is equal to $\Delta p$ in Equation 52, and insert the result into Equation 5-2 and solve for deflection a relationship between velocity and deflection for a given pressure coefficient and altitude is formed into Equation 5-4. 


$$
W_{0}=\frac{C_{p} \rho U_{\infty}^{2}}{5.35}-0.2621
$$

It is important to remember that this set of equations, 5-3 and 5-4, is only valid for neoprene. A separate curve fit and corresponding equation would be required for each material. Taking the data from the Cessna 172 airfoil and assuming an altitude of 1000 feet a plot of displacement based on velocity was developed and is shown in Figure 5.1-3.

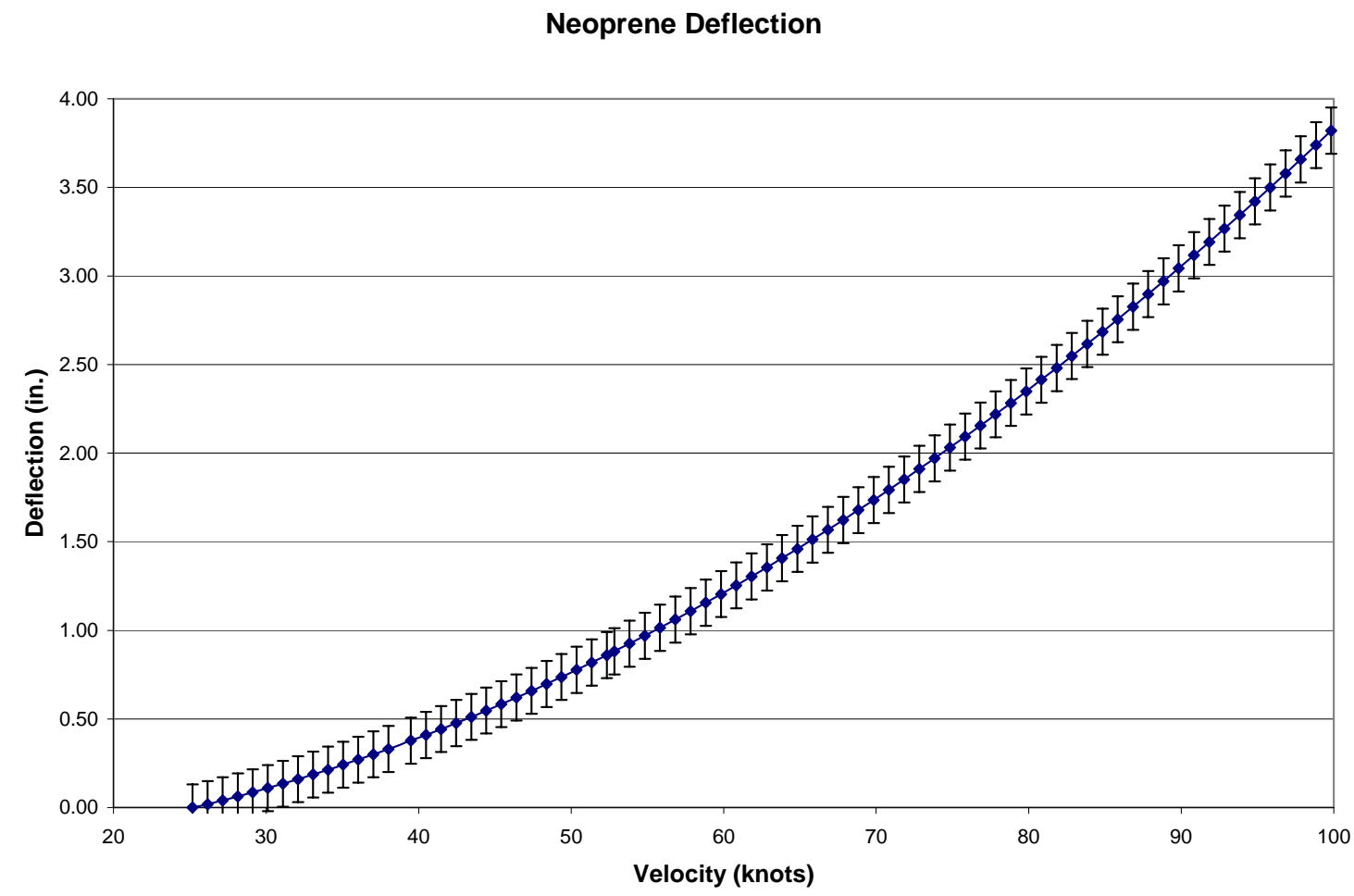

Figure 5.1-3. Theoretical velocity and deflection plot for neoprene rubber on a NACA 2412 airfoil with $8^{\circ}$ angle of attack and at 1000 feet altitude.

As stated before this is the type of information that can greatly increase the design efficiency of aircraft utilizing flexible structures.

There has also been some interest in creating a low pressure inside the wing structure to keep the material from deflecting from the wing structure. This method could increase the range of air speed a certain material could be subjected to. To produce this low 
pressure inside the wing additional mechanisms would need to be introduced onto the aircraft. These additional apparatus may increase the weight, which could decrease efficiency. The effects of this additional weight would need to be addressed to ensure the morphing wing still provides an increase in efficiency over a conventional wing design.

Although it was initially thought that using the bulge test would give the ability to obtain material properties such as Young's Modulus, it was not possible. The reason is behind the fact that since the materials tested were very elastic the Young's Modulus would only be valid for small strains. The regulator was not precise enough at low pressures to provide enough data points before the material deflected at a rate higher than the pressure increased. This actually caused a stress strain curve with a negative slope.

\subsection{Test Apparatus Improvements}

As in most research there are always improvements that can be done to the research methods and apparatus. The following are some modifications, changes, and upgrades that could be made to the test apparatus.

The infrared LED distance sensor and pressure transducer was initially connected to a desktop computer data acquisition card. A program was written using LabVIEW software to read the voltage outputs of the two devices and convert them to the corresponding distance and pressure. The distance sensor output carried a great deal of electronic noise, in that the voltage output of the sensor fluctuated and needed signal conditioning to filter this noise. A signal conditioner was not available and would have been a costly purchase. When the distance sensor was connected to a multimeter the noise was filtered by the signal conditioning inherent to the multimeter. Therefore, the voltage was recorded directly from the multimeter and converted to a distance using a Microsoft Excel spreadsheet. This method was also used for the pressure transducer. An 
improvement to the bulge test apparatus would be to either replace the infrared LED distance sensor with a more accurate and less noisy optical distance sensor, or condition the signal to produce a steady voltage when read by a computer data acquisition card. This would better automate data collection and reduce human error.

An additional modification that could be made to the test apparatus deals with the fatigue test. The current setup uses two electronic solenoid valves that are manually energized to return the chamber to atmospheric pressure, and then shut off to return the chamber to the pressure set by the regulator. The output of the displacement sensor and the pressure transducer is recorded in the same manner as the static bulge test. To improve this test an electronically controlled regulator could be installed and connected to a computer, along with the distance sensor output and pressure transducer output. Also, the energizing of the solenoid valves could also be controlled by the computer. This way a pressure could be set and controlled electronically, then the computer program would energize the solenoid valves, shut them off, wait for the system to return to the predetermined pressure, and continue the cycle. At the same time the computer program would record the distance sensor and pressure transducer outputs. This would automate the fatigue test allowing for a greater amount of cycles, the goal being fatiguing the materials to failure.

\subsection{Additional Testing}

As stated previously the focus of this research was on the materials flexibility, recovery, and fatigue characteristics. A morphing wing skin material has additional requirements that need to be met as well. It would be ideal to develop test apparatus that investigate abrasion resistance, change in properties due to temperature, and chemical and environmental resistance. 
It would also be ideal if all the materials tested had the same thickness. This would provide a better basis for comparison. The thicknesses used during this research were limited to what could be purchased or what was already available. Additionally, testing different thicknesses of each material to observe change in pressure deflection behavior as a function of material thickness would be interesting. This additional information could provide insight as to what thickness of each material would be appropriate for a particular application.

To better investigate the recovery curves of each material it may be beneficial to pressurize the material and then back the pressure off at each increment. This would give the ability to find the critical pressure that initiates permanent deformation and the poor recovery curve. This may prove to be another valuable tool when comparing materials. 


\section{CHAPTER 6: CONCLUSIONS}

The results of this research provide a very effective way of evaluating the behavior of flexible materials under different pressures. The key motivation was to predict when or if a material would deform due to the aerodynamic forces exhibited during flight. The bulge test accomplished this goal by providing a direct correlation between pressure coefficient and maximum velocity before material deflection. This can reduce design time, make material selection more efficient, and give a theoretical basis on material selection and implementation. A simplified example was provided to give insight on the methodology that could be used to predict the onset of material separation.

The woven material, Lycra, showed a great combination of ability to stretch along with great recovery behavior. The weight of the Lycra was also far below any of the other materials tested. In addition, woven materials can be developed to provide stretch in only certain directions. This provides an interesting area of thought when developing flexible structures. Further investigation into utilizing woven materials as flexible aerospace structures could provide viable solutions to aircraft morphing obstacles.

It was also shown that latex and neoprene rubbers provided satisfactory results. They deformed at reasonable pressures and exhibited good recovery behavior. Latex was used successfully on the WVU Flight Demonstrator without adverse effects caused by "ballooning". This was due to only the small gaps between the wing "feathers" being covered with latex, as opposed to the entire outer third span as modeled in the wind tunnel. This confirms the ability for elastic rubbers to be used on smaller scale aircraft such as UAVs and MAVs.

An important conclusion is that the evaluation of materials for flexible structures is application specific. There is not one material that can cover a wide variety of aerospace 
applications. The flight conditions encountered during flight must be known and taken into account when evaluating the materials. The location of the material on the aircraft must also be noted. There are a variety of pressures encountered on an aircraft's surface, both above and below atmospheric pressure. The pressures encountered at the planned location of a flexible material should be modeled to design a suitable structure that provide efficient flexibility while withstanding the aerodynamic forces encountered during flight.

The bulge test facility designed for this research can also be used for future work that may not necessarily be associated with morphing wing materials. The procedures outline can also be used to test a variety of materials and material coatings. 


\section{REFERENCES}

[1] Great Images in NASA (GRIN) website: http:/grin.hq.nasa.gov/index.html, October 2006.

[2] U.S. Navy website: http://www.navy.mil, October 2006.

[3] U.S. Air Force website: http://www.af.mil, October 2006.

[4] Curry, Marty, "NASA AFTI/F-111 MAW Fact Sheet" NASA Dryden Flight Research Center, http://www.dfrc.nasa.gov/Gallery/Photo/F111AFTI/HTML/EC88-0052-4.html, Dec. 2004.

[5] Curry, Marty, "NASA AAW Fact Sheet FS-061-DFRC" NASA Dryden Flight Research Center, http://www.nasa.gov/centers/dryden/news/FactSheets/FS-061DFRC.html, Jul. 2006.

[6] Marks, Paul, "The next 100 years of flight - part two", Online magazine NewScientist.com news service, http://www.newscientist.com/article.ns?id=dn4484, Dec. 2003.

[7] Garcia, H. M., Abdulrahim, M., and Rick Lind, "Roll Control for a Micro Air Vehicle Using Active Wing Morphing”, AIAA Paper AIAA-2003-5347, 2003.

[8] Guiler, R., and Huebsch, W., "Development and testing of a wing morphing mechanism for the control of a swept wing tailless aircraft", SAE Technical Papers, 2005-01-3391, 2005.

[9] Northrop, John, K., "The Development of All-Wing Aircraft" 35th Wilbur Wright Memorial Lecture, London, May 29, 1947.

[10] Secanell, M., Suleman, A., and Gamboa, P., "Design of a Morphing Airfoil Using Aerodynamic Shape Optimization”, AIAA Journal, Vol. 44, No. 7, July 2006. 
[11] Lian, Y., and Shyy, W., "Laminar-Turbulent Transition of a Low Reynolds Number Rigid or Flexible Airfoil”, AIAA Journal, Vol. 45, No. 7, July 2007.

[12] Waszak, R. M., Jenkins, N. L., and Ifju, P., "Stability and Control Properties of an Aeroelastic Fixed Wing Micro Aerial Vehicle," AIAA Atmospheric Flight Mechanics Conference and Exhibit, Montreal, Canada, AIAA Paper 2001-4005, 2001.

[13] Lian, Y., and Shyy, W., "Numerical Simulations of Membrane Wing Aerodynamics for Micro Air Vehicle Applications," Journal of Aircraft, Vol. 42, No. 4, 2005, pp. 865-873.

[14] Jacob, J.D., "On the Fluid Dynamics of Adaptive Airfoils", Proceedings of 1998 ASME International Mechanical Engineering Congress and Exposition, November 15-20, 1998, Anaheim, CA.

[15] Wleizen, R.W., Horner, G. C., McGowan, A. R., Padula, S. L., Scott, M. A., Silcox, R. J., and Simpson, J. O., "The Aircraft Morphing Program," 39th Structures, Structural Dynamics, and Materials Conference and Exhibit, Long Beach, CA, AIAA Paper 98-1927, 1998.

[16] Nam, Changho, and Kim, Youdan, "Optimal Design of Composite Lifting Surface for Flutter Suppression with Piezoelectric Actuators", AIAA Journal, Vol. 33, No. 10, October 1995.

[17] Kikuta, Michael Thomas, "Mechanical Properties of Candidate Materials for Morphing Wings," Master of Science Thesis, Virginia Polytechnic Institute and State University, 2003.

[18] McPherson, A.T., and Alexander Klemin, Engineering Uses of Rubber. New York, NY: Reinhold Publishing Corporation, 1956.

[19] Dupont's website:

http://www.dupontelastomers.com/Products/Neoprene/neoprene.asp, October 2006. 
[20] Dow Corning website: http://www.dowcorning.com/content/rubber/siliconerubber.asp, May 2007.

[21] McMaster-Carr website: http://www.mcmaster.com, October 2006.

[22] Szycher, Michael, Szycher's Handbook of Polyurethane, Boca Raton, FL: CRC Press, 1999.

[23] Advanced Elastomeric Systems website: http://www.santoprene.com, June 2007.

[24] Roff, W. J., and Scott, J. R., Fibres, Films, Plastics and Rubbers: A Handbook of Common Polymers, London, England: Butterworth \& Co. Ltd, 1971.

[25] Reisch, Marc, "What's That Stuff?", Chemical and Engineering News, Vol. 77, Issue 7, pp.70, 1999.

[26] Burton, Walter E., Engineering with Rubber, New York, NY: McGraw-Hill Book Company, Inc., 1949.

[27] Tabata, O., Kawahata, K., Sugiyama, S., and Isemi Igarashi, "Mechanical Property Measurements of Thin Films Using Load-Deflection of Composite Rectangular Membrane", Sensors and Actuators, Vol. 20, pp. 135-141, 1989.

[28] Mitchell, J. S., Zorman, C. A., Kicher, T., Roy, S., and Mehran Mehregany, "Examination of Bulge Test for Determining Residual Stress, Young's Modulus, and Poisson's Ratio of 3C-SiC Thin Films", Journal of Aerospace Engineering, Vol. 16, Issue 2, pp. 46-54, 2003.

[29] Sharp Microelectronics, Optoelectronic Device Applications. Ch. 12, pp. 12-2 12-3, 2005.

[30] Omega Engineering website: http://www.omega.com, June 2007. 
[31] Maier-Schneider, Dieter, Maibach, J., and Obermeier, Ernst, "A New Analytical Solution for the Load-Deflection of Square Membranes", Journal of Microelectromechanical Systems, Vol. 4, No. 4, 1995.

[32] Anderson, John D., Introduction to Flight, New York, NY: McGraw-Hill Book Company, Inc., 1978. 


\section{APPENDIX A: Material Properties of Candidate Materials}

Latex Rubber

\begin{tabular}{|l|l|}
\hline Thickness & $.014 "$ \\
\hline Durometer & Medium Soft \\
\hline Durometer Rating & $40 \mathrm{~A}$ \\
\hline Durometer Hardness Tolerance & \pm 5 \\
\hline Temperature Range & $-65^{\circ}$ to $+180^{\circ} \mathrm{F}$ \\
\hline Tensile Strength & $4000 \mathrm{psi}$ \\
\hline Stretch Limit & $780 \%$ \\
\hline Density & 58 lbs./cu. ft. \\
\hline Properties & $\begin{array}{l}\text { Abrasion Resistant and Tear Resistant and } \\
\text { Impact Resistant and Chemical Resistant and } \\
\text { Electrical Resistant }\end{array}$ \\
\hline
\end{tabular}

McMaster-Carr, 2006

Neoprene Rubber

\begin{tabular}{|l|l|}
\hline Thickness & $.015^{\prime \prime}$ \\
\hline Durometer & Medium Soft and Medium Hard \\
\hline Durometer Rating & $50 \mathrm{~A}$ \\
\hline Durometer Hardness Tolerance & \pm 5 \\
\hline Temperature Range & $-30^{\circ}$ to $+200^{\circ} \mathrm{F}$ \\
\hline Tensile Strength & $1500 \mathrm{psi}$ \\
\hline Stretch Limit & $300 \%$ \\
\hline Density & 74 lbs./cu. ft. \\
\hline Compression Recovery & Good \\
\hline Specifications Met & $\begin{array}{l}\text { American Society for Testing and Materials } \\
(\text { ASTM })\end{array}$ \\
\hline ASTM Specification & ASTM D2000 BC \\
\hline Properties & $\begin{array}{l}\text { Oil Resistant and Abrasion Resistant and } \\
\text { Impact Resistant and Weather Resistant and } \\
\text { Flame Resistant }\end{array}$ \\
\hline
\end{tabular}

McMaster-Carr, 2006 
Silicone Rubber

\begin{tabular}{|l|l|}
\hline Thickness & $.015^{\prime \prime}$ \\
\hline Durometer & Soft and Medium Soft \\
\hline Durometer Rating & $35 \mathrm{~A}$ \\
\hline Durometer Hardness Tolerance & \pm 5 \\
\hline Temperature Range & $-80^{\circ}$ to $+425^{\circ} \mathrm{F}$ \\
\hline Tensile Strength & $800 \mathrm{psi}$ \\
\hline Stretch Limit & $450 \%$ \\
\hline Compression Recovery & Good \\
\hline Properties & Weather Resistant and Electrical Resistant \\
\hline
\end{tabular}

McMaster-Carr, 2006

ECH Rubber

\begin{tabular}{|l|l|}
\hline Thickness & $1 / 32 "$ \\
\hline Durometer & Medium Hard \\
\hline Durometer Rating & $60 \mathrm{~A}$ \\
\hline Durometer Hardness Tolerance & \pm 5 \\
\hline Temperature Range & $-40^{\circ}$ to $+240^{\circ} \mathrm{F}$ \\
\hline Tensile Strength & $1200 \mathrm{psi}$ \\
\hline Stretch Limit & $250 \%$ \\
\hline Density & $87 \mathrm{lbs} . / \mathrm{cu}$. ft. \\
\hline Compression Recovery & Good \\
\hline Specifications Met & $\begin{array}{l}\text { American Society for Testing and Materials } \\
\text { (ASTM) }\end{array}$ \\
\hline ASTM Specification & ASTM D2000 CH \\
\hline Properties & $\begin{array}{l}\text { Oil Resistant and Abrasion Resistant and } \\
\text { Weather Resistant and Chemical } \\
\text { Resistant and Electrical Resistant }\end{array}$ \\
\hline
\end{tabular}

McMaster-Carr, 2006 
Polyurethane

\begin{tabular}{|l|l|}
\hline Thickness & $.015^{\prime \prime}$ \\
\hline Durometer & Hard \\
\hline Durometer Rating & $85 \mathrm{~A}$ \\
\hline Durometer Hardness Tolerance & \pm 5 \\
\hline Temperature Range & $-40^{\circ}$ to $+225^{\circ} \mathrm{F}$ \\
\hline Tensile Strength & $7000 \mathrm{psi}$ \\
\hline Stretch Limit & $400 \%$ \\
\hline Density & $74 \mathrm{lbs} . / \mathrm{cu} . \mathrm{ft}$. \\
\hline Compression Recovery & Good \\
\hline Properties & $\begin{array}{l}\text { Oil Resistant and Abrasion Resistant and } \\
\text { Tear Resistant and Impact Resistant and } \\
\text { Weather Resistant and Chemical } \\
\text { Resistant and Electrical Resistant }\end{array}$ \\
\hline
\end{tabular}

McMaster-Carr, 2006

Santoprene TPE (Thermoplastic Elastomer)

\begin{tabular}{|l|l|}
\hline Thickness & $1 / 32^{\prime \prime}$ \\
\hline Durometer & Medium Hard \\
\hline Durometer Rating & $55 \mathrm{~A}$ \\
\hline Durometer Hardness Tolerance & \pm 5 \\
\hline Temperature Range & $-50^{\circ}$ to $+275^{\circ} \mathrm{F}$ \\
\hline Tensile Strength & $640 \mathrm{psi}$ \\
\hline Stretch Limit & $330 \%$ \\
\hline Density & $75 \mathrm{lbs} . / \mathrm{cu} . \mathrm{ft}$. \\
\hline Compression Recovery & Fair \\
\hline Properties & $\begin{array}{l}\text { Abrasion Resistant and Impact Resistant and } \\
\text { Weather Resistant }\end{array}$ \\
\hline
\end{tabular}

McMaster-Carr, 2006 
Polyvinyl Chloride (PVC)

\begin{tabular}{|l|l|}
\hline Thickness & $1 / 16 "$ \\
\hline Durometer & Hard \\
\hline Durometer Rating & $70 \mathrm{~A}$ \\
\hline Durometer Hardness Tolerance & \pm 5 \\
\hline Temperature Range & $+20^{\circ}$ to $+160^{\circ} \mathrm{F}$ \\
\hline Tensile Strength & $900 \mathrm{psi}$ \\
\hline Stretch Limit & $200 \%$ \\
\hline Density & $96 \mathrm{lbs} . / \mathrm{cu} . \mathrm{ft}$. \\
\hline Properties & $\begin{array}{l}\text { Oil Resistant and Impact Resistant and } \\
\text { Weather Resistant }\end{array}$ \\
\hline
\end{tabular}

McMaster-Carr, 2006 


\section{APPENDIX B: Distance Sensor Specifications}

- Analog output

- Effective Range: 10 to $80 \mathrm{~cm}$

- LED pulse cycle duration: $32 \mathrm{~ms}$

- Typical response time: $39 \mathrm{~ms}$

- Typical start up delay: $44 \mathrm{~ms}$

- Average current consumption: $33 \mathrm{~mA}$

- Detection area diameter @ 80 cm:6 cm

\section{DESCRIPTION}

The GP2D12 is a distance measuring sensor with integrated signal processing and analog voltage output.

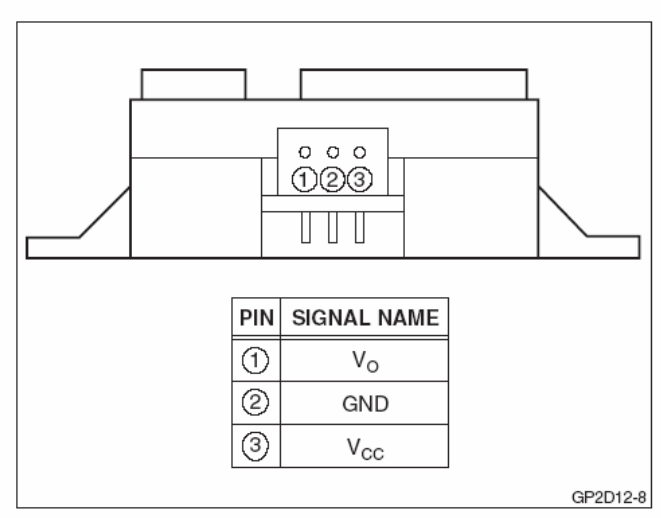

Figure 1. Pinout

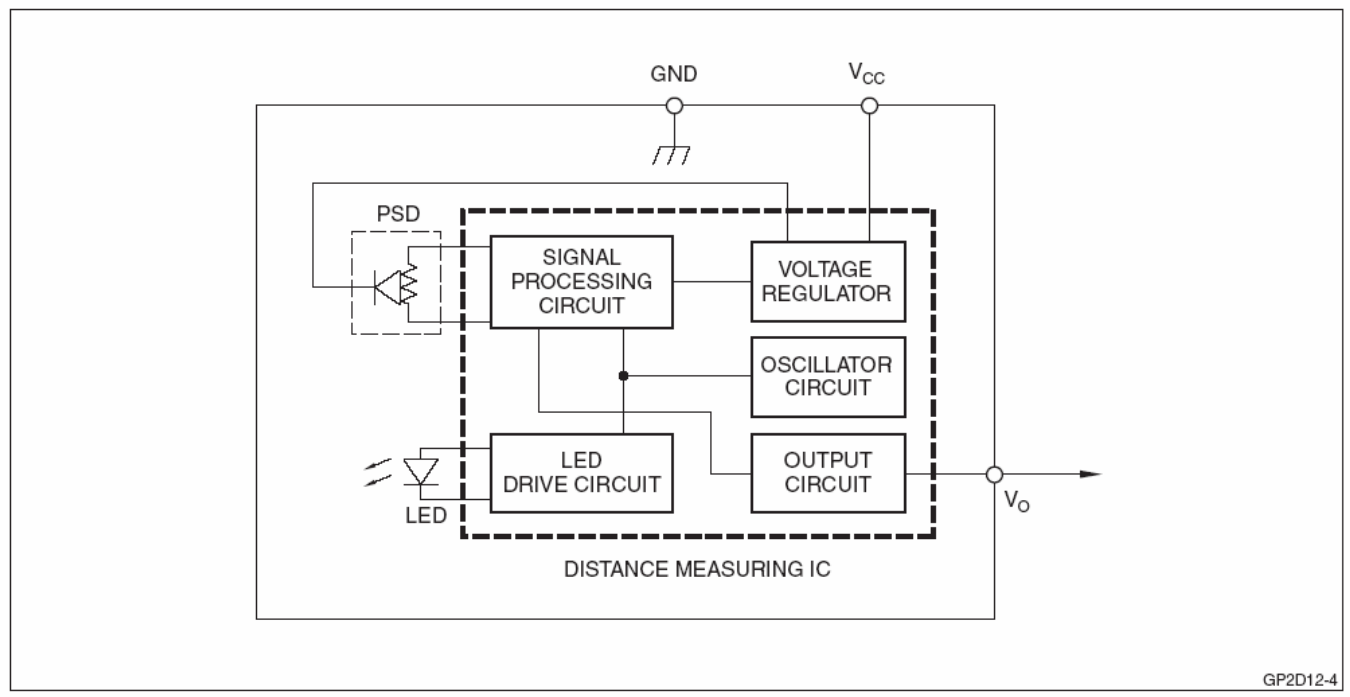

Figure 2. Block Diagram 


\section{ELECTRICAL SPECIFICATIONS}

Absolute Maximum Ratings

$\mathrm{Ta}=25^{\circ} \mathrm{C}, \mathrm{V}_{\mathrm{CC}}=5 \mathrm{VDC}$

\begin{tabular}{|l|c|l|c|}
\hline \multicolumn{1}{|c|}{ PARAMETER } & SYMBOL & \multicolumn{1}{c|}{ RATING } & UNIT \\
\hline \hline Supply Voltage & $\mathrm{V}_{\mathrm{CC}}$ & -0.3 to +7.0 & $\mathrm{~V}$ \\
\hline Output Terminal Voltage & $\mathrm{V}_{\mathrm{O}}$ & -0.3 to $\left(\mathrm{V}_{\mathrm{CC}}+0.3\right)$ & $\mathrm{V}$ \\
\hline Operating Temperature & $\mathrm{Topr}$ & -10 to +60 & ${ }^{\circ} \mathrm{C}$ \\
\hline Storage Temperature & $\mathrm{Tstg}$ & -40 to +70 & ${ }^{\circ} \mathrm{C}$ \\
\hline
\end{tabular}

Operating Supply Voltage

\begin{tabular}{|c|c|c|c|}
\hline PARAMETER & SYMBOL & RATING & UNIT \\
\hline \hline Operating Supply Voltage & $\mathrm{V}_{\mathrm{CC}}$ & 4.5 to 5.5 & $\mathrm{~V}$ \\
\hline
\end{tabular}

\section{Electro-optical Characteristics}

$\mathrm{Ta}=25^{\circ} \mathrm{C}, \mathrm{V}_{\mathrm{CC}}=5 \mathrm{VDC}$

\begin{tabular}{|l|c|l|c|c|c|c|c|}
\hline \multicolumn{1}{|c|}{ PARAMETER } & SYMBOL & \multicolumn{1}{c|}{ CONDITIONS } & MIN. & TYP. & MAX. & UNIT & NOTES \\
\hline \hline Measuring Distance Range & $\Delta \mathrm{L}$ & & 10 & - & 80 & $\mathrm{~cm}$ & 1,2 \\
\hline Output Voltage & $\mathrm{V}_{\mathrm{O}}$ & $\mathrm{L}=80 \mathrm{~cm}$ & 0.25 & 0.4 & 0.55 & $\mathrm{~V}$ & 1,2 \\
\hline Output Voltage Difference & $\Delta \mathrm{V}_{\mathrm{O}}$ & $\begin{array}{l}\text { Output change at L change } \\
(80 \mathrm{~cm}-10 \mathrm{~cm})\end{array}$ & 1.75 & 2.0 & 2.25 & $\mathrm{~V}$ & 1,2 \\
\hline Average Supply Current & $\mathrm{I}_{\mathrm{CC}}$ & $\mathrm{L}=80 \mathrm{~cm}$ & - & 33 & 50 & $\mathrm{~mA}$ & 1,2 \\
\hline
\end{tabular}

NOTES:

1. Measurements made with Kodak R-27 Gray Card, using the white side, ( $90 \%$ reflectivity).

2. $\mathrm{L}=$ Distance to reflective object.

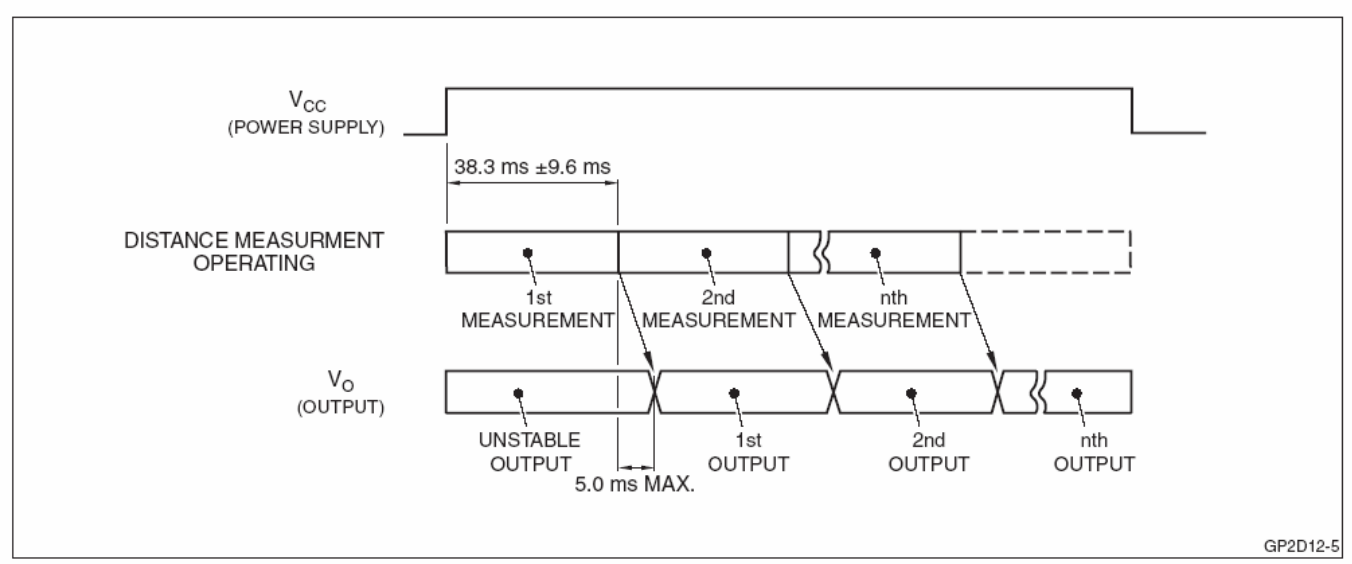

Figure 3. Timing Diagram 


\section{RELIABILITY}

The reliability of requirements of this device are listed in Table 1.

Table 1. Reliability

\begin{tabular}{|c|c|c|c|}
\hline TEST ITEMS & TEST CONDITIONS & $\begin{array}{l}\text { FAILURE } \\
\text { JUDGEMENT } \\
\text { CRITERIA }\end{array}$ & $\begin{array}{l}\text { SAMPLES (n), } \\
\text { DEFECTIVE (C) }\end{array}$ \\
\hline Temperature Cycling & $\begin{array}{l}\text { One cycle }-40^{\circ} \mathrm{C}(30 \mathrm{~min} .) \text { to }+70^{\circ} \mathrm{C} \text { in } 30 \\
\text { minutes, repeated } 25 \text { times }\end{array}$ & \multirow{7}{*}{$\begin{array}{l}\text { Initial } \times 0.8>V_{O} \\
V_{O}>\text { Initial } \times 1.2\end{array}$} & $\mathrm{n}=11, \mathrm{C}=0$ \\
\hline $\begin{array}{l}\text { High Temperature and } \\
\text { High Humidity Storage }\end{array}$ & $+40^{\circ} \mathrm{C}, 90 \% \mathrm{RH}, 500 \mathrm{~h}$ & & $\mathrm{n}=11, \mathrm{C}=0$ \\
\hline High Temperature Storage & $+70^{\circ} \mathrm{C}, 500 \mathrm{~h}$ & & $\mathrm{n}=11, \mathrm{C}=0$ \\
\hline Low Temperature Storage & $-40^{\circ} \mathrm{C}, 500 \mathrm{~h}$ & & $\mathrm{n}=11, \mathrm{C}=0$ \\
\hline $\begin{array}{l}\text { Operational Life } \\
\text { (High Temperature) }\end{array}$ & $+60^{\circ} \mathrm{C}, \mathrm{V}_{\mathrm{CC}}=5 \mathrm{~V}, 500 \mathrm{~h}$ & & $\mathrm{n}=11, \mathrm{C}=0$ \\
\hline Mechanical Shock & $\begin{array}{l}100 \mathrm{~m} / \mathrm{s}^{2}, 6.0 \mathrm{~ms} \\
3 \text { times } / \pm \mathrm{X}, \pm \mathrm{Y}, \pm \mathrm{Z} \text { direction }\end{array}$ & & $\mathrm{n}=6, \mathrm{C}=0$ \\
\hline Variable Frequency Vibration & $\begin{array}{l}\text { 10-to- } 55 \text {-to- } 10 \mathrm{~Hz} \text { in } 1 \text { minute } \\
\text { Amplitude: } 1.5 \mathrm{~mm} \\
2 \mathrm{~h} \text { in each } \mathrm{X}, \mathrm{Y}, \mathrm{Z} \text { direction }\end{array}$ & & $\mathrm{n}=6, \mathrm{C}=0$ \\
\hline
\end{tabular}

NOTES:

1. Test conditions are according to Electro-optical Characteristics, shown on page 2.

2. At completion of the test, allow device to remain at nominal room temperature and humidity (non-condensing) for two hours.

3. Confidence level: $90 \%$, Lot Tolerance Percent Defect (LTPD): $20 \% / 40 \%$.

\section{MANUFACTURER'S INSPECTION}

\section{Inspection Lot}

Inspection shall be carried out per each delivery lot.

\section{Inspection Method}

A single sampling plan, normal inspection level II based on ISO 2859 shall be adopted.

Table 2. Quality Level

\begin{tabular}{|l|l|c|}
\hline \multicolumn{1}{|c|}{ DEFECT } & \multicolumn{1}{c|}{ INSPECTION ITEM and TEST METHOD } & AQL (\%) \\
\hline \hline Major Defect & Electro-optical characteristics defect & 0.4 \\
\hline Minor Defect & Defect to appearance or dimensions (crack, split, chip, scratch, stain) ${ }^{\star}$ & 1.0 \\
\hline
\end{tabular}

NOTE: *Any one of these that affects the Electro-optical Characteristics shall be considered a defect. 


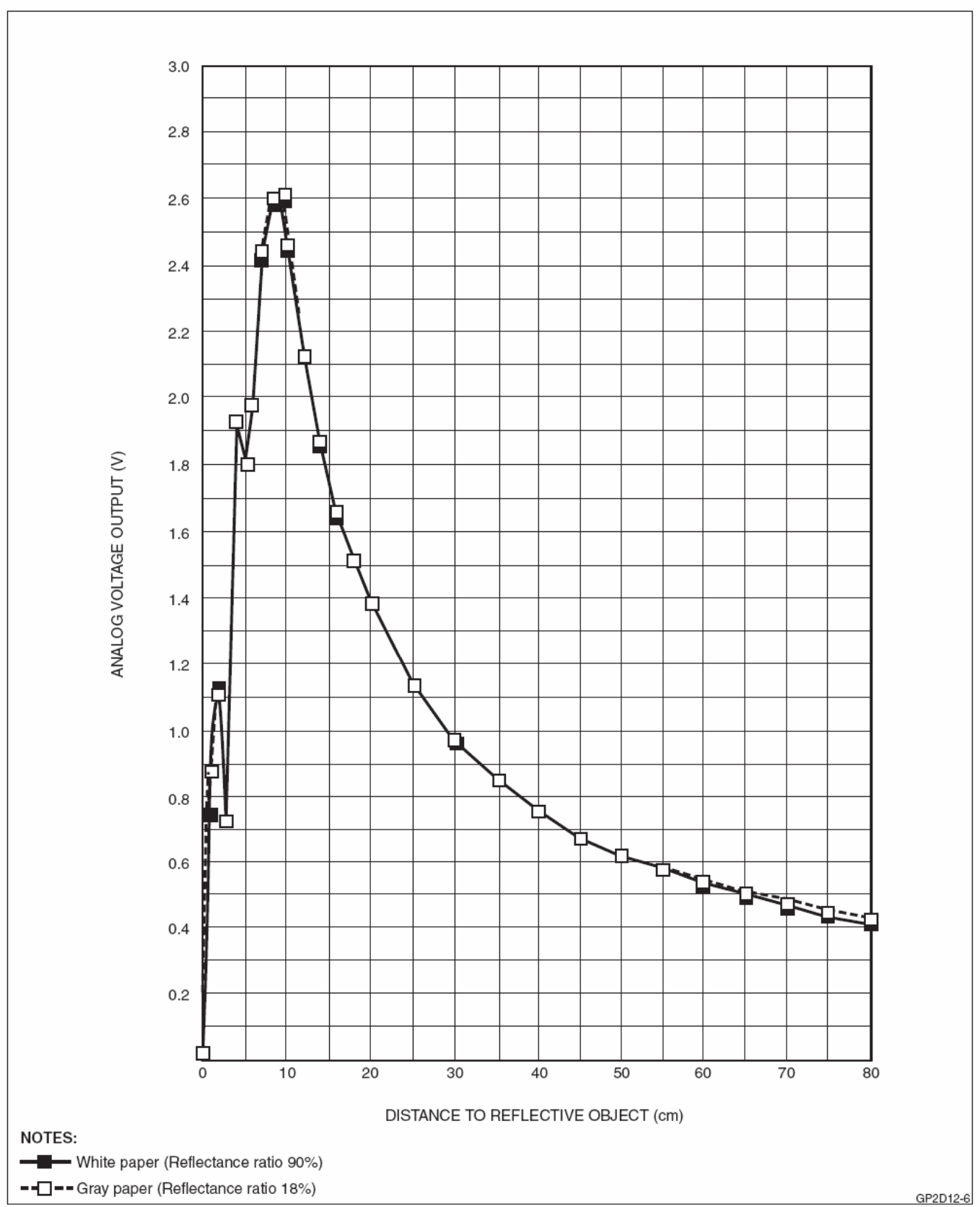

Figure 4. GP2D12 Example of Output/Distance Characteristics 


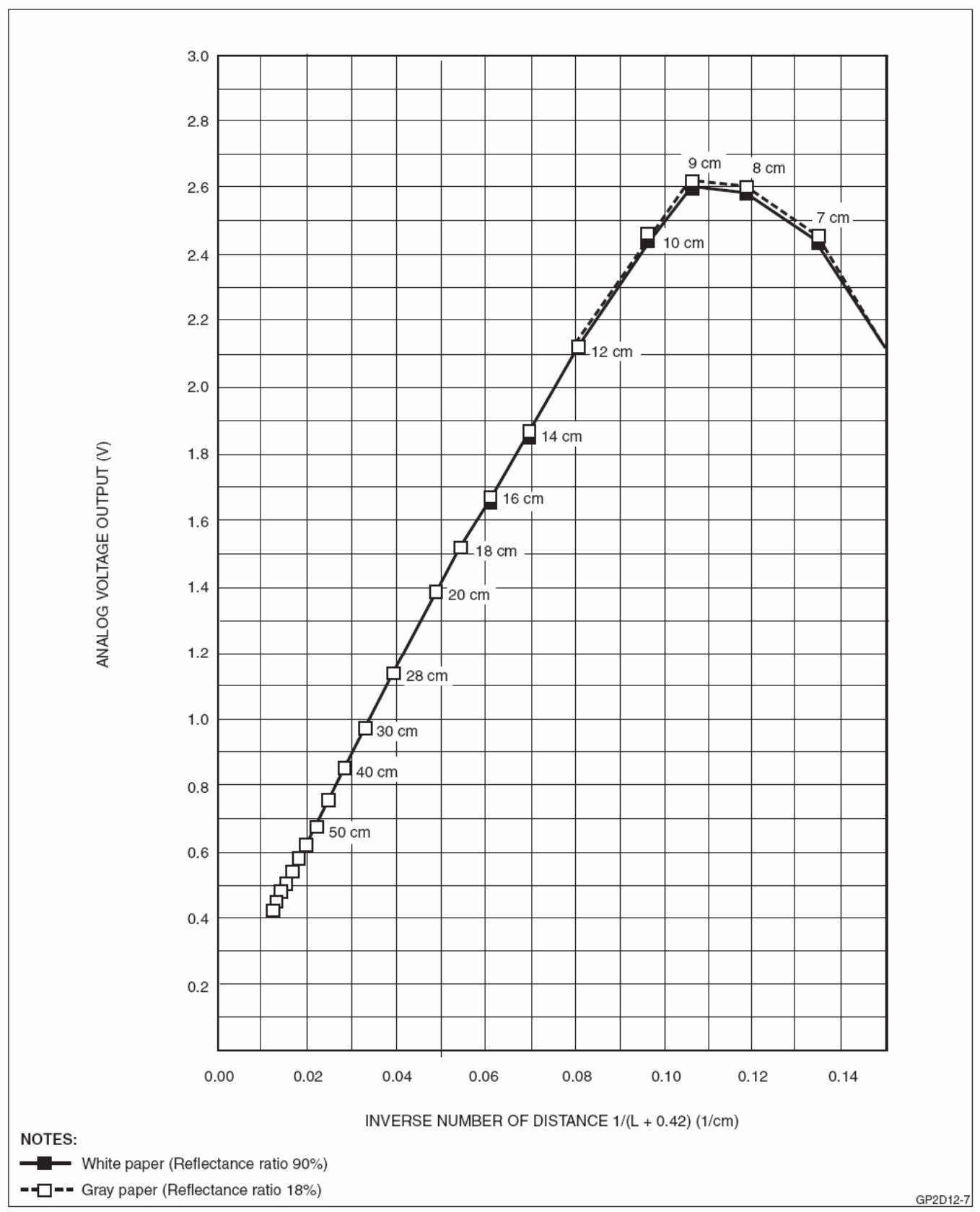

Figure 5. GP2D12 Example of Output Characteristics with Inverse Number of Distance 


\section{PACKAGE SPECIFICATIONS}

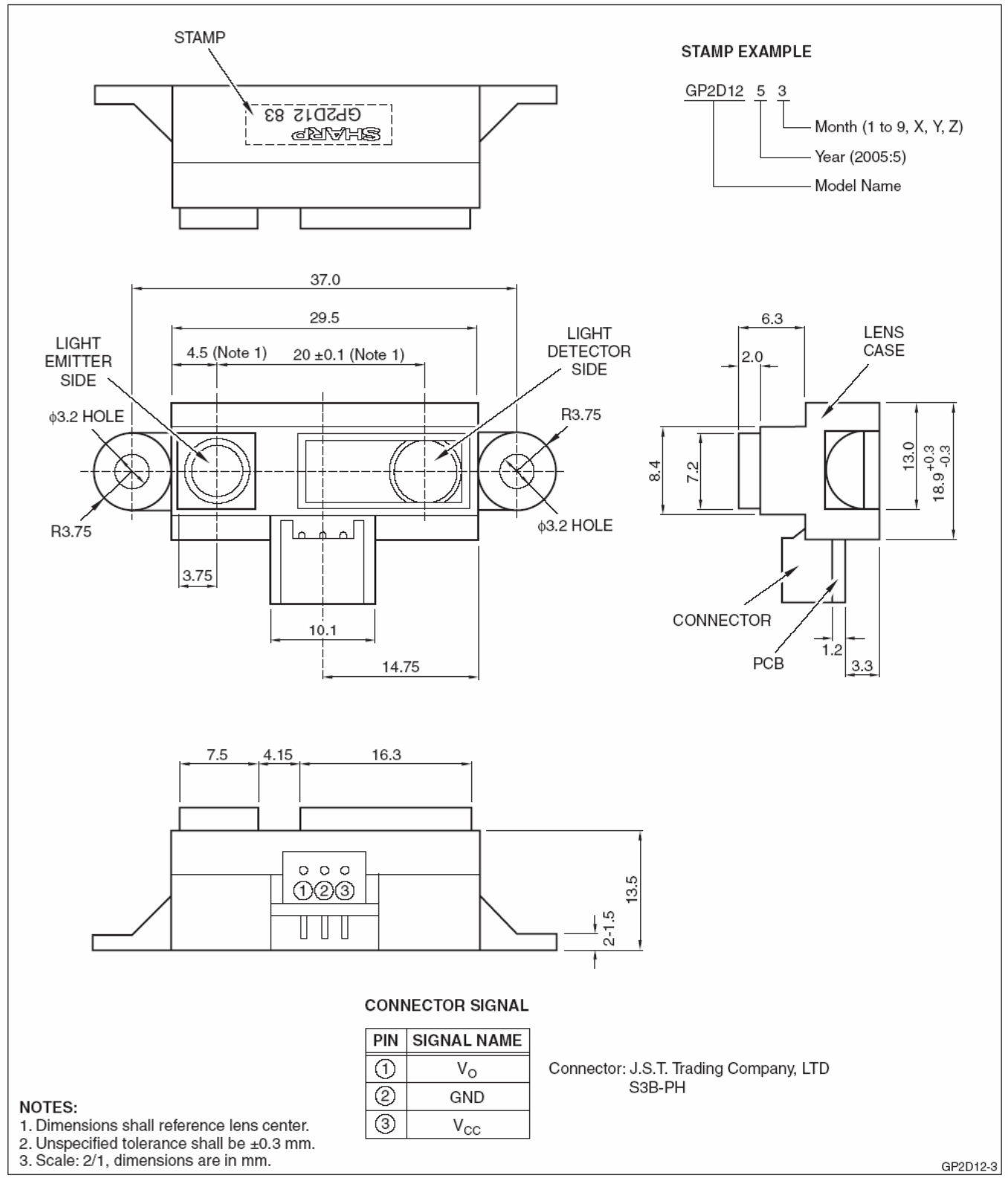




\section{APPENDIX C: Distance Sensor Calibration/Error}

To check the accuracy and precision of the curve fit a set of known distances were measured. Markings were placed on a piece of paper at an increment of 0.2 inches starting at 2 inches from the sensor extending to 6 inches. A flat board was then moved to each increment and the voltage output was recorded. The results and error analysis are shown in Table 3-1.

$$
\ell=\frac{5.3012}{V}-0.4426
$$

Error analysis of infrared LED distance sensor.

\begin{tabular}{|r|r|r|}
\hline $\begin{array}{c}\text { Known Distance } \\
\text { (in.) }\end{array}$ & $\begin{array}{c}\text { Measured Distance } \\
\text { (in.) }\end{array}$ & $\begin{array}{c}\text { Error Magnitude } \\
\text { (in.) }\end{array}$ \\
\hline 6.00 & 5.98 & 0.02 \\
\hline 5.80 & 5.83 & 0.03 \\
\hline 5.60 & 5.56 & 0.04 \\
\hline 5.40 & 5.43 & 0.03 \\
\hline 5.20 & 5.20 & 0.00 \\
\hline 5.00 & 4.97 & 0.03 \\
\hline 4.80 & 4.77 & 0.03 \\
\hline 4.60 & 4.64 & 0.04 \\
\hline 4.40 & 4.40 & 0.00 \\
\hline 4.20 & 4.22 & 0.02 \\
\hline 4.00 & 4.00 & 0.00 \\
\hline 3.80 & 3.80 & 0.00 \\
\hline 3.60 & 3.62 & 0.02 \\
\hline 3.40 & 3.39 & 0.01 \\
\hline 3.20 & 3.20 & 0.00 \\
\hline 3.00 & 3.02 & 0.02 \\
\hline 2.80 & 2.78 & 0.02 \\
\hline 2.60 & 2.61 & 0.01 \\
\hline 2.40 & 2.40 & 0.00 \\
\hline 2.20 & 2.19 & 0.01 \\
\hline 2.00 & 2.00 & 0.00 \\
\hline & Average Error (in.) & 0.02 \\
\hline & Maximum Error (in.) & 0.04 \\
\hline & &
\end{tabular}




\section{APPENDIX D: Pressure Transducer Specifications}

\section{Model PX612}

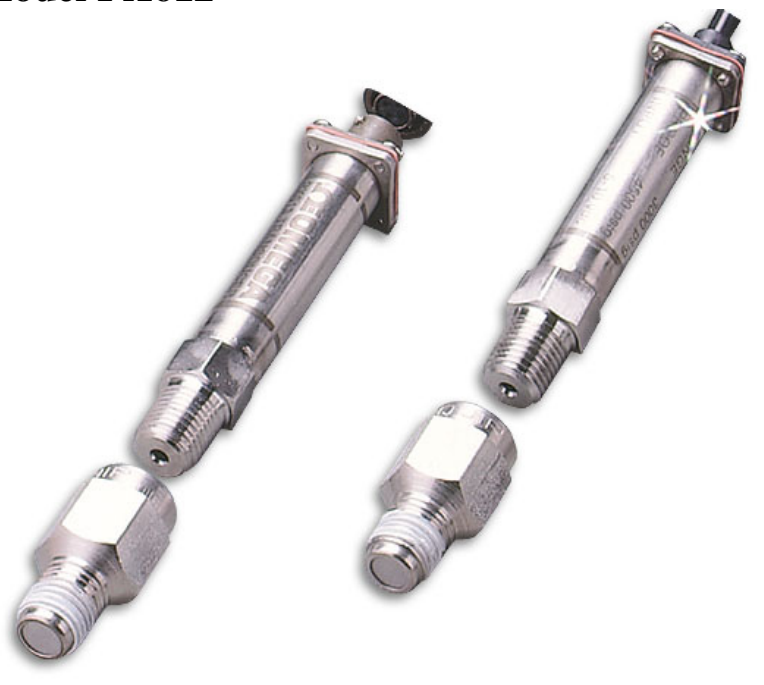

Excitation: $10 \mathrm{Vdc}$ (5 to $10 \mathrm{Vdc}$ limits)

Output: 0 to $100 \mathrm{mV} @ 10 \mathrm{Vdc}$

Sensitivity: $10 \mathrm{mV} / \mathrm{V}$

Input Impedance: $1500 \Omega$

Output Impedance: $100 \Omega$

Insulation Resistance: $100 \mathrm{M} \Omega @ 50 \mathrm{Vdc}$

Accuracy: $\pm 0.4 \%$ BFSL

Hysteresis: $\pm 0.2 \%$

Repeatability: $\pm 0.05 \%$

Stability: $\pm 1 \% /$ year

Zero Balance: $\pm 1 \%$

Durability: 100 million cycles

Operating Temp.: -29 to $82^{\circ} \mathrm{C}\left(-20\right.$ to $\left.180^{\circ} \mathrm{F}\right)$

Compensated Temp.: -29 to $71^{\circ} \mathrm{C}\left(-20\right.$ to $\left.160^{\circ} \mathrm{F}\right)$

Thermal Zero Effect: $\pm 0.04 \% \mathrm{FS} /{ }^{\circ} \mathrm{F}$

Thermal Span Effect: $\pm 0.04 \% \mathrm{FS} /{ }^{\circ} \mathrm{F}$

Proof Pressure: 15 to $2000 \mathrm{psi}=200 \% ; 3000$ to $5000=150 \%$; 7500 to $20000=120 \%$

Burst Pressure: 15 to $2000 \mathrm{psi}=800 \% ; 3000$ to $20000=500 \%$

Gages: Thin film polysilicon

Diaphragm: 17-4PH stainless steel

Case: 300 Series stainless steel

Pressure Connection: 15 to 10,000 PSI: $1 / 4$ NPT; 15,000 and 20,000 psi $=9 / 16-18 \mathrm{UNF}$

Aminco fitting

Electrical Connection: 36 " braided shield PVC Cable or connector

Weight: $2.5 \mathrm{oz}$. without cable

Response time: $5 \mathrm{~ms}$

Construction: Sealed units (except PX602 $\leq 500$ psi is vented to room) 


\section{APPENDIX E:Bulge Shape Measurements}

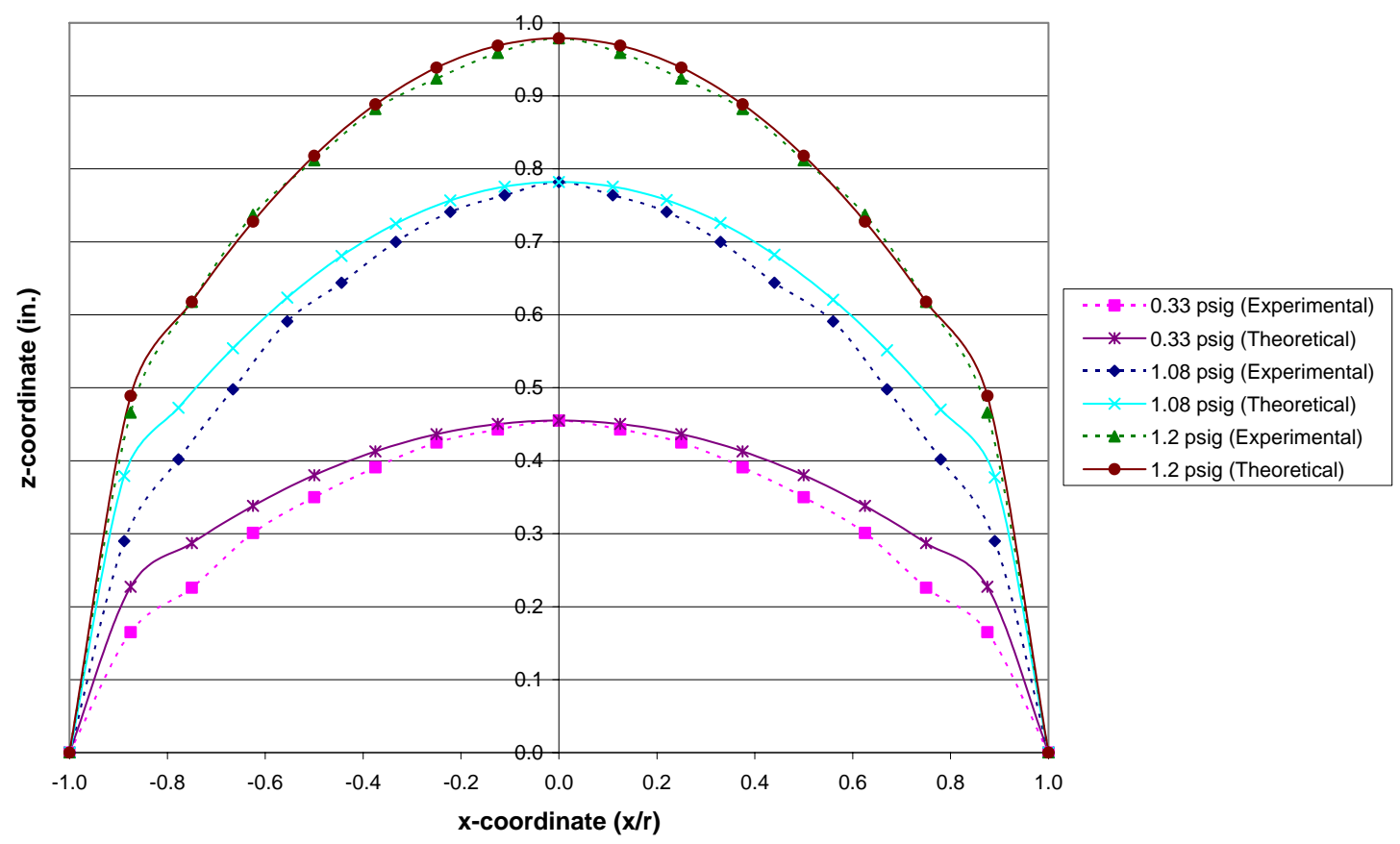

Latex Rubber

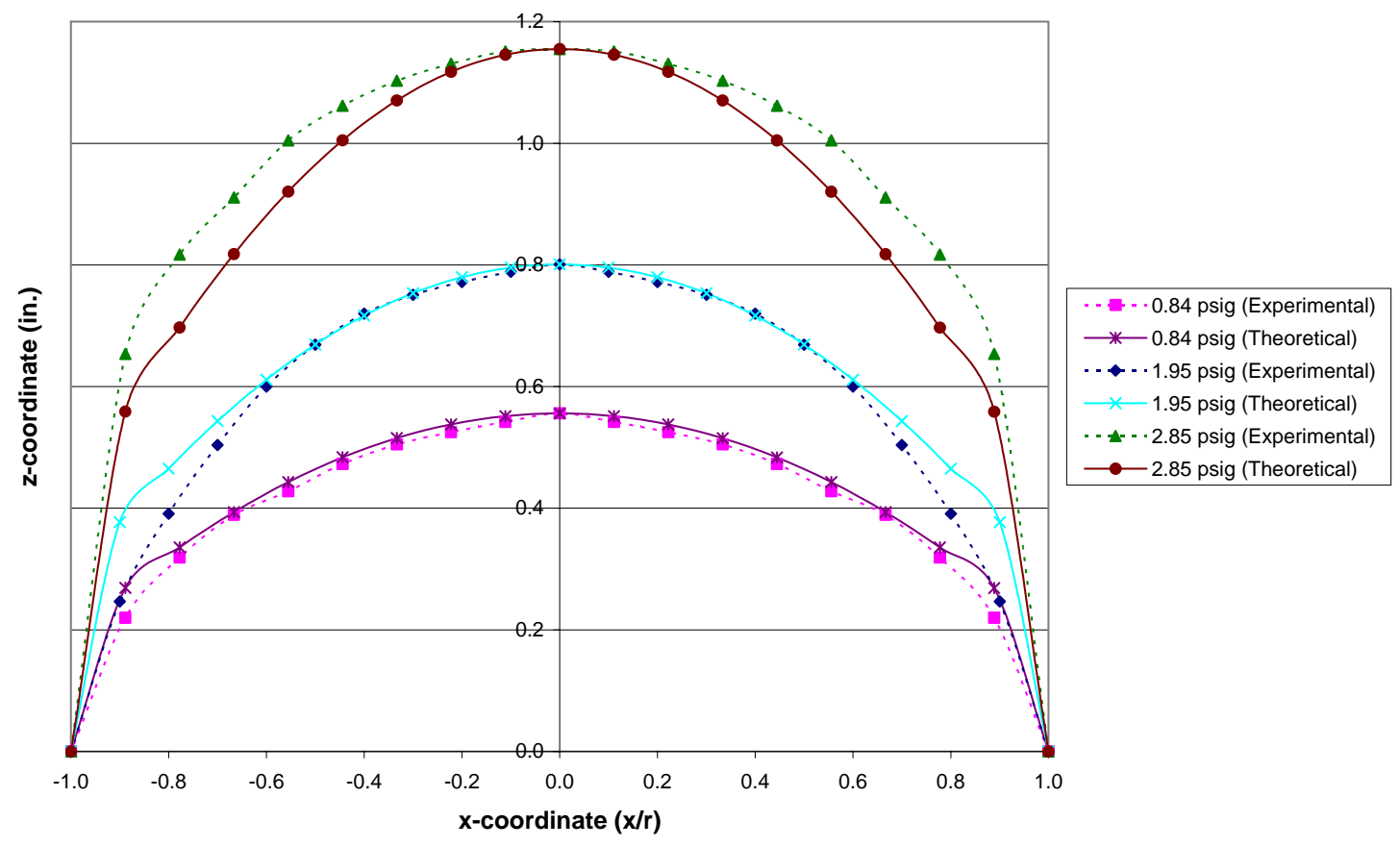

Neoprene Rubber 


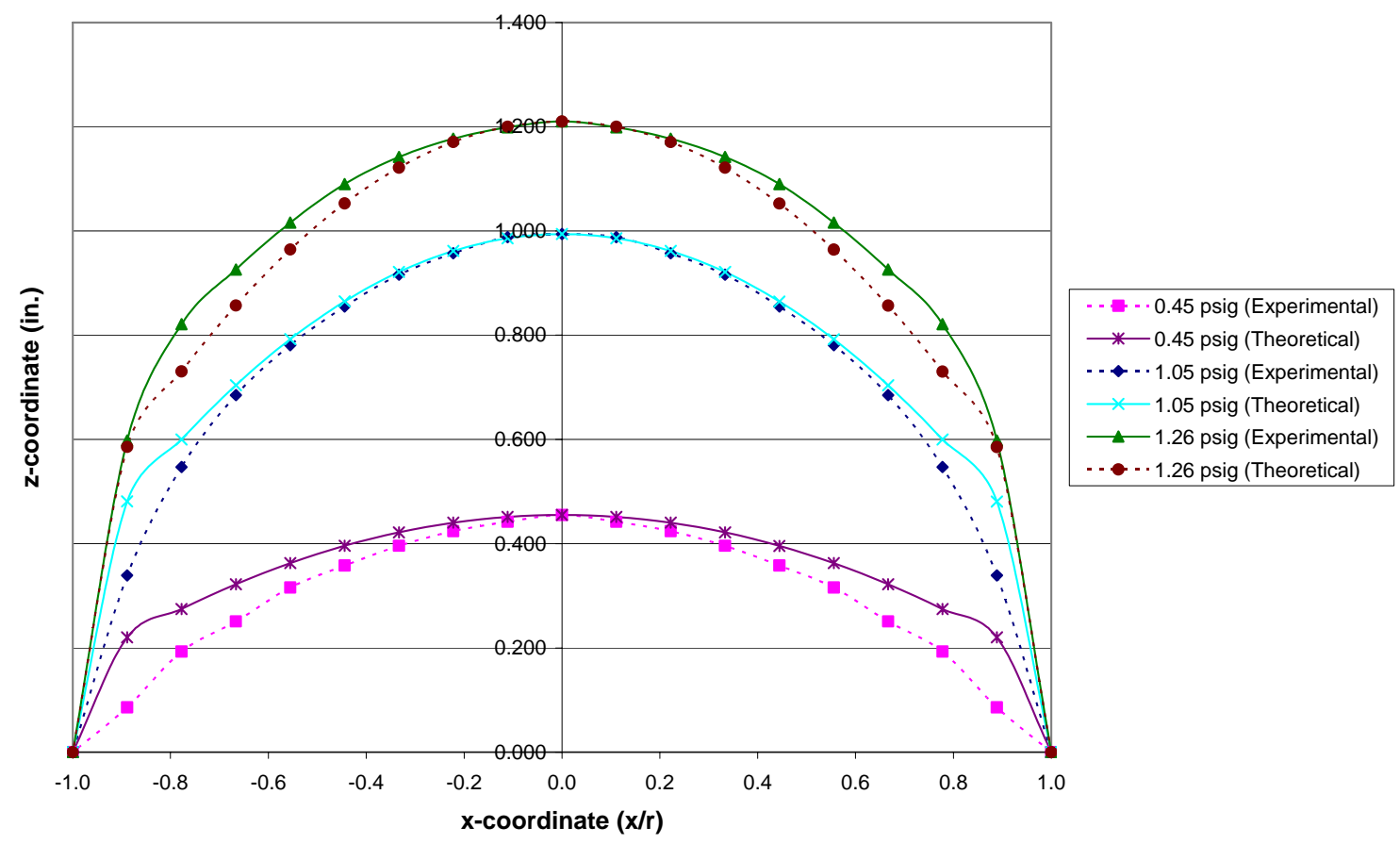

Silicone Rubber

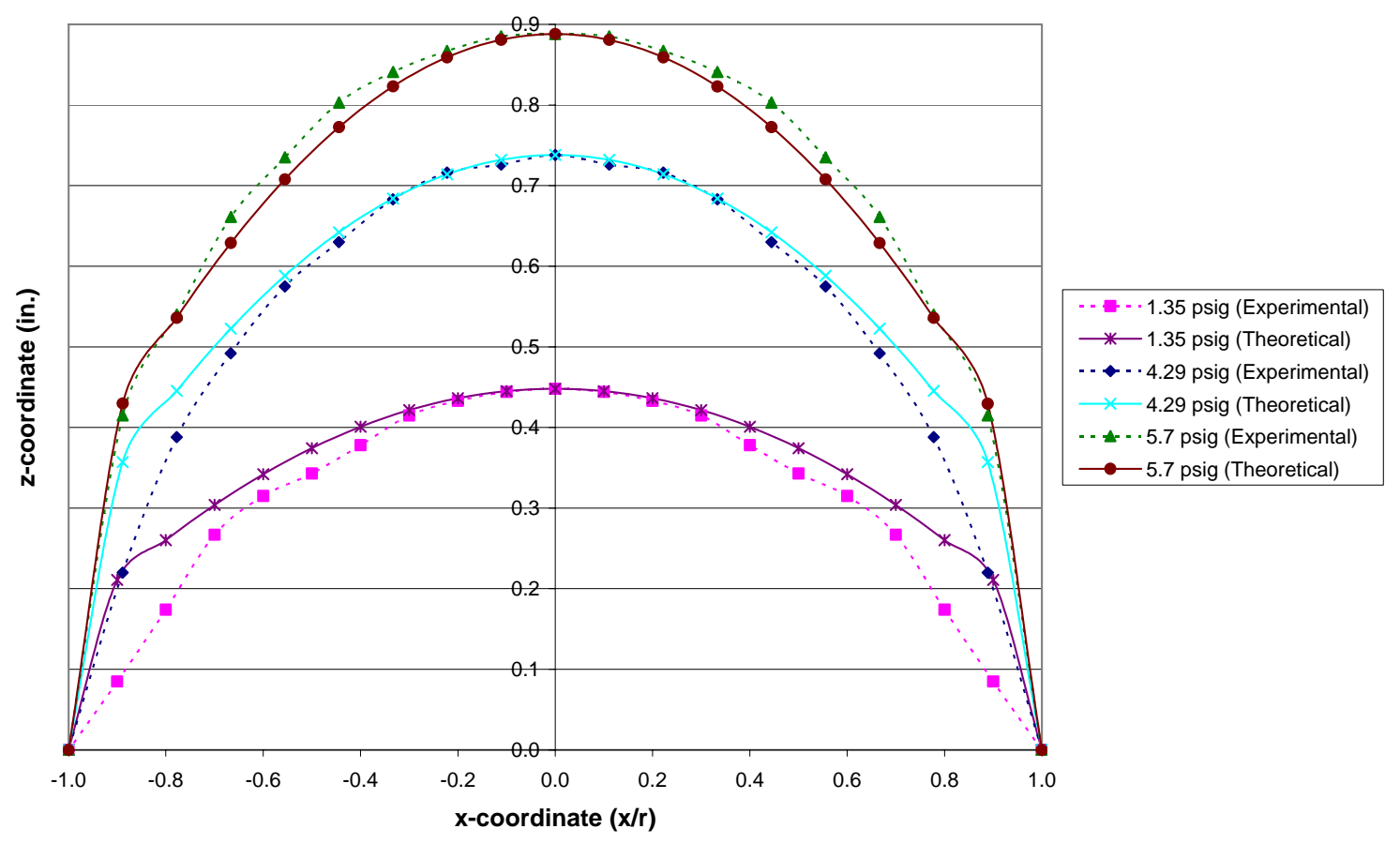

ECH (Epichlorohydrin) 


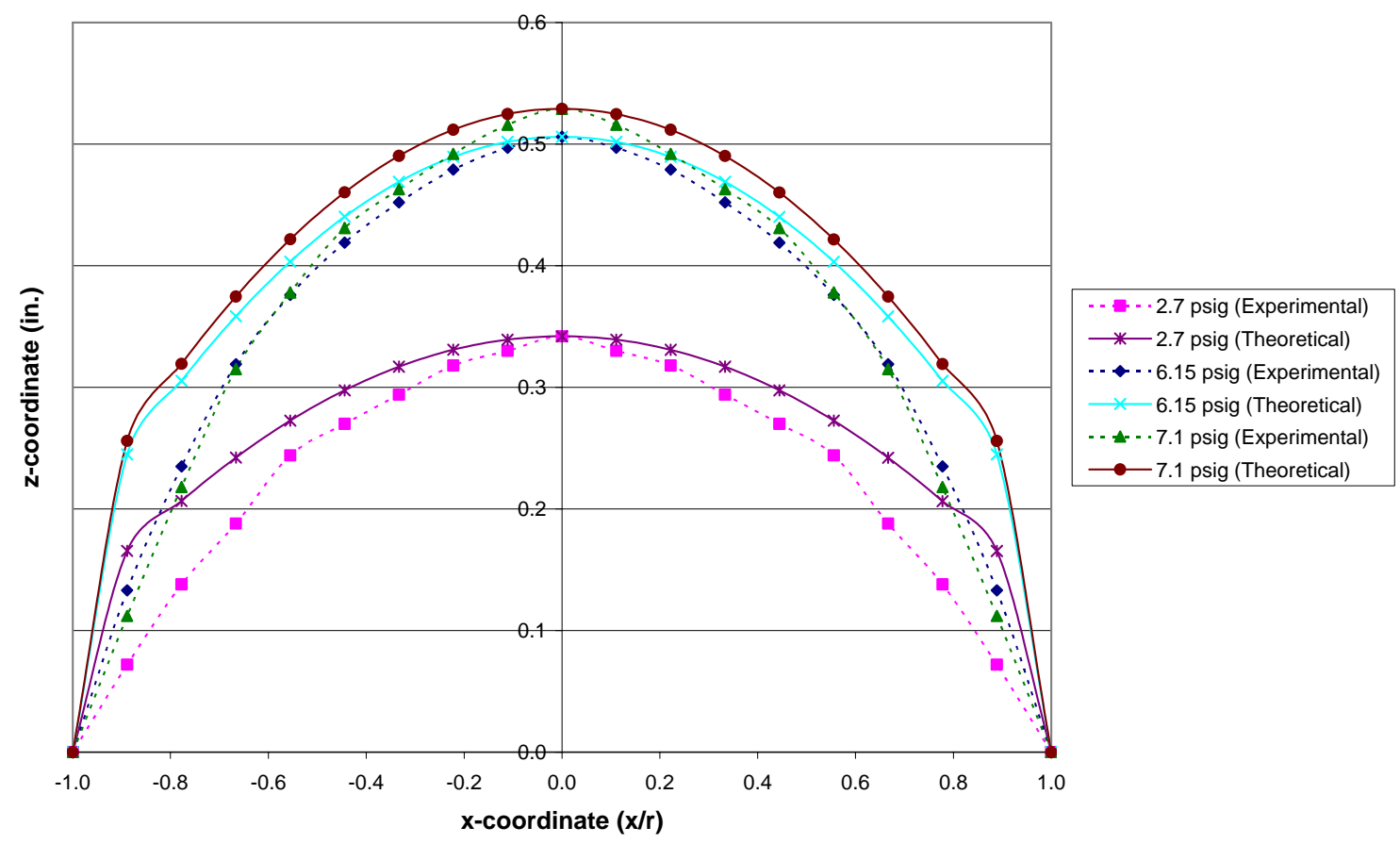

Polyurethane

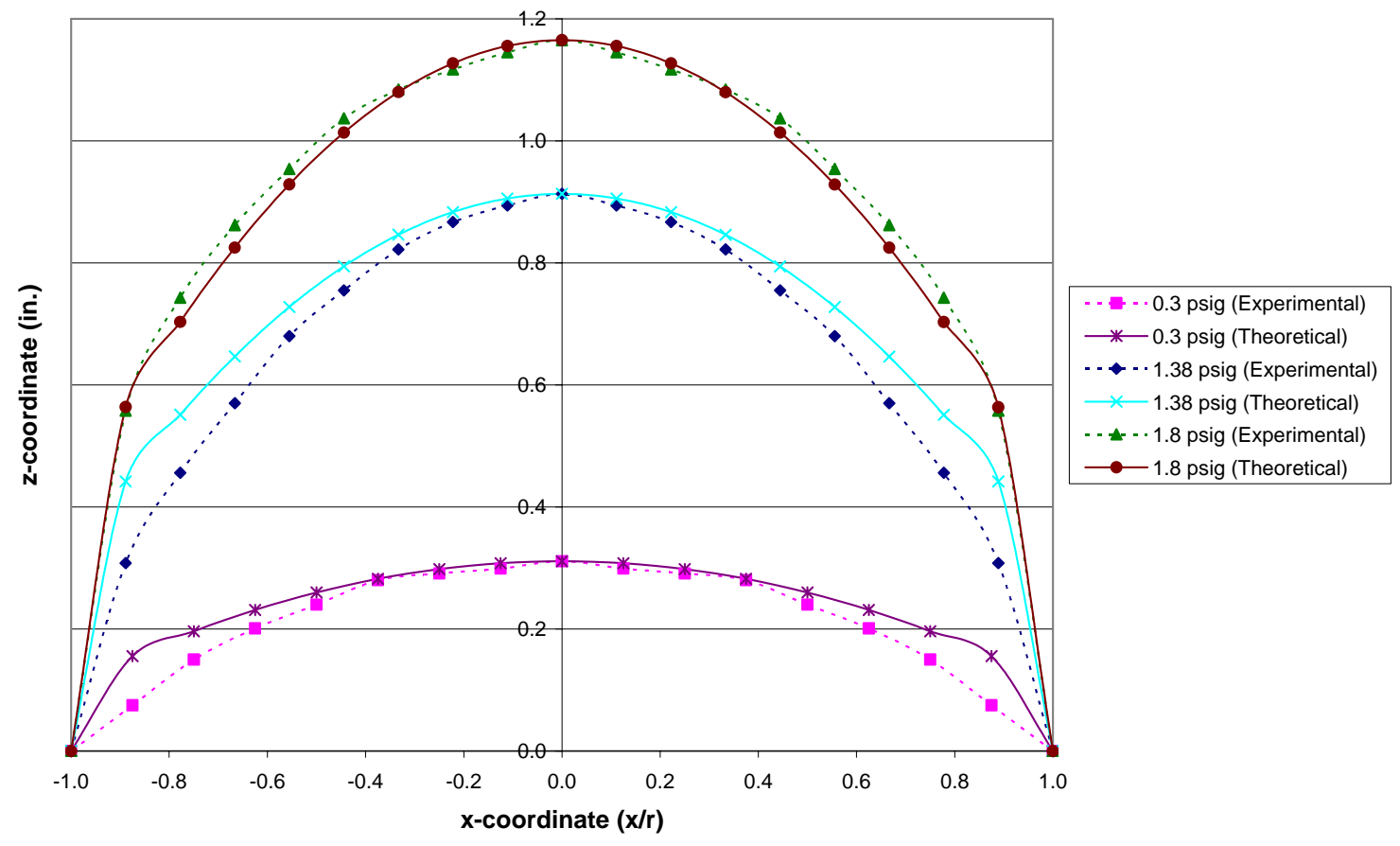

\section{Lycra}




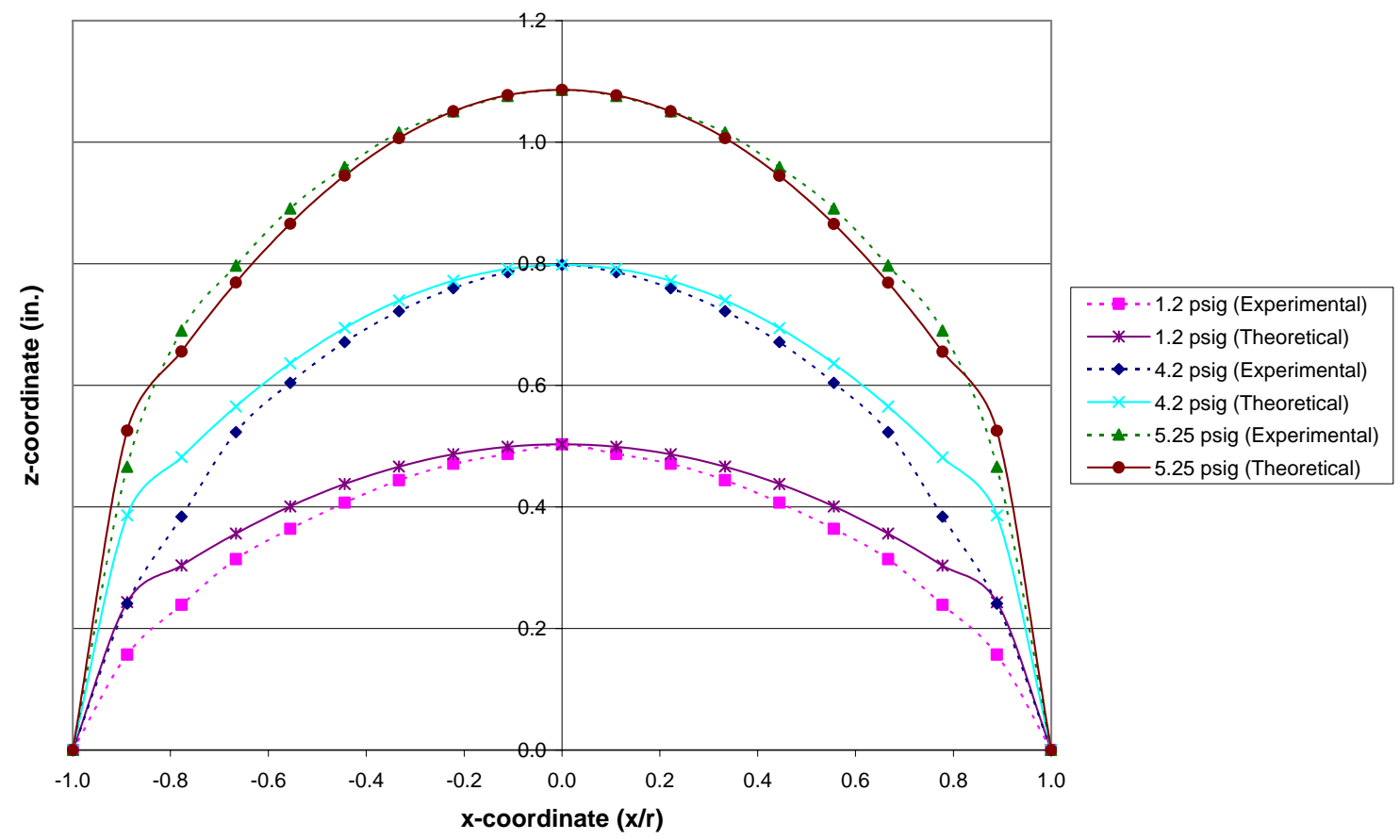

Santoprene

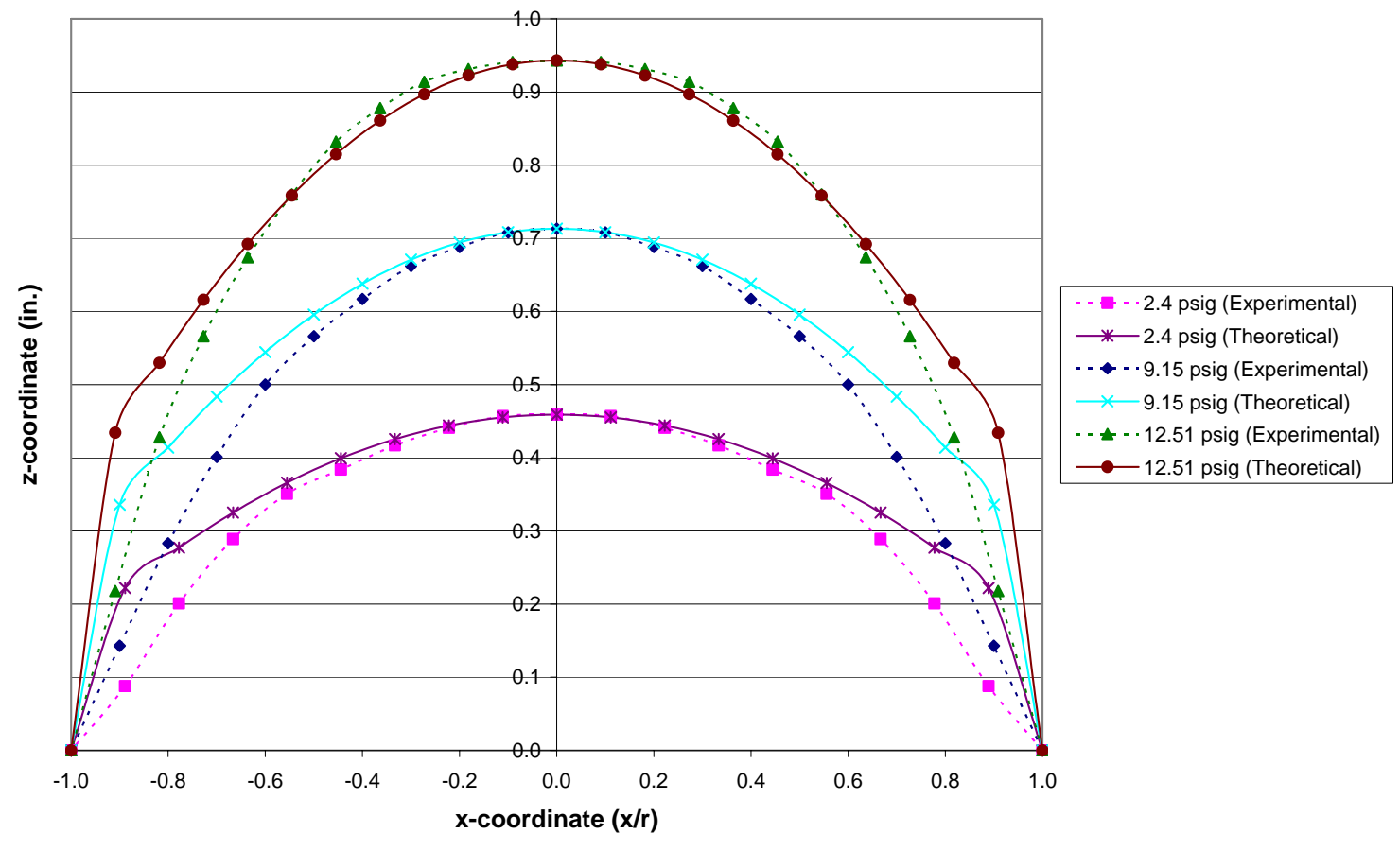

PVC (Polyvinyl Chloride) 